Prepared in cooperation with the U.S. Army Corps of Engineers, Chicago District

\title{
Evaluation of a Mass-Balance Approach to Determine Consumptive Water Use in Northeastern Illinois
}

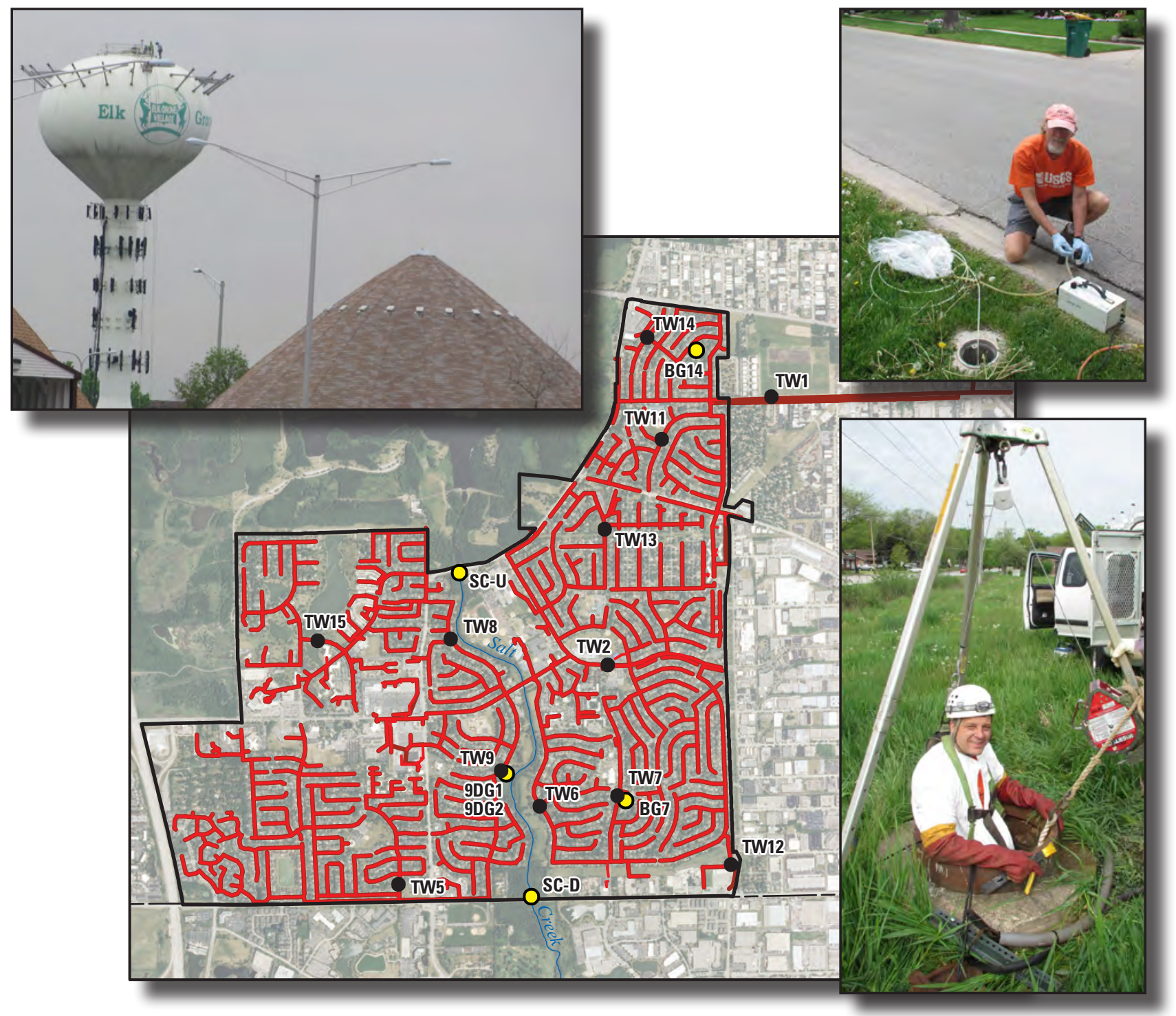

Scientific Investigations Report 2014-5176 
Front-cover images: Top left photograph shows a public-water supply tower in the Village of Elk Grove, Illinois; photograph by Patrick Mills, U.S. Geological Survey (USGS). Top right photograph shows groundwater sampling for optical brighteners at an observation well adjacent to a sewer line; photograph by Jim Duncker, USGS. Bottom left image shows a map of the municipal sewer lines, interceptor sewer, and groundwater and surface-water sampling sites. Bottom right photograph shows a tri-pod hoist set-up and the use of personal protective equipment as part of the safety protocol for access when installing and servicing monitoring equipment in the interceptor line of the sewer system. Other images-All other photographic images by Patrick Mills, USGS, with the exception of figure $9 \mathrm{~A}$ (Salt Creek, looking downstream); figure $15 \mathrm{C}$ (groundwater-level measurement at observation well TW7); figure 16A (groundwater sampling at well TW1); and figure 16B (groundwater sampling at well TW9), each by Jim Duncker, USGS. 


\section{Evaluation of a Mass-Balance Approach to Determine Consumptive Water Use in Northeastern Illinois}

By Patrick C. Mills, James J. Duncker, Thomas M. Over, Marian M. Domanski, and Frank L. Engel

Prepared in cooperation with the U.S. Army Corps of Engineers, Chicago District

Scientific Investigations Report 2014-5176 


\title{
U.S. Department of the Interior SALLY JEWELL, Secretary
}

\section{U.S. Geological Survey \\ Suzette M. Kimball, Acting Director}

\author{
U.S. Geological Survey, Reston, Virginia: 2014
}

For more information on the USGS - the Federal source for science about the Earth, its natural and living resources, natural hazards, and the environment, visit http://www.usgs.gov or call 1-888-ASK-USGS.

For an overview of USGS information products, including maps, imagery, and publications, visit http://www.usgs.gov/pubprod

To order this and other USGS information products, visit http://store.usgs.gov

Any use of trade, firm, or product names is for descriptive purposes only and does not imply endorsement by the U.S. Government.

Although this information product, for the most part, is in the public domain, it also may contain copyrighted materials as noted in the text. Permission to reproduce copyrighted items must be secured from the copyright owner.

Suggested citation:

Mills, P.C., Duncker, J.D., Over, T.M., Domanski, M.M., and Engel, F.L., 2014, Evaluation of a mass-balance approach to determine consumptive water use in northeastern Illinois: U.S. Geological Survey Scientific Investigations Report 2014-5176, 90 p., http://dx.doi.org/10.3133/sir20145176.

ISSN 2328-0328 (online) 


\section{Acknowledgments}

The authors gratefully acknowledge the Village of Elk Grove Village, Illinois and, in particular, Scott Bernholdt, Deputy Director of Operations, Elk Grove Village Department of Public Works (DPW). Without their overwhelming support of this project, including sharing of water delivery and other data as well as technical insights, this project could not have been completed. Their support involved extensive effort to serve the provided data and map products through use of their geographical information systems (GIS) database. As part of this GIS support, we additionally would like to recognize the effort of Steve Kaiser at MGP, Inc., on behalf of Elk Grove Village. Thanks also are extended to Greg Yarnik, Metropolitan Water Reclamation District of Greater Chicago (MWRD), for his assistance in identifying Elk Grove Village as an appropriate study area because of the status of their sewershed infrastructure and potential as a willing partner in the study. Finally, John Watson, a former student employee of the U.S. Geological Survey (USGS) and present engineer with the MWRD, must be recognized for his contributions to processing water delivery data and collecting field data during the early stages of the study. 


\section{Contents}

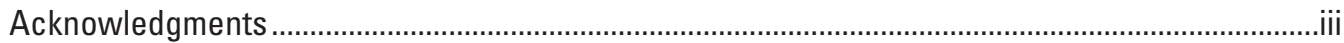

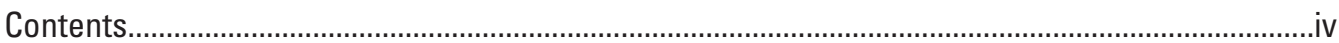

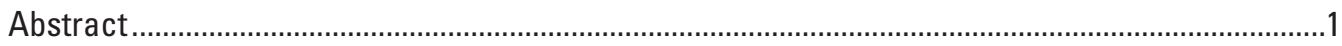

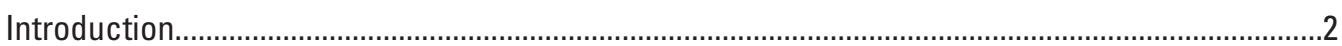

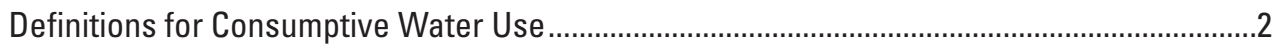

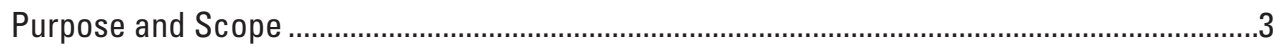

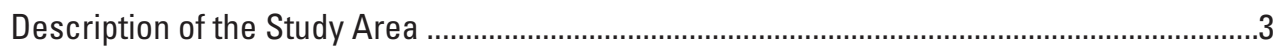

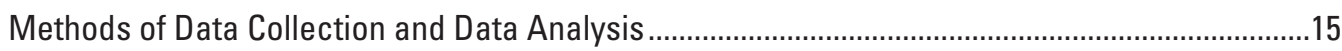

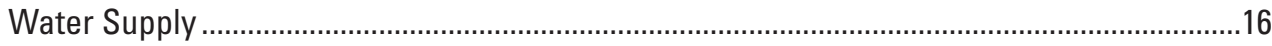

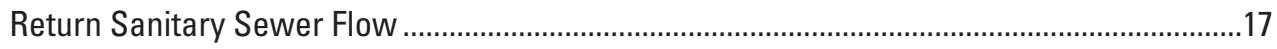

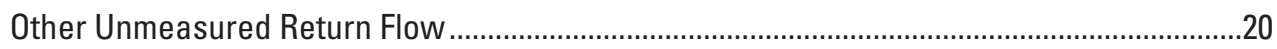

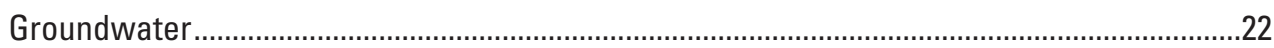

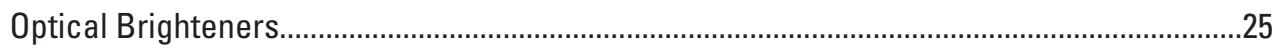

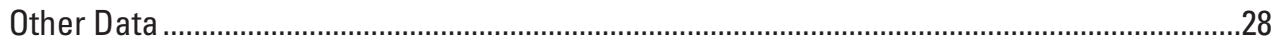

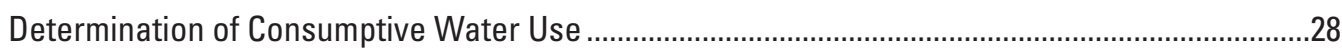

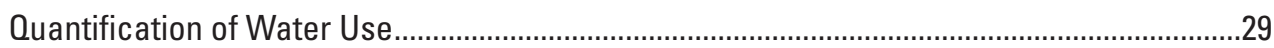

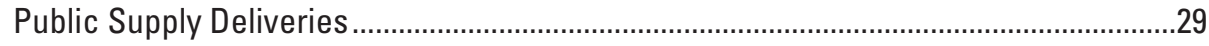

Self-Supplied Withdrawals ........................................................................................

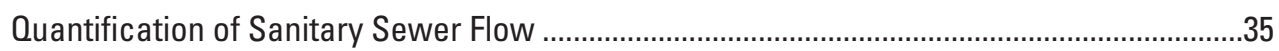

Other Aspects of Return Flow ..............................................................................................40

Groundwater Relation to Sanitary Sewer Flow ............................................................41

Potential for Infiltration .........................................................................................4

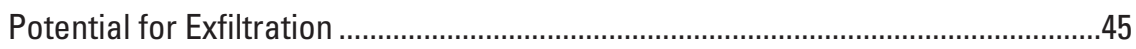

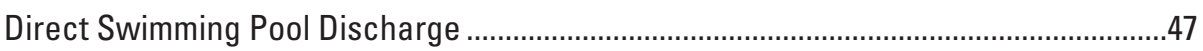

Direct Carwash Discharge ...........................................................................................

Summary Estimation of Consumptive Use ..........................................................................48

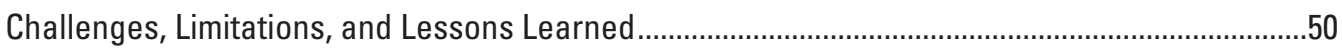

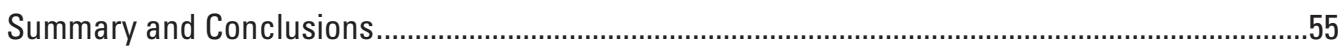

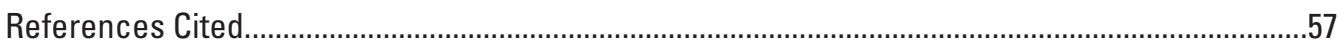

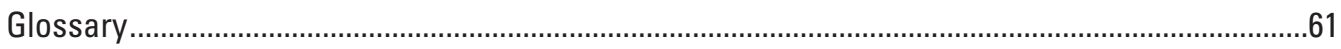

Appendix 1. Estimation of Direct Discharge from Swimming Pools and Carwashing to Storm Sewers as Other Unmeasured Return Flow .........................................................65

Appendix 2. Well Construction and Lithology at Selected Observation Wells Installed Adjacent to Sanitary Sewers in the Study Area, Elk Grove Village, Illinois.................69

Appendix 3. Collection and Quality Assurance of Optical Brightener Samples..............................75

Appendix 4. Monthly Hydrographs of Sewer Discharge and Precipitation in and near Elk Grove Village, Illinois, March 4, 2012-March 3, 2013 ..........................................79

Appendix 5. Findings of Related Assessments ........................................................................ 


\section{Figures}

1. Map showing location of the study area in Elk Grove Village, Illinois, as defined by the sanitary sewershed and including the metered public-water delivery area .........4

2. Map showing local sanitary sewer lines, Metropolitan Water Reclamation District of Greater Chicago (MWRD) interceptor sewer, observation wells, and other sample sites in the study area, Elk Grove Village Illinois...

3. Map showing general land use in the study area, Elk Grove Village, Illinois....................7

4. Map showing approximate volume of public water supplied at metered locations during 2010 in the study area, Elk Grove Village, Illinois .

5. Photographs showing sanitary sewer line inspection and upgrade operations in the study area, Elk Grove Village, Illinois .

6. Map showing locations of sanitary sewer pipes lined after installation or otherwise sealed and of observation wells with ranges of optical brightener concentrations in the study area, Elk Grove Village, Illinois, April 2012-May 2013 ........10

7. Photographs showing typical manholes adjacent to observation wells in the study area, Elk Grove Village, Illinois

8. Map showing topography and areas of reported shallow sand deposits in the study area, Elk Grove Village, Illinois

9. Photographs showing Salt Creek drainage in the study area, Elk Grove Village, Illinois, May 17, 2013.

10. Graph showing monthly precipitation at the National Oceanic and Atmospheric Administration weather station Chicago 0'Hare Airport near Elk Grove Village, Illinois.

11. Diagrams showing relation between the presence and concentration of optical brighteners in sanitary sewer flow and groundwater and the gain or loss of sanitary sewer flow from or to groundwater

12. Diagram and photograph showing principles of flow measurement with an acoustic Doppler current-velocity meter (ADVM) used in the sanitary sewer installation.

13. Diagram and photographs showing U.S. Geological Survey station Sewer at Oakton at Elk Grove Village, Illinois, in the interceptor near observation well TW1 .......19

14. Aerial photographs showing examples of visual accounting of swimming pools in the study area, Elk Grove Village, Illinois .

15. Photographs showing field and benchtop instrumentation used in the determination of consumptive use in the study area, Elk Grove Village, Illinois

16. Photographs showing collection of groundwater samples for analysis of optical brighteners in the study area, Elk Grove Village, Illinois

17. Graph showing number of water meters, by date, contributing to the daily total metered water supply in the study area, Elk Grove Village, Illinois, March 2012February 2013

18. Graphs showing relative impact of negative water supply values on estimation of daily-metered water supply deliveries 
19. Graph showing estimated daily total metered water supply deliveries in the study area, Elk Grove Village, Illinois, March 2012-February 2013.

20. Graph showing estimated monthly metered water supply deliveries in the study area, Elk Grove Village, Illinois, March 2012-February 2013.

21. Map showing approximate volume of public water supplied at metered locations in the study area, Elk Grove Village, Illinois, March 2012-February 2013.

22. Map showing approximate locations of supply wells and their depths in the study area, Elk Grove Village, Illinois, March 2013

23. Hydrographs showing sanitary sewer flow at the U.S. Geological Survey station Sewer at Oakton at Elk Grove Village, Illinois.

24. Hydrographs showing sanitary sewer flow at the U.S. Geological Survey sewer flow monitoring station Sewer at Oakton at Elk Grove Village, Illinois, March 2012-February 2013

25. Graphs showing groundwater and sanitary sewer invert depths and concentrations of optical brighteners at observation wells installed adjacent to sanitary sewers in the study area, Elk Grove Village, Illinois, April 2012-May 2013.......42

26. Graph showing relation between depth to groundwater at observation well TW5 and amount of precipitation, Elk Grove Village, Illinois, August 21September 20, 2012.

27. Graph showing relation between depth to groundwater, magnitude of the seasonal range in depth to groundwater, and depth to sanitary sewer invert, Elk Grove Village, Illinois, April 2012-March 2013..

\section{Tables}

1. Well construction and sewer invert information for observation wells installed adjacent to sanitary sewers in the study area, Elk Grove Village, Illinois

2. Hydrogeologic information for observation wells installed adjacent to sanitary sewers in the study area, Elk Grove Village, Illinois, March 2012-May 2013

3. Optical brightener concentrations in sanitary sewer flow and groundwater from observation wells in the study area, Elk Grove Village, Illinois, April 2012May 2013

4. Estimated monthly metered water supply deliveries in the study area, Elk Grove Village, Illinois, March 2012-February 2013

5. Periods of missing record, poor-quality record, and satisfactory record influenced by stormwater runoff, from measurements at the U.S. Geological Survey station Sewer at Oakton at Elk Grove Village, Illinois, in the Metropolitan Water Reclamation District of Greater Chicago interceptor near observation well TW1, Elk Grove Village, Illinois, March 2012-February 2013

6. Monthly mean monthly sanitary sewer flow, as measured at the U.S. Geological Survey station Sewer at Oakton at Elk Grove Village, Illinois, March 2012-February 2013 
7. Summary of input components of the consumptive use mass-balance equation for the study area, Elk Grove Village, Illinois, March 2012-February 2013

5-1. Additional hydrogeologic and optical brightener information for the study area, Elk Grove Village, Illinois, June 2012-March 2013

\section{Conversion Factors and Abbreviations}

Inch/Pound to SI

\begin{tabular}{|c|c|c|}
\hline Multiply & By & To obtain \\
\hline \multicolumn{3}{|c|}{ Length } \\
\hline inch (in.) & 25.4 & millimeter (mm) \\
\hline foot $(\mathrm{ft})$ & 0.3048 & meter $(\mathrm{m})$ \\
\hline mile (mi) & 1.609 & kilometer $(\mathrm{km})$ \\
\hline \multicolumn{3}{|c|}{ Area } \\
\hline acre & 0.004047 & square kilometer $\left(\mathrm{km}^{2}\right)$ \\
\hline square inch $\left(\right.$ in $\left.^{2}\right)$ & 645.2 & square millimeter $\left(\mathrm{mm}^{2}\right)$ \\
\hline square foot $\left(\mathrm{ft}^{2}\right)$ & 0.09290 & square meter $\left(\mathrm{m}^{2}\right)$ \\
\hline square mile $\left(\mathrm{mi}^{2}\right)$ & 2.590 & square kilometer $\left(\mathrm{km}^{2}\right)$ \\
\hline \multicolumn{3}{|c|}{ Volume } \\
\hline gallon (gal) & 3.785 & liter $(\mathrm{L})$ \\
\hline gallon (gal) & 0.003785 & cubic meter $\left(\mathrm{m}^{3}\right)$ \\
\hline million gallons (Mgal) & 3,785 & cubic meter $\left(\mathrm{m}^{3}\right)$ \\
\hline cubic foot $\left(\mathrm{ft}^{3}\right)$ & 0.02832 & cubic meter $\left(\mathrm{m}^{3}\right)$ \\
\hline \multicolumn{3}{|c|}{ Flow rate } \\
\hline cubic foot per second $\left(\mathrm{ft}^{3} / \mathrm{s}\right)$ & 0.02832 & cubic meter per second $\left(\mathrm{m}^{3} / \mathrm{s}\right)$ \\
\hline gallon per minute (gal/min) & 0.06309 & liter per second $(\mathrm{L} / \mathrm{s})$ \\
\hline gallon per day (gal/d) & 0.003785 & cubic meter per day $\left(\mathrm{m}^{3} / \mathrm{d}\right)$ \\
\hline $\begin{array}{l}\text { gallon per day per person } \\
\qquad[(\mathrm{gal} / \mathrm{d}) / \mathrm{p}]\end{array}$ & 0.001461 & $\begin{array}{l}\text { cubic meter per day per person } \\
\qquad\left[\left(\mathrm{m}^{3} / \mathrm{d}\right) / \mathrm{p}\right]\end{array}$ \\
\hline million gallons per day (Mgal/d) & 3,785 & cubic meter per day $\left(\mathrm{m}^{3} / \mathrm{d}\right)$ \\
\hline inch per day (in/d) & 0.6096 & meter per day $(\mathrm{m} / \mathrm{d})$ \\
\hline \multicolumn{3}{|c|}{ Pressure } \\
\hline pound per square inch $\left(\mathrm{lb} / \mathrm{in}^{2}\right)$ & 6.895 & kilopascal $(\mathrm{kPa})$ \\
\hline
\end{tabular}


Abbreviated water-quality units used in this report: Optical brightener concentrations, samplebottle volumes, and water temperatures are given in metric units. Constituent concentrations are given in micrograms per liter $(\mu \mathrm{g} / \mathrm{L})$. Micrograms per liter are considered equivalent to parts per billion at the reported concentrations. Bottle volumes are given in milliliter $(\mathrm{mL})$ and liter (L).

Abbreviated water-use unit: Rate of water use generally is given in million gallons per day (Mgal/d), which may be converted to an equivalent flow rate given in cubic feet per second $\left(\mathrm{ft}^{3} / \mathrm{s}\right)$, as follows:

$\mathrm{ft}^{3} / \mathrm{s}=\mathrm{Mgal} / \mathrm{d} \times 0.0438$

\section{Additional Abbreviations and Acronyms}

Frequency, as used in acoustic Doppler flow measurement, is given in megahertz $(\mathrm{MHz})$. Temperature in degrees Fahrenheit $\left({ }^{\circ} \mathrm{F}\right)$ may be converted to degrees Celsius $\left({ }^{\circ} \mathrm{C}\right)$ as follows:

${ }^{\circ} \mathrm{C}=\left({ }^{\circ} \mathrm{F}-32\right) / 1.8$

Horizontal coordinate information is referenced to the North American Datum of 1983 (NAD 83).

Vertical coordinate information is referenced to the North American Vertical Datum of 1988 (NAVD 88).

Elevation, as used in this report, refers to distance above or below NAVD 88.

$\begin{array}{ll}\text { ADVM } & \text { acoustic Doppler current-velocity meter } \\ \text { DPW } & \text { Department of Public Works } \\ \text { EXF } & \text { exfiltration } \\ \text { GIS } & \text { geographical information system } \\ \text { HHT } & \text { Hilbert-Huang transform } \\ \text { IN } & \text { inflow } \\ \text { INF } & \text { infiltration } \\ \text { IMF } & \text { intrinsic mode functions } \\ \text { ISWS } & \text { Illinois State Water Survey } \\ \text { MWRD } & \text { Metropolitan Water Reclamation District of Greater Chicago } \\ \text { NOAA } & \text { National Oceanic and Atmospheric Administration } \\ \text { NPDES } & \text { National Pollutant Discharge Elimination System } \\ \text { NWIS } & \text { U.S. Geological Survey National Water Information System } \\ \text { OB } & \text { optical brightener } \\ \text { PE } & \text { polyethylene } \\ \text { PVC } & \text { polyvinyl chloride } \\ \text { RFU } & \text { raw fluorescence unit } \\ \text { UV } & \text { ultraviolet } \\ \text { USGS } & \text { U.S. Geological Survey }\end{array}$




\title{
Evaluation of a Mass-Balance Approach to Determine Consumptive Water Use in Northeastern Illinois
}

\author{
By Patrick C. Mills, James J. Duncker, Thomas M. Over, Marian M. Domanski, and Frank L. Engel
}

\section{Abstract}

A principal component of evaluating and managing water use is consumptive use. This is the portion of water withdrawn for a particular use, such as residential, which is evaporated, transpired, incorporated into products or crops, consumed by humans or livestock, or otherwise removed from the immediate water environment. The amount of consumptive use may be estimated by a water (mass)-balance approach; however, because of the difficulty of obtaining necessary data, its application typically is restricted to the facility scale. The general governing mass-balance equation is: Consumptive use $=$ Water supplied - Return flows.

This study explored a mass-balance field-based computation of consumptive use in a residential setting at the scale of a sanitary sewer service area (sewershed). In addition, the feasibility (cost and difficulty) and relative uncertainties (accuracies) associated with applying the approach at this scale were evaluated. The study was conducted during 2011-13 within a 3.5-square mile $\left(\mathrm{mi}^{2}\right)$ sewershed confined to a predominantly residential area of Elk Grove Village, Illinois. Following background evaluation of the geohydrologic setting, sewershed infrastructure, and possible components of supplied and returned water, the identified primary components were

1. public water deliveries by the Elk Grove Village Department of Public Works,

2. self-served groundwater withdrawals in an included unincorporated neighborhood with public sanitary sewer service,

3. return flows to the sanitary sewer system, and

4. direct return of water discharged from swimming pools to Salt Creek.

Water volumes principally were reported for deliveries, measured for sanitary sewer returns by using an acoustic Doppler current-velocity meter, and estimated for domestic withdrawals and swimming pool discharges to storm sewers. All water volumes required some degree of estimation. Observation wells were installed adjacent to sewer pipelines (lines) to determine the depth of the water table relative to that of the sewer lines and to collect water samples for detection of optical brighteners, as they are routinely discharged as clotheswashing waste to sanitary sewers. These data provided qualitative information on gains (inflow and infiltration) and losses (exfiltration) of sewer flow by pipe leakage, which might otherwise not be considered in the sewer flow return measurements. Hydrographs of sewer flow also were evaluated to identify and estimate storm-associated inputs to sewer flow.

The volume of sanitary sewer return flow (778 million gallons per year $[\mathrm{Mgal} / \mathrm{yr}]$ ) was determined to substantially exceed the volume of supplied water (566 Mgal/yr), thus, for this study setting, voiding the utility of the applied massbalance approach for estimating consumptive water use. Mass-balance components, including sanitary sewer flow and supplied-water use, were estimated within reasonable limits of uncertainty. Evidence of a water table that is typically shallower than the area's sewer lines, yet is sometimes depressed near more deeply buried sewer lines, suggests groundwater infiltration into the sewers contributes to the excess volume of return flow. Technical obstacles and project resources precluded accurate quantification of infiltration volumes and other gains and losses to sanitary sewer flow. As estimated from various simplified methods, a minimum of 26 percent of return flow measured in the sanitary sewer represented groundwater infiltration and stormwater inflow; separately, about 2 percent of return flow was estimated as inflow. On the basis of the alternative winter base-rate method, consumptive use in the sewershed was estimated as 13 percent, which compares favorably with that used by the State of Illinois for Lake Michigan allocation accounting (10 percent) and other States and Canadian Provinces in the Great Lakes region (generally 10-15 percent).

The study also provided other findings considered useful to studies of water use and to performance evaluation of sanitary sewer infrastructure. In urban residential settings, the comparatively small volumes of nonpublic sources of water (self-supplied) and direct (nonsanitary) return flow potentially can be ignored in the estimation of consumptive use. An acoustic Doppler current-velocity meter can be used in sanitary sewers to accurately measure discharge and reasonably estimate storm-associated inflows. Hourly to daily patterns of water use can be readily identified and quantified in the return 
flow record for the sanitary sewers. Relative volumes of infiltration gains (and exfiltration losses) can be substantial, even in sewer systems of communities making significant investments in system upgrades to limit sewer line leakage. Monitoring of optical brighteners in groundwater (and potentially in sanitary sewer flow) can provide a useful means of identifying probable leakage from (and to) sewer lines. Accurate quantification of gains and losses to sanitary sewer flow at the sewershed scale will require additional research effort and technical advances.

Under ideal conditions, accurate quantification of consumptive use at the sewershed scale by the described massbalance approach might be possible. Under most prevailing conditions, quantification likely would be more costly and time consuming than that of the present study, given the freely contributed technical support of the host community and relatively appropriate conditions of the study area. Essentials to quantification of consumptive use are a fully cooperative community, storm and sanitary sewers that are separate, and newer sewer infrastructure and (or) a robust program for limiting infiltration, exfiltration, and inflow.

\section{Introduction}

In the Great Lakes region, as in many parts of the Nation, supplies of clean, fresh water often are viewed as an almost unlimited resource. However, the large and growing population within the Great Lakes Basin' ${ }^{1}$ (Mills and Sharpe, 2010) is straining the limits of local groundwater supplies and, in the not too distant future, possibly the river water supplies (Meyer and others, 2009, 2012). As an apparent, ready water source, municipalities both inside and outside the Basin have sought to obtain water from the Great Lakes. Federal (United States and Canada) and state governments have joined by legislative agreement to manage the demand for and protection of Basin water for its sustainable use (Great Lakes Commission, 2013; U.S. Environmental Protection Agency, 2012). An important component of the effort to manage demand on water supplies in the Great Lakes Basin and similar demand elsewhere is better accounting of groundwater and surface water withdrawals and diversions and other metrics of water use, including consumptive use.

\section{Definitions for Consumptive Water Use}

Consumptive water use is defined as the portion of water withdrawn for a particular use, such as residential, that is discharged to the atmosphere by way of evapotranspiration, incorporated into products or crops, consumed by humans or livestock, or otherwise removed from the immediate water environment (Shaffer and Runkle, 2007). Historically, the components of consumptive use have been difficult to

\footnotetext{
${ }^{1}$ Terms in bold text can be found in the glossary near the end of the report.
}

determine through direct measurement, especially at spatial scales greater than the level of a facility, such as an industrial plant. Where metered or reasonably estimated water supply and returns data might be available, they generally are not freely available from the collecting sources or agencies for aiding researchers' or water managers' efforts to improve estimation of consumptive use. The complexity and uncertainty associated with measuring the components of consumptive use increase as spatial scales of study become increasingly larger. Therefore, consumptive use typically is estimated based on a coefficient that is assumed or of unknown origin (Shaffer and Runkle, 2007). Consumptive-use coefficients are derived either in terms of "water consumed / water withdrawn" or "water withdrawn - water returned / water withdrawn" and expressed either as a ratio or percentage (ratio $\times 100$ ).

Although consumptive use is expected to vary, the great disparity in its estimated coefficients reflects the wide range of spatial scales of study, methods used, and assumptions applied, and thus, the uncertainty associated with these various methods. This disparity is exemplified by the wide range of 0-74 percent for consumptive use coefficients representing predominantly residential water use (domestic public supply deliveries and domestic self-supply) in the Great Lakes Basin (Shaffer and Runkle, 2007).

Consumptive use can be quantified more directly through a mass-balance consideration of the total water supply and its use. This makes the approach useful for large scales of study. Each measured component of the mass-balance equation is quantified and consumptive use is determined as the only unknown variable in the equation:

$$
\text { Consumptive use }=\text { Water supplied }- \text { Return flows }
$$

The resulting estimate of consumptive water use includes all of the uncertainties and errors in measurement for the components of the mass-balance equation. Equation 2, from LaTour (1991), is an expanded version of equation 1:

$$
\begin{gathered}
\text { Consumptive use }=(\text { Deliveries }+ \text { Self-supplied withdrawals }) \text { (2) } \\
-(\text { Returns to sewage treatment plants }+ \text { Direct returns to } \\
\text { surface water and groundwater sources })
\end{gathered}
$$

Although, as noted, with increasing scale of study, the complexities of measurement and quantifying consumptive use increase. Such complexities include delineating water supply and return service areas, measuring water volumes, and identifying and quantifying unaccounted-for ${ }^{2}$ use, inflows (IN), infiltration (INF), and exfiltration (EXF).

Recent improvements in hydroacoustic flow and continuous water quality monitoring instrumentation as well as automated metering of public water (community water supply) deliveries have made the direct and accurate measurement of sewer discharge (thus, return flow to surface waters by way of sewage treatment plants) and accounting of publicly

\footnotetext{
${ }^{2}$ As used here, this term refers the portion of water lost to leakage in the distribution system or other unidentified, unmeasured uses. Elsewhere in the report, this term is used when discussing aspects of water use that were not considered for quantification in this study.
} 
supplied water more feasible. As a result, consumptive use potentially can be determined more accurately at increasingly larger spatial scales of study.

The use of science-based coefficients quantified from measurable field values of supplied and returned water, rather than traditional reference coefficients often derived by outdated and (or) untested means, could be valuable to U.S. States and Canadian Provinces in the Great Lakes Basin in their efforts to more accurately account for their withdrawals, diversions, and consumptive uses of water (Great Lakes Commission, 2011). In Illinois, accounting of water diversion from Lake Michigan is of substantial importance, as allocation limits are established under Supreme Court Decree (Illinois Department of Natural Resources, 2013a). The Lake Michigan Water Allocation Program manages the diversion, comprised of three components - domestic water supply, direct diversion, and stormwater runoff. For accounting in Illinois, a consumptive-use coefficient of 0.10 is applied, as determined indirectly from a water budget analysis based on records of water supply pumpage and treatment plant flow and results of numerical simulation (Espey and others, 2009). The Final Report of Findings of the Fifth Technical Committee for Review of Diversion Flow Measurements and Accounting Procedures (Espey and others, 2004) concluded that this coefficient appears to be inaccurate, with the actual coefficient possibly higher. The potential for any bias (uncertainty error) in the applied consumptive-use coefficient can affect the management of the State's Lake Michigan water allocation.

- The benefits of updated, science-based coefficients of consumptive water use will extend well beyond the Great Lakes region, serving the Nation as a whole. Attentive management and accurate accounting of our water resources are increasingly required to ensure the sustained use and availability of these resources.

- With respect to improved accounting of our water resources, this study attempted the application of the field-based mass-balance approach to estimate consumptive use at the sewershed scale and evaluated the feasibility (cost and difficulty) and relative uncertainties (accuracies) associated with its application. The study relied on in situ measurements of sewer discharge and address-based accounting of supplied water in a predominantly residential community. Uncertainties in the determining components of consumptive use were minimized by:

1. the well-defined land use and sewer network;

2. separation of the sanitary and storm sewer systems;

3. extensive engineering and municipal efforts to limit undesirable discharges and losses of flow to and from the sewers;
4. metering of supplied water; and

5. limited unregulated or unrecorded supply from private wells.

Of the many methods described in the annotation of over 100 reports for estimating coefficients of consumptive use (Shaffer and Runkle, 2007), not a single method bore similarity to the mass-balance approach applied in this study.

\section{Purpose and Scope}

The purpose of this report is to present the results of a consumptive-use estimation study conducted in Elk Grove Village, Illinois during 2011-13 and focusing on the annual period March 2012-February 2013. The report describes the (1) application of a field-based mass-balance approach to determine consumptive use within a predominantly residential water supply and sewer service area (sewershed), and (2) evaluation of the feasibility (cost and difficulty) and relative uncertainties of its application. Included are quantified estimations of supplied water from public delivery, sanitary sewer return flows from direct measurement within an interceptor, and other variously compiled data necessary to account for supplementary volumes of supplied water and return flow. These volumes consist, in part, of self-supplied well water withdrawals and discharges of water from swimming pools to storm sewers. Also provided are measured groundwater levels, concentrations of optical brighteners (hereafter referred to as $\mathrm{OBs}$ ), and sewer flow measurements, as necessary to evaluate uncertainty associated with unmeasured volumes of IN, INF, and EXF. In its summation, the study discusses relative measurement and estimation uncertainties (accuracies) and the limitations of this mass-balance approach for estimating consumptive use of water; also presented are lessons learned to aid its possible future use, including application to larger spatial scales and more diverse types of physical settings and water uses.

\section{Description of the Study Area}

The study area for this feasibility evaluation of a directmeasurement, mass-balance approach to estimating consumptive use was a 3.5 square mile $\left(\mathrm{mi}^{2}\right)$ sanitary sewer service area (sewershed) within the municipal boundary of Elk Grove Village, Illinois (figs. 1; 2). The village is a suburban community about 21 miles (mi) northwest of downtown Chicago and 16 mi west of the limits of the Great Lakes (Lake Michigan) Basin. The sanitary sewer service area contributes sewage discharge to a Metropolitan Water Reclamation District of Greater Chicago (MWRD) interceptor sewer that drains to a nearby dropshaft of their deep tunnel system (Metropolitan Water Reclamation District of Greater Chicago, 2013). 


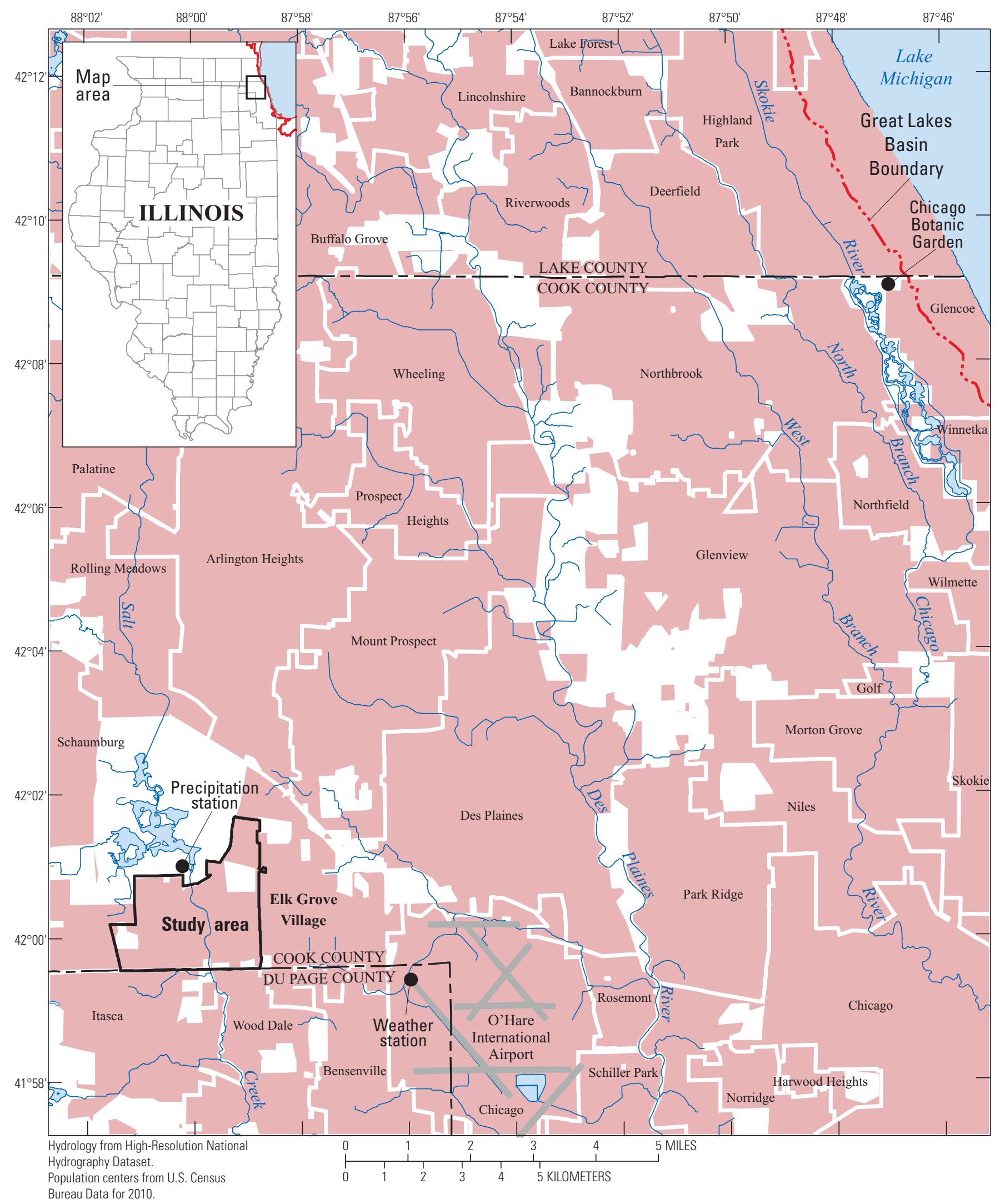

Figure 1. Location of the study area in Elk Grove Village, Illinois, as defined by the sanitary sewershed and including the metered public-water delivery area. 


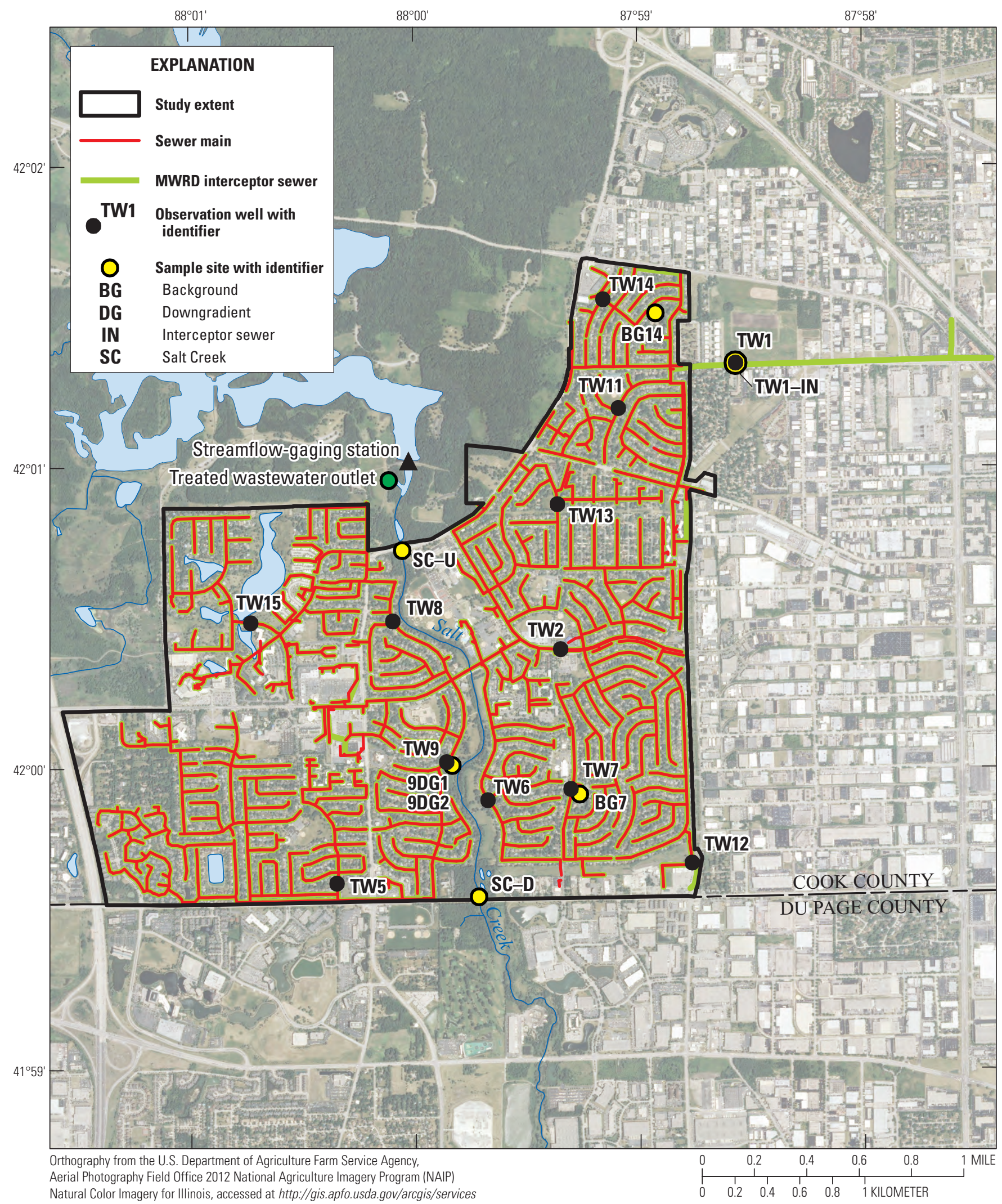

Figure 2. Local sanitary sewer lines, Metropolitan Water Reclamation District of Greater Chicago (MWRD) interceptor sewer, observation wells, and other sample sites in the study area, Elk Grove Village Illinois. 
The study area contains a population of about 19,000 residents (derived from block data of the 2010 Census [U.S. Census Bureau, 2013a]). About 80 percent of the study area is single- or multiple-family residential properties, about 15 percent commercial properties, (businesses, schools, medical facilities, and public properties other than public parks), and about 5 percent public parks. About 2 percent of the commercial area consists of a medical complex that includes a hospital. Within the study area (and the municipal boundaries of Elk Grove Village) are several unincorporated land tracts (fig. 3). The largest is a neighborhood of about $0.15 \mathrm{mi}^{2}$ (about 100 acres), with a resident population of about 382 (2010 Census; U.S. Census Bureau, 2013a). All of its homes are connected to the village's sanitary sewer system, but only a few are connected to its public water supply system (Scott Bernholdt, Department of Public Works, Elk Grove Village, Illinois, oral commun., 2011). Homes and businesses in the smaller unincorporated neighborhoods and commercial land tracts within the study area are neither supplied public water nor connected to the village's sanitary sewer system.

Lake Michigan is the public water source for Elk Grove Village, with the water treated, purified, and served to the village by the Northwest Suburban Municipal Joint Action Water Agency. The village also operates high capacity wells for infrequent emergency use, one of which is in the study area (Scott Bernholdt, Department of Public Works, Elk Grove Village, Illinois, oral commun., 2011). The village's Department of Public Works (DPW) manages the local public water supply distribution system, including maintenance of its infrastructure and billing. Public supply distribution for all uses in the study area totaled about 527.5 million gallons (Mgal) in 2010 (Scott Bernholdt, Department of Public Works, Elk Grove Village, Illinois, written commun., 2012) (fig. 4). The majority of this use is for domestic purposes. Groundwater withdrawals for the single village-operated emergency use well in the study area totaled about $2 \mathrm{Mgal}$ in 2010 (Timothy Bryant, Illinois State Water Survey, ${ }^{3}$ Illinois Water Inventory Program, written commun., 2012), or about 0.4 percent of total withdrawals. These withdrawals, made to maintain the functionality of the well, discharged directly to the storm sewer system. (Scott Bernholdt, Department of Public Works, Elk Grove Village, Illinois, oral commun., 2013).
The sanitary sewer system within the study area consists of about $106 \mathrm{mi}$ of branch and trunk lines and a primary interceptor (fig. 2). Numerous smaller diameter laterals (often about 4-6 inches [in.]), connected to the homes and commercial facilities, drain sewerage by gravity to the increasingly larger diameter branch and trunk lines (often as large as 12 in.) and ultimately to the interceptor (5-foot [ft] diameter in the study area). A single lift station (adjacent to well TW2, fig. 2) pumps much of the area's gravity drainage to higher elevation lines for continued gravity drainage to the interceptor. As indicated by measurements in manholes made adjacent to and near the study's observation wells, the inverts of the lines that drain to the interceptor range in depth from about 7-22 ft below land surface (table 1). The invert of the interceptor is about $52 \mathrm{ft}$ below land surface.

The sanitary sewer pipes are constructed of a variety of materials, including vitrified clay, cast iron, ductile iron, polyvinyl chloride (PVC), reinforced concrete, and TRUSS composite. After pipe installation, the village's DPW has made efforts to reduce INF and EXF of water into and sewer flow out of lines that may have deteriorated with age including:

- regular inspections of the lines,

- cutting of intruding roots,

- insertion of cured-in-place linings,

- and, in coordination with developers, installation of pipes, such as TRUSS composites, that are constructed and connected by using modern technologies (fig. 5).

As of 2013, these lined and TRUSS composite pipes, which prevent unwanted water flow into and out of the sewer lines, represent about 44 percent of the sanitary sewer system (excluding private lateral lines) in the study area (fig. 6). Older sewer manholes in the system typically are constructed of mortared brick; newer manholes typically are constructed of precast concrete (fig. 7). The percentage of each of these types of construction is unknown within the study area. Depending on the methods of construction and the age of the lines, various types of materials are used to seal connections between sewer lines and between lines and manholes. These sealing materials may include solvent welds, compression O-ring gaskets, cement mortar, bituminous mastic, or lead and oakum.

It is expected that most of the smaller diameter laterals were installed at depths above the seasonal high water table depth and most of the larger diameter trunk and interceptor lines were installed below the seasonal low water table depth. Excavated trenches for older sewer lines typically are backfilled with native fine-grained soils that were removed during trenching. Trenches for newer lines and reconstructed older lines typically are backfilled with a gravel pack that may surround the line, with that pack covered by native fine-grained soils (Scott Bernholdt, Department of Public Works, Elk Grove Village, Illinois, oral commun., 2011).

\footnotetext{
${ }^{3}$ A unit of the Prairie Research Institute of the University of Illinois at Urbana-Champaign
} 


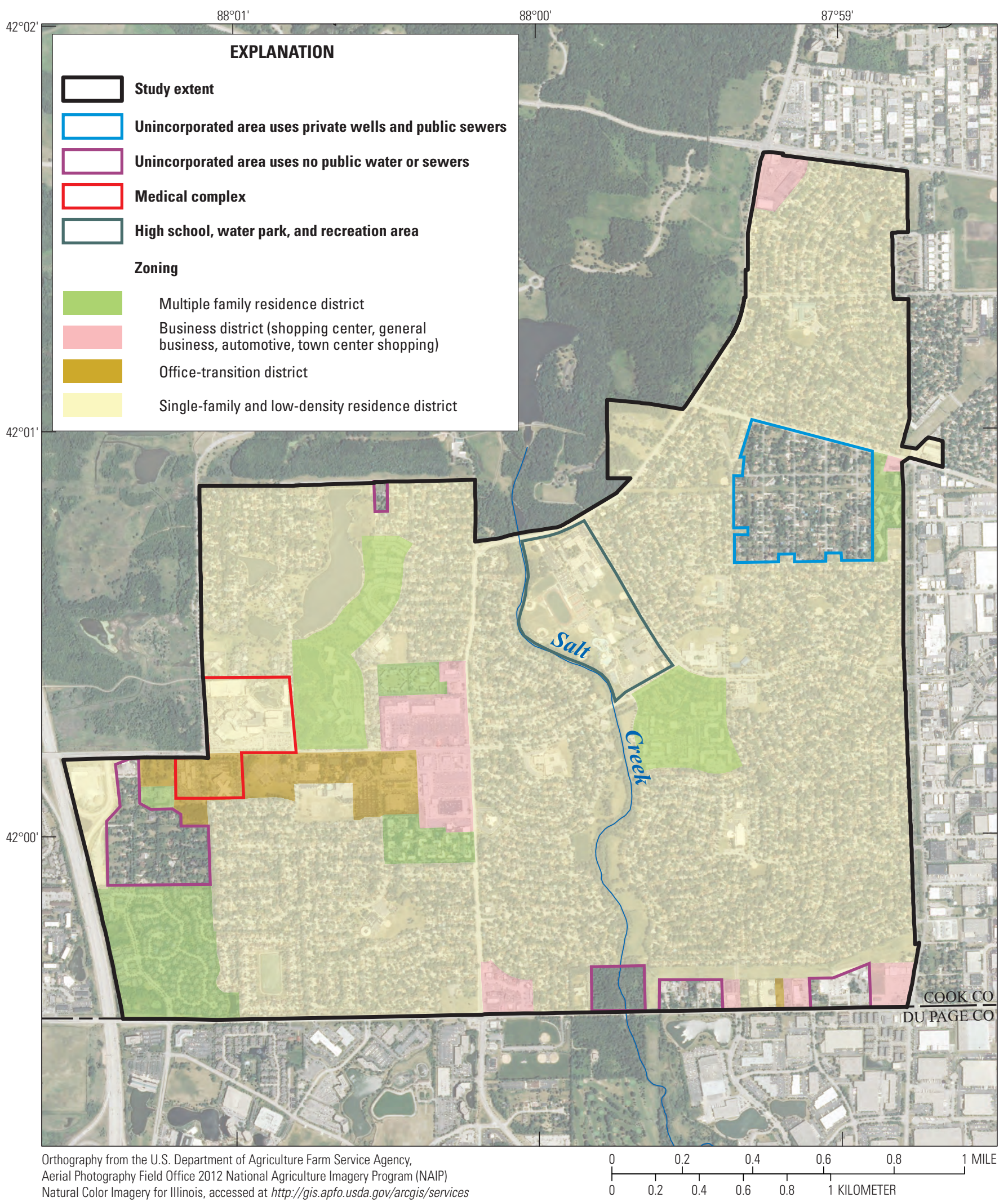

Figure 3. General land use in the study area, Elk Grove Village, Illinois. 


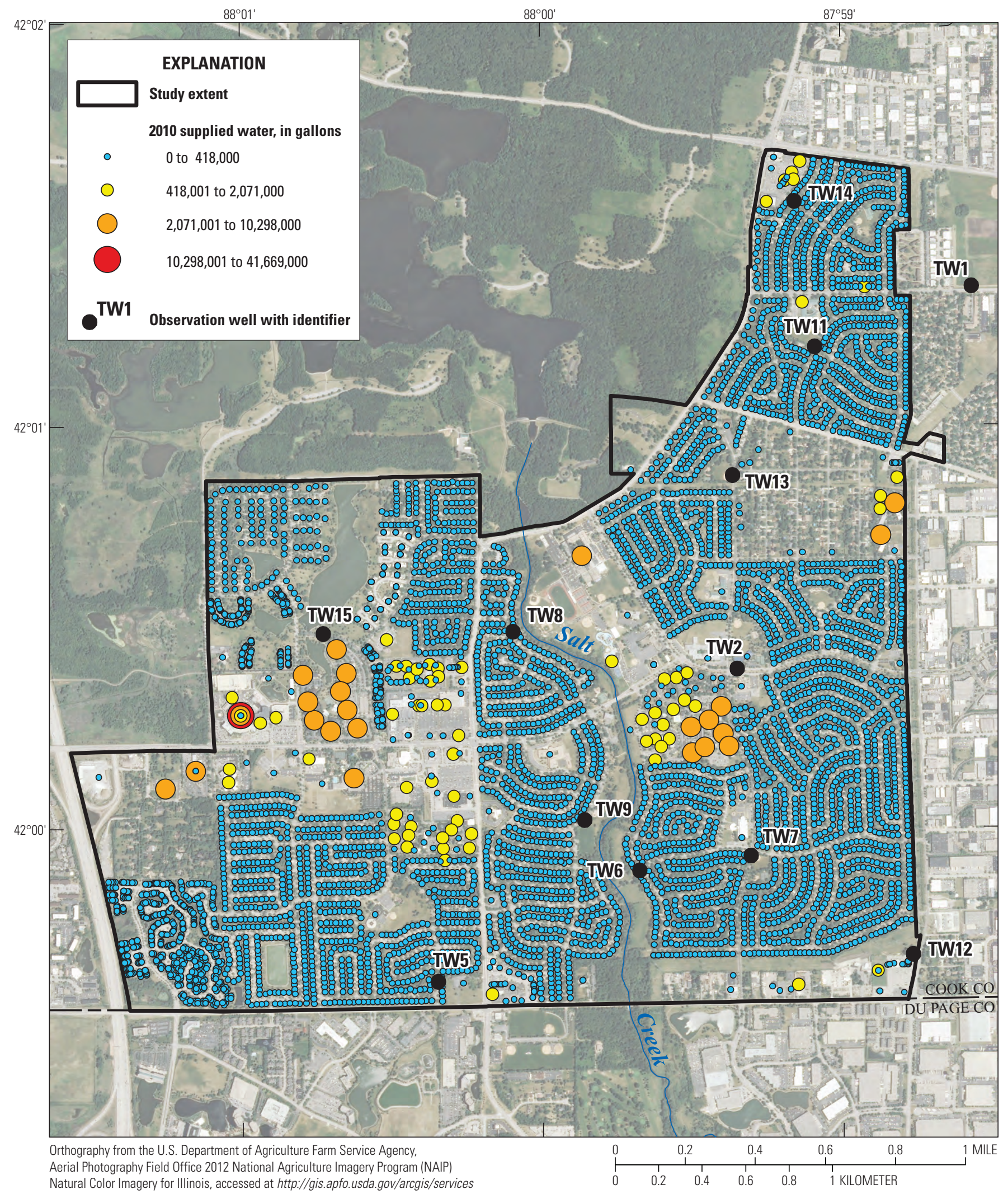

Figure 4. Approximate volume of public water supplied at metered locations during 2010 in the study area, Elk Grove Village, Illinois. 
Table 1. Well construction and sewer invert information for observation wells installed adjacent to sanitary sewers in the study area, Elk Grove Village, Illinois.

[NWIS, U.S. Geological Survey National Water Information System; ft bls, feet below land surface]

\begin{tabular}{|c|c|c|c|c|c|c|}
\hline $\begin{array}{l}\text { NWIS site } \\
\text { identification }\end{array}$ & $\begin{array}{l}\text { Local } \\
\text { name }\end{array}$ & Latitude & Longitude & $\begin{array}{l}\text { Total depth } \\
\text { of well, } \\
\text { in ft bls }\end{array}$ & $\begin{array}{l}\text { Open interval } \\
\text { of well, } \\
\text { in ft bls }\end{array}$ & $\begin{array}{l}\text { Approximate } \\
\text { depth to } \\
\text { sewer invert, } \\
\text { in ft bls }\end{array}$ \\
\hline 420121087583401 & TW1 & $42^{\circ} 01 ’ 20.64 \prime$ & $87^{\circ} 58^{\prime} 33.84^{\prime \prime}$ & 43.7 & $38.6-43.6$ & 52 \\
\hline 420024087592101 & TW2 & $42^{\circ} 00^{\prime} 23.64 \prime$ & $87^{\circ} 59^{\prime} 20.94 \prime$ & 20.0 & $14.9-19.9$ & 22 \\
\hline 415937088002101 & TW5 & $41^{\circ} 59^{\prime} 37.08^{\prime \prime}$ & $88^{\circ} 00^{\prime} 20.94^{\prime \prime}$ & 13.8 & $8.7-13.7$ & 8 \\
\hline 415954087594101 & TW6 & $41^{\circ} 59^{\prime} 53.58^{\prime \prime}$ & $87^{\circ} 59^{\prime} 40.56^{\prime \prime}$ & 14.2 & $9.1-14.1$ & 8 \\
\hline 415956087591801 & TW7 & $41^{\circ} 59^{\prime} 55.74^{\prime \prime}$ & $87^{\circ} 59^{\prime} 18.36^{\prime \prime}$ & 19.0 & $13.9-18.9$ & 14 \\
\hline 420029088000601 & TW8 & $42^{\circ} 00^{\prime} 29.28^{\prime \prime}$ & $88^{\circ} 00^{\prime} 05.76^{\prime \prime}$ & 22.0 & $16.9-21.9$ & 18 \\
\hline 420001087595201 & TW9 & $42^{\circ} 00^{\prime} 01.14^{\prime \prime}$ & $87^{\circ} 59^{\prime} 51.54^{\prime \prime}$ & 20.2 & $15.1-20.1$ & 16.5 \\
\hline 420112087590501 & TW11 & $42^{\circ} 01^{\prime} 11.64^{\prime \prime}$ & $87^{\circ} 59^{\prime} 05.22^{\prime \prime}$ & 15.2 & $10.1-15.1$ & 10 \\
\hline 415941087584601 & TW12 & $41^{\circ} 59^{\prime} 40.98^{\prime \prime}$ & $87^{\circ} 58^{\prime} 46.02^{\prime \prime}$ & 16.1 & $11.0-16.0$ & 7 \\
\hline 420053087592201 & TW13 & $42^{\circ} 00^{\prime} 52.50^{\prime \prime}$ & $87^{\circ} 59^{\prime} 21.72 ”$ & 15.1 & $10.0-15.0$ & 10.5 \\
\hline 420133087590901 & TW14 & $42^{\circ} 01^{\prime} 33.30^{\prime \prime}$ & $87^{\circ} 59^{\prime} 09.24 \prime \prime$ & 13.3 & $8.2-13.2$ & 9 \\
\hline 420029088004401 & TW15 & $42^{\circ} 00 ’ 29.04$ ' & $88^{\circ} 00^{\prime} 43.74 \prime$ & 20.0 & 14.9-19.9 & 16 \\
\hline
\end{tabular}

${ }^{1}$ The level (depth) of the inside bottom of a sewer pipe.

A

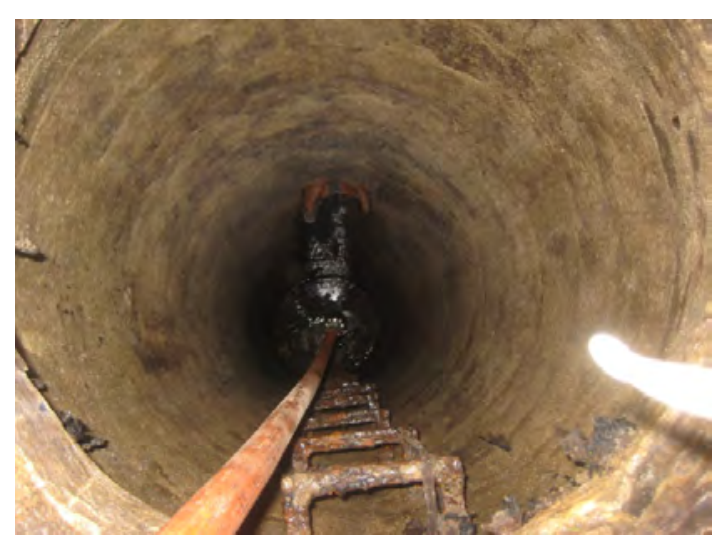

C

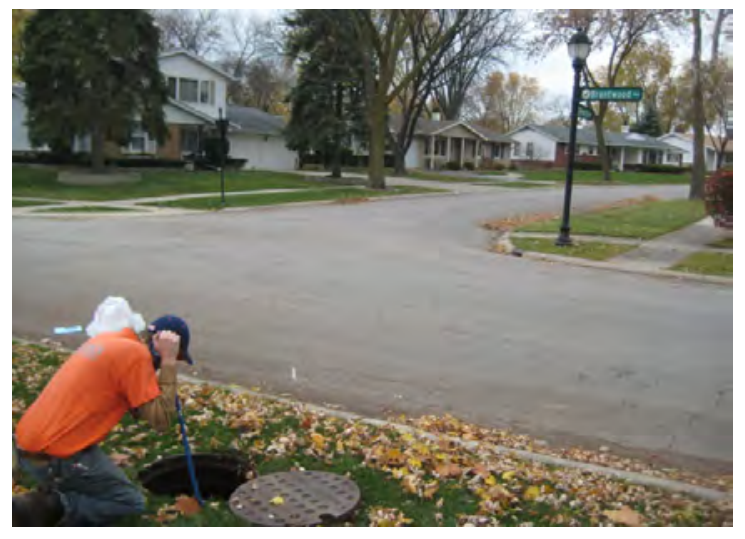

B

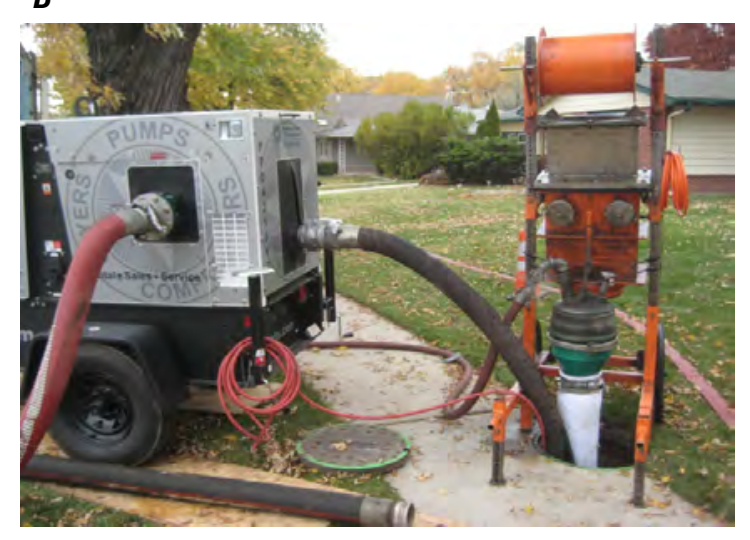

Figure 5. Photographs showing sanitary sewer line inspection and upgrade operations in the study area, Elk Grove Village, Illinois. $A$, Camera inspection of the trunk line near observation well TW7. B, Cured-inplace lining operation of the trunk line near well TW7. $C$, Study-related inspection of a manhole near well TW9 by U.S. Geological Survey staff. 


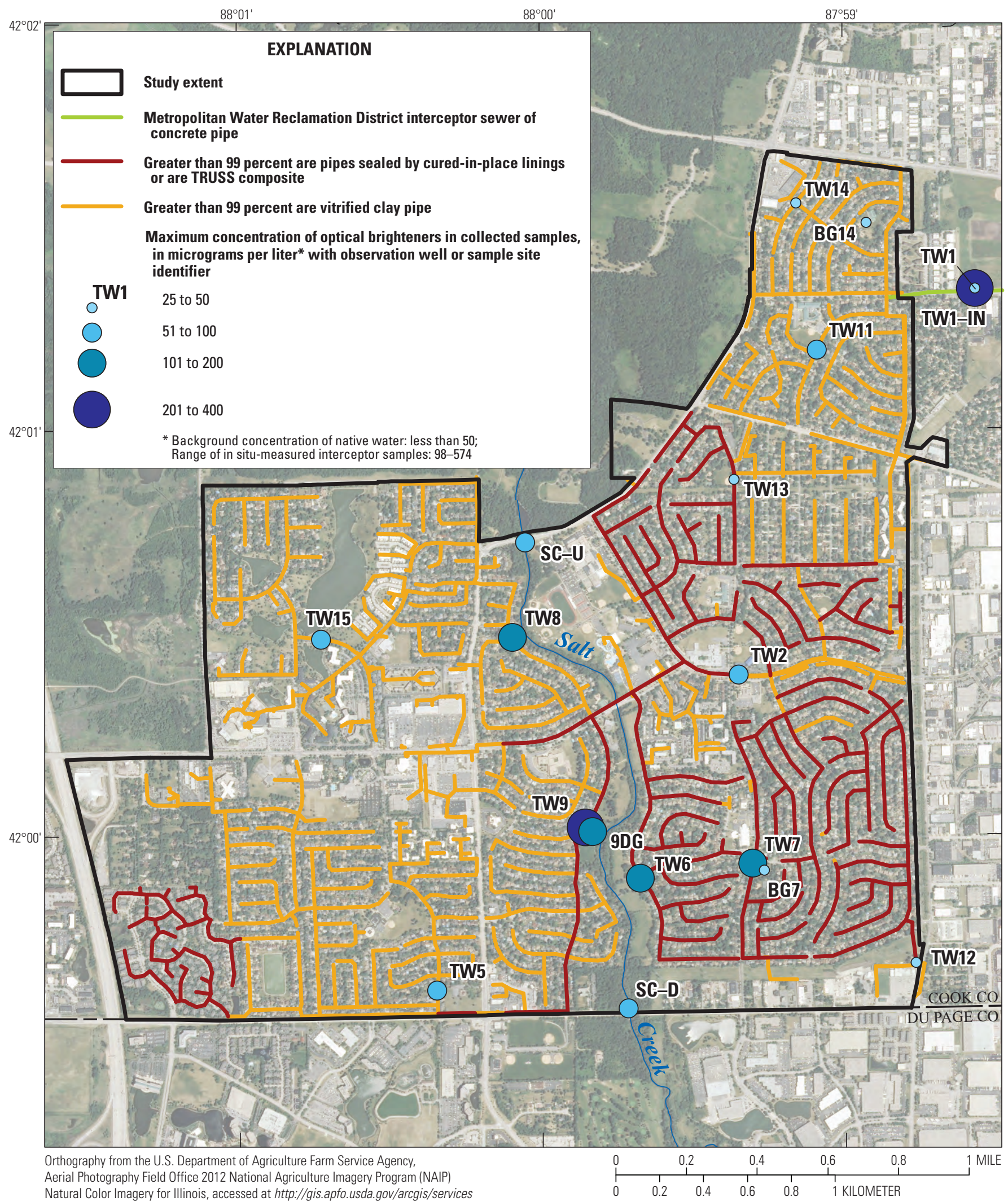

Figure 6. Locations of sanitary sewer pipes lined after installation or otherwise sealed and of observation wells with ranges of optical brightener concentrations in the study area, Elk Grove Village, Illinois, April 2012-May 2013. (See fig. 2 for explanation of sample site designations.) 
A

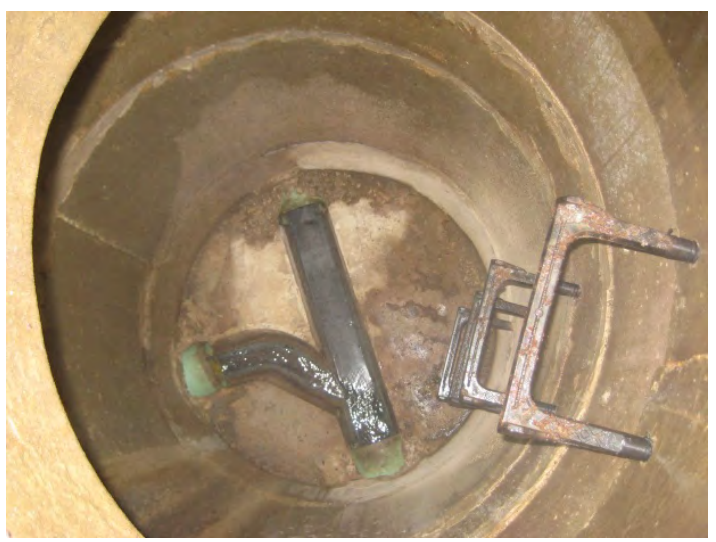

C

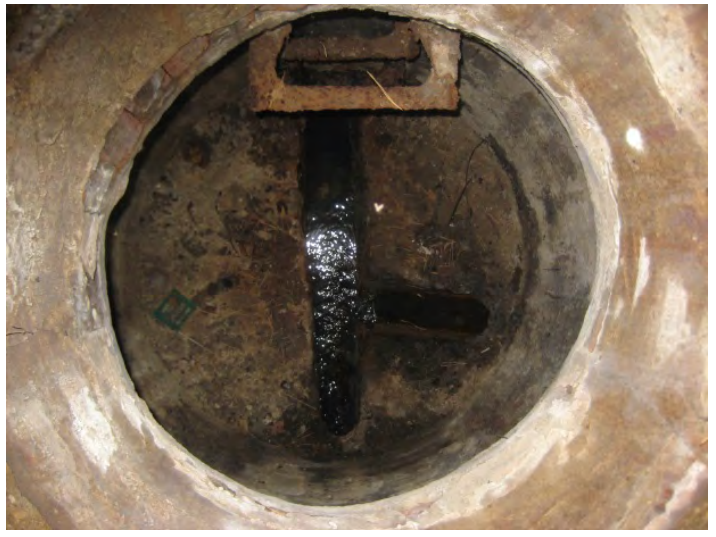

E

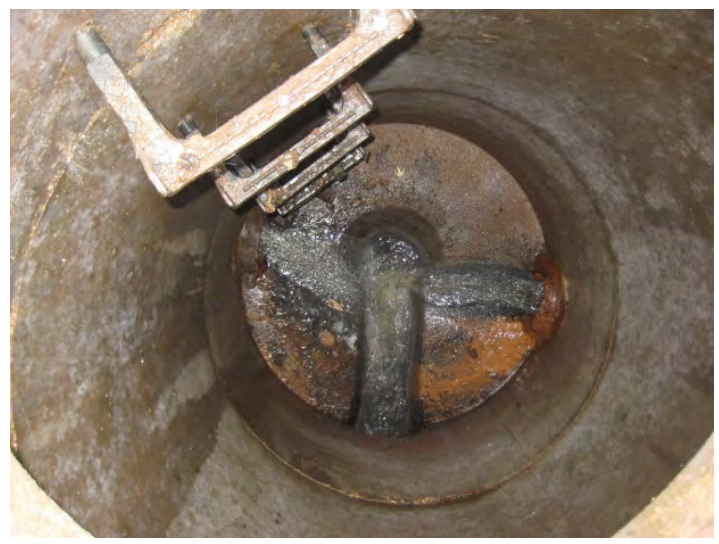

B

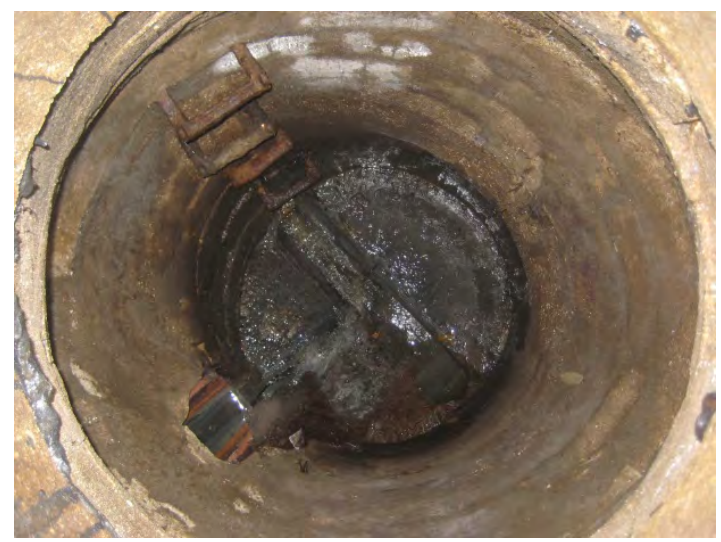

$\boldsymbol{D}$

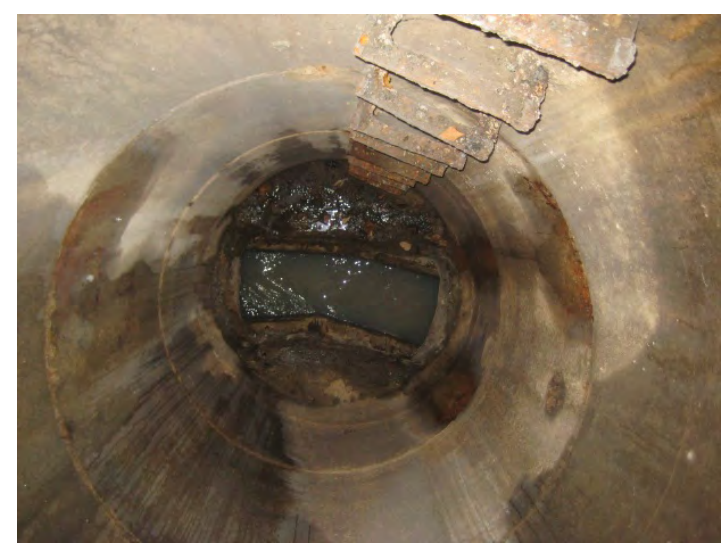

Figure 7. Typical manholes adjacent to observation wells in the study area, Elk Grove Village, Illinois. $A$, Newer modular precast concrete units, near well TW15. B, Precast concrete blocks, at well TW11. $C$, Mortar-faced bricks, at well TW12. D, Modular precast concrete units, near well TW9. E, Modular precast units, near well TW13.

The study area falls within the Wheaton Morainal Country of the Great Lake Section of the Central Lowland Province (Illinois State Geological Survey, 2009). The surficial geology is comprised of Wisconsin Episode till plain deposits of the Wadsworth Formation ${ }^{4}$ (Kolata and Nimz, 2010). The study area, with little topographic relief, is bisected into approxi- mate eastern and western halves by Salt Creek (figs. 8; 9), a tributary of the Des Plaines River (hydrologic cataloging unit 07120004). No other surface water drainages are present in the study area; a few spring-fed lakes, ponds, and stormwater retention basins are present, particularly in the northwest part (fig. 2).

\footnotetext{
${ }^{4}$ The stratigraphic nomenclature used in this report is that of the Illinois State Geological Survey (ISGS) ${ }^{1}$ and does not necessarily follow the usage of the U.S. Geological Survey (USGS).
} 


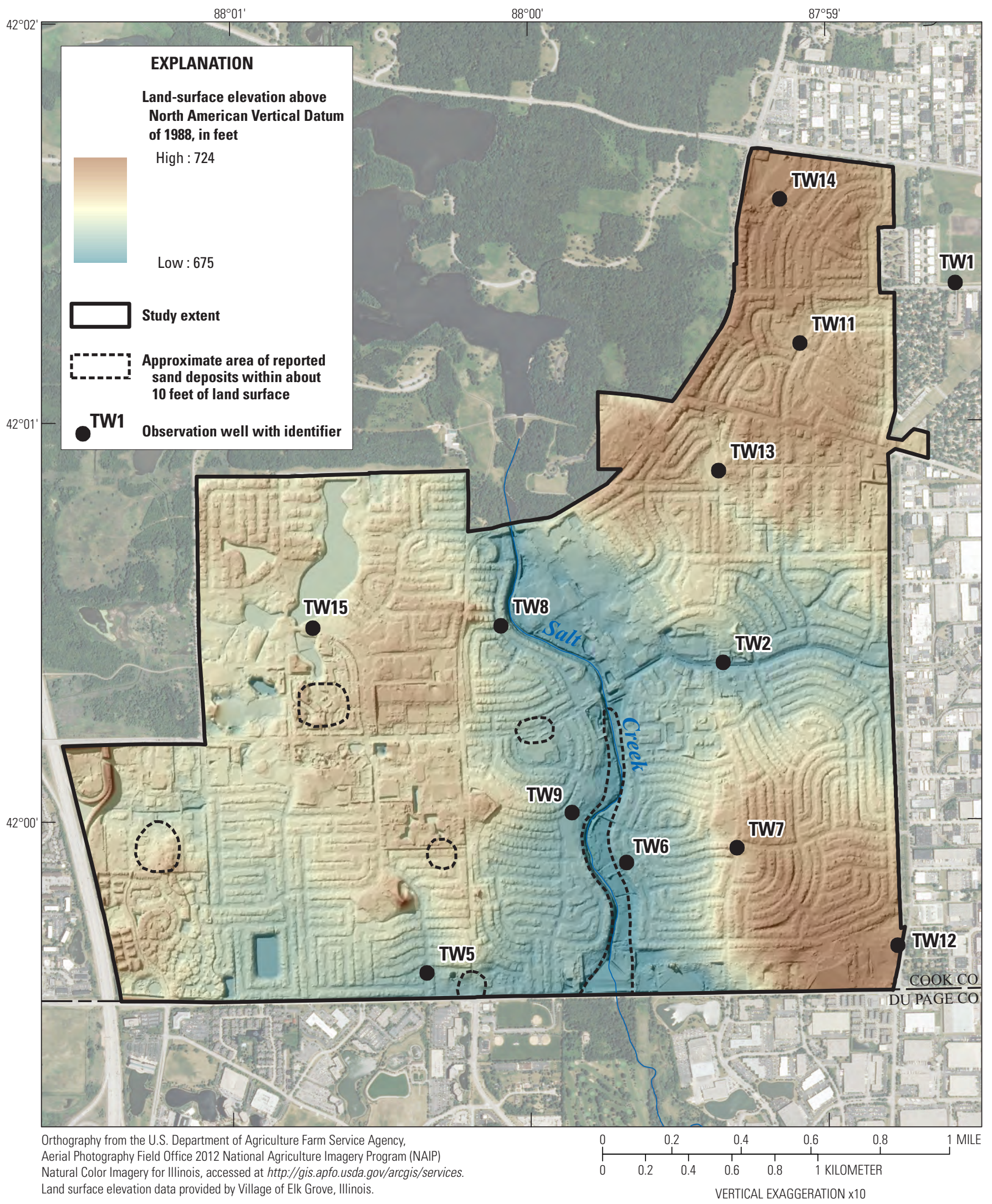

Figure 8. Topography and areas of reported shallow sand deposits in the study area, Elk Grove Village, Illinois. 
$\boldsymbol{A}$

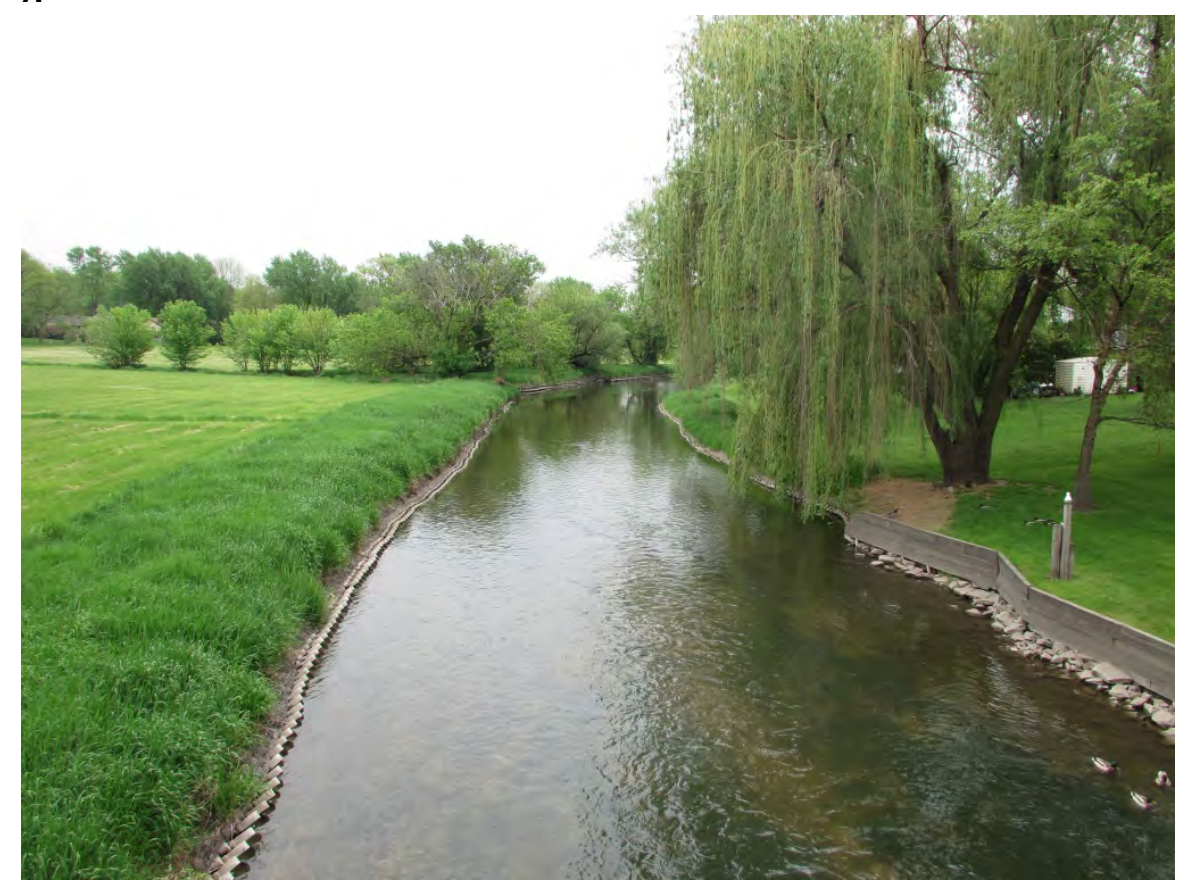

B

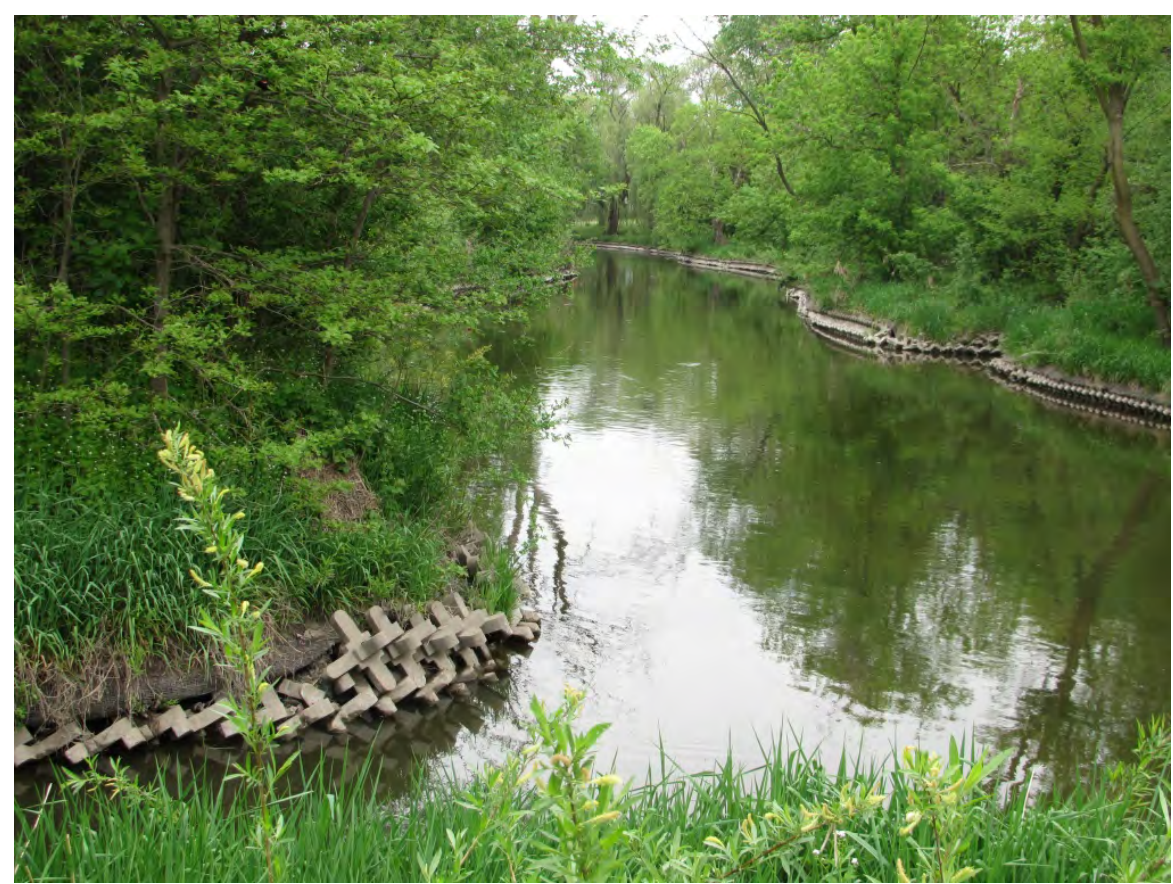

Figure 9. Photographs showing Salt Creek drainage in the study area, Elk Grove Village, Illinois, May 17, 2013. A, Near observation well TW6, looking downstream. $B$, Near well TW9, looking upstream. 
The climate in the region of the study area is continental, characterized by relatively hot summers, cold winters, and moderate precipitation. Climate history (1891-2010) is well defined by records of the National Oceanic and Atmospheric Administration (NOAA) weather station Chicago O'Hare Airport (Angel, 2013a), about 3 mi southeast of the study area (fig. 1). Annual average (1981-2010) precipitation is 36.89 in., with monthly averages ranging from a low of 1.73 in. in January to a high of 4.90 in. in August. Annual average snowfall, recorded from October-April, is 36.7 in., with a maximum monthly average of 10.8 in. in January. Annual average temperature is 59 degrees Fahrenheit $\left({ }^{\circ} \mathrm{F}\right)$, with monthly averages ranging from $28^{\circ} \mathrm{F}$ in December and January to $74^{\circ} \mathrm{F}$ in July.

During much of 2012, most of Illinois, including the northeastern part, was under drought conditions represented by extended periods of higher than normal temperatures (National Oceanic and Atmospheric Administration, 2013;
WeatherSpark, 2013) and unusually low rainfall totals (Illinois Department of Natural Resources, 2013b). For the 12-month primary period of data collection and analysis of this study (March 2012-February 2013), precipitation recorded at weather station Chicago O'Hare Airport (Angel, 2013b) indicated a deficit of 6.5 in. from the long-term annual average. Most of this difference was the result of below average precipitation during April-November 2012 (fig. 10).

Recent trends (1998-2009) in pan evaporation within the study area are defined adequately by records from measurements at the NOAA Chicago Botanic Garden weather station, located about $14 \mathrm{mi}$ northeast of the study area in Glencoe, Illinois (fig. 1). The measurement record is provided by the Illinois State Climatologist's Office of the Illinois State Water Survey (ISWS) (Angel, 2013c). Annual average pan evaporation, recorded from May-October, is about 27 in., or about 75 percent of precipitation.

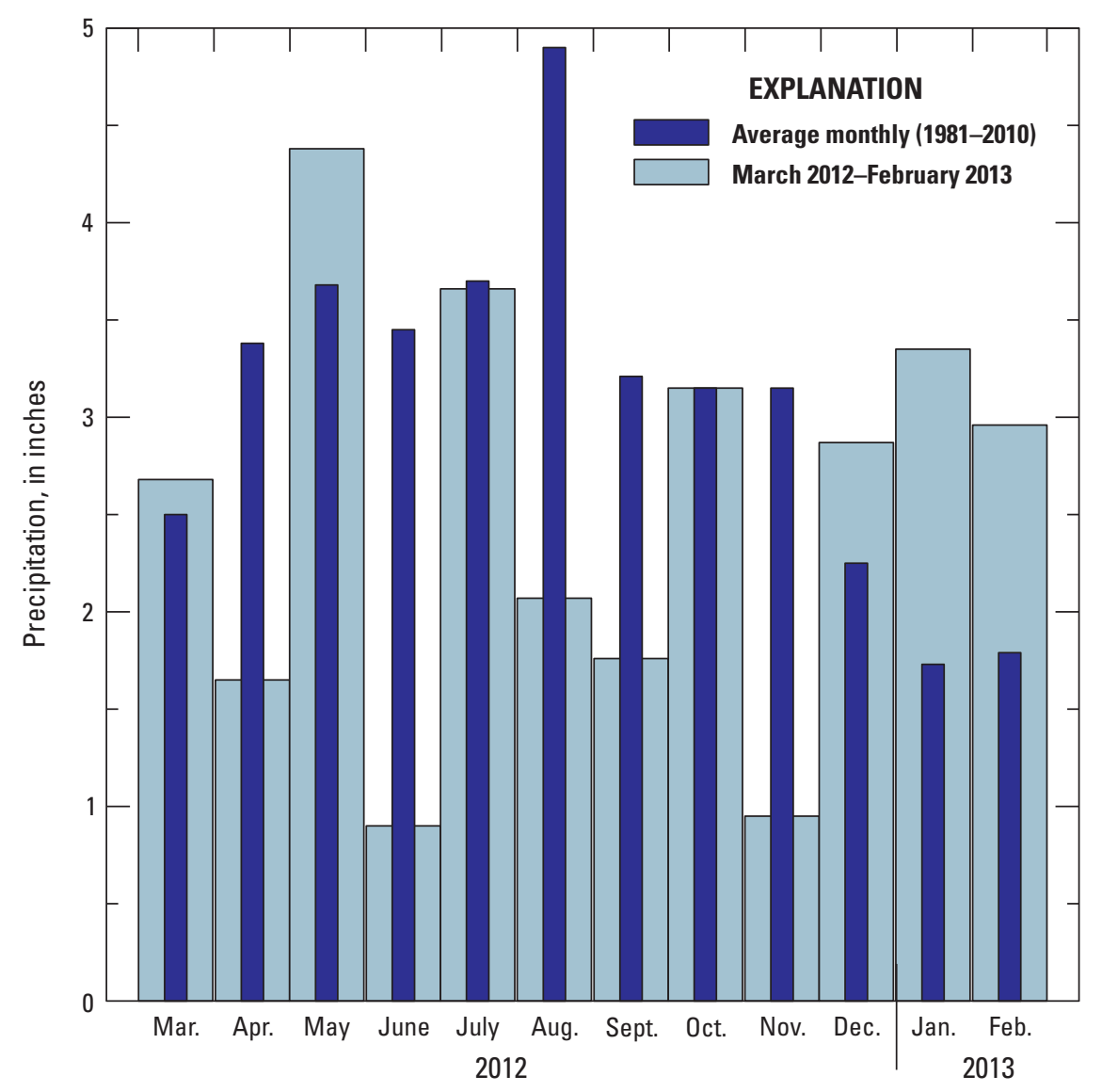

Figure 10. Monthly precipitation (average and March 2012-February 2013) at the National Oceanic and Atmospheric Administration weather station Chicago O'Hare Airport near Elk Grove Village, Illinois. (Precipitation data from Angel, 2013a, b.) 


\section{Methods of Data Collection and Data Analysis}

Methods of data collection and analysis are described for quantification of (1) supplied water by means of public water delivery records of the Elk Grove Village DPW and private well withdrawals, (2) sewer flow returns by means of direct measurements in the MWRD interceptor sewer, (3) and other unmeasured volumes of water, including discharge of swimming pools to storm sewers. Measures taken to address and limit the extent of uncertainty and bias associated with compiled data records (public water deliveries), direct measurements (sewer flow), and unmeasured IN, INF, and EXF are described.

In most water accounting, the difference between the amount of water supplied and the amount of water returned to the sewers would be considered the consumptive water use. However, this consideration fails to include possible groundwater INF to sewer flow, sewer flow EXF to groundwater, or undesirable IN of stormwater. Such unaccounted-for inputs of groundwater and stormwater will result in overestimation of sewer flow returns at the terminal measuring point in the sewershed, and in turn, result in underestimation of consumptive use (fig. 11). Alternatively, unaccounted-for losses of sewer flow to deeper groundwater by EXF through seams, cracks, or breaks in the sewer lines will result in underestimation of sewer flow returns at the terminal measuring point in the sewershed, and in turn, result in overestimation of consumptive use. In this study, groundwater observation wells installed near the representative sewer lines defined the relation of the height of the water table to the depth of the adjacent sewer invert and, thus, the likelihood of INF of groundwater into the sewers or EXF of sewer flow to groundwater. Continuous monitoring of sewer flow to determine the presence and variability in concentration of OBs was attempted to help qualify the extent of groundwater INF and storm-associated IN (the principal source of periodic, large-volume, freshwater discharge to sanitary sewers) by assessing the relative magnitude and temporal patterns of dilution of the OBs in the sewer flow. Concentrations of OBs also were monitored from periodic grab samples collected from the network of study wells to help qualify the extent of sewer flow EXF to groundwater (fig. 11).

Other data were obtained for more limited objectives of this study. A few grab samples for analysis of OBs were collected from the interceptor sewer, Salt Creek, and groundwater at locations other than those represented by the observation wells. The samples were used to further assess the spatial and temporal distribution of OBs throughout the sewershed and, as a result, gain a better understanding of the integrity of the sanitary sewer system and water use patterns. Meteorological and pan-evaporation data from available sources were used in the evaluation of sanitary sewer return flow.
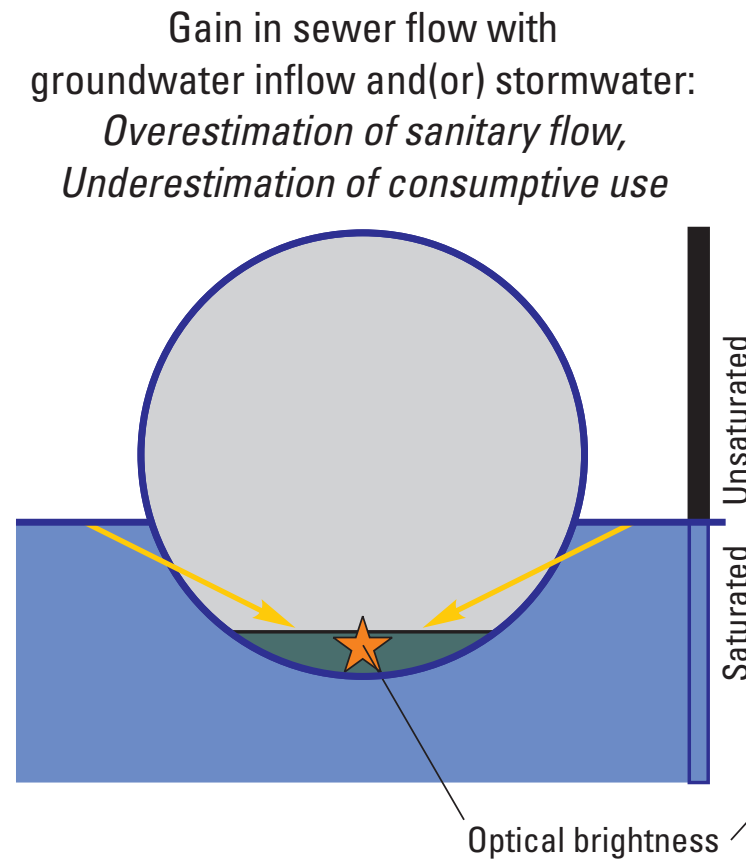

Size infers relative concentration

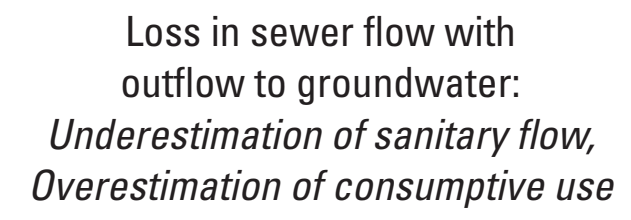

Loss in sewer flow with

outflow to groundwater: Overestimation of consumptive use

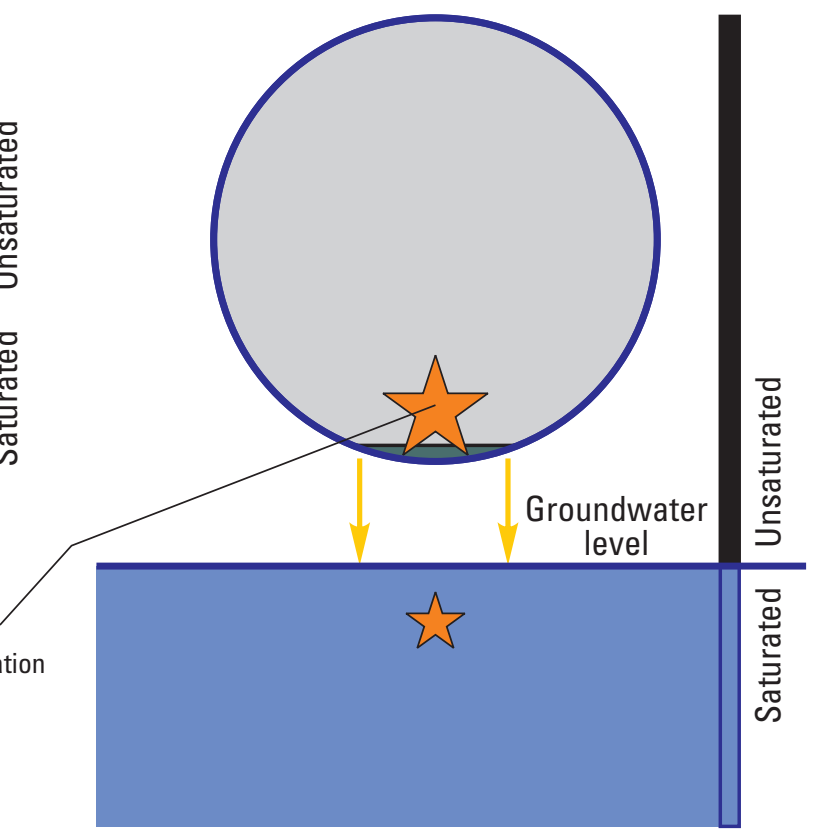

Figure 11. Relation between the presence and concentration of optical brighteners in sanitary sewer flow and groundwater and the gain or loss of sanitary sewer flow from or to groundwater. 
The components of the water balance method for estimation of consumptive use (equation 1) were measured for a full year to capture expected seasonal variation and determine annual totals of the components. Groundwater levels were measured and water was sampled for OBs from March 1, 2012, to May 17, 2013, and sewer flow was measured from March 4, 2012, to March 3, 2013. The designated annual period for estimation of consumptive use was from March 1, 2012, to February 28, 2013. Data were collected after this designated period primarily to address possible sewer system response to a period of record precipitation resulting in local flooding (about 10.5 in. during March 5-April 23; Chicago O'Hare Airport weather station).

\section{Water Supply}

Water supply data for the study area included deliveries from the public water provider, the Elk Grove Village DPW (Elk Grove Village, Illinois, 2011), and self-served supply from private wells. Elk Grove Village DPW meters the municipal water supply deliveries and maintains a record of the monthly water billing by address for each household and commercial or municipal facility served by public supply. Access to those records provided direct measurements supplemented with some estimates (as described below) of most of the supply side of the water balance equation. The service area for water delivery to the included households and facilities was defined by the sewershed. Because supplied water was estimated by using metered water delivery volumes recorded at place of use rather than point of distribution, the additional uncertainty associated with identifying and quantifying conveyance losses is avoided. However, it is recognized that in some applications, such as the Lake Michigan allocation, conveyance losses are included in the definition and estimation of consumptive use (Tzuoh-Ying Su, U.S. Army Corps of Engineers-Chicago District, written commun., 2013).

Elk Grove Village DPW collects readings of each water meter in its service area from approximately half of the service area each month (thus, bimonthly readings for each half). Records of the meter readings of water deliveries (without personal information) were provided in a geodatabase table format to the USGS for each meter in the sewershed. Because these water supply data were not collected simultaneously across the full sewershed, some estimation of the data was necessary to determine a daily rate of use necessary for the approach used in this study to estimate consumptive use. Detailed description of the estimation method and summary results is presented in the section "Quantification of Water Use."
As noted, a single public high-capacity well operates within the sewershed for emergency purposes. Because its limited withdrawals were discharged to a storm sewer during the period of study and not distributed and returned to a sanitary sewer, it was unnecessary to include these withdrawal data in the estimation of consumptive use. Assessment of the water delivery records provided by the Elk Grove Village DPW and the 2012 annual water-use audit record (LOM-2) used for Illinois' Lake Michigan allocation accounting (Tzuoh-Ying Su, U.S. Army Corps of Engineers-Chicago District, written commun., 2013) suggested there might be a limited volume (possibly $22 \mathrm{Mgal}$ ) of unmetered water use for public purposes. The majority of that use seems to be hydrant use (about $17 \mathrm{Mgal}$ ) for purposes such as fire fighting and construction. The remainder (possibly about $5 \mathrm{Mgal}$ ) appears to be for public facilities; it is unclear if this use is included in the delivery records provided by Elk Grove Village PWD. Given the negligible volume of this apparently unmetered use (about 4 percent of metered deliveries) and the likelihood that the majority of this use is for purposes that result in limited return to sanitary sewers, it was determined that the use could reasonably be ignored in the quantification of supplied water necessary for estimation of consumptive use.

Self-served water supply was estimated, as records of withdrawals were not available from private well owners. This estimation was limited to those users connected to the sanitary sewer system. To assess the possible effort required for this estimation, the ILWATER well and boring database (Illinois State Geological Survey, 2013) was reviewed for private supply wells that might have been installed in the study area. ILWATER is not a complete record of installed wells, some wells can be mislocated, and not all included wells are still in use. Confirmation of the mapped locations and continued use of these wells required additional driveby inspection of selected properties and firsthand knowledge of land development, zoning, and sources of residential water supply in the study area as provided by the village (Scott Bernholdt, Department of Public Works Elk Grove, oral commun., 2011). From these various resources and efforts, the number of wells reasonably expected to be in use was tallied.

Of note, many of the mapped locations of wells from the ILWATER database appeared to be mislocated, which hampered verification of their present usage status. Mislocation of wells on the database map is common because of unavoidable error associated with derivation of latitude-longitude mapping coordinates from the township-range-section coordinates recorded on most supply well construction logs in the database. With the mapping issues, which are particularly problematic in urban settings, full field verification of the location and use status of the mapped wells was not attempted. 
The well tally provided the basis for estimating the number of persons relying on the use of each well and from this, the withdrawal quantities associated with use of the wells. These private well withdrawal quantities within the sewershed were estimated by application of the following equation:

$$
Q=(W * U P H * P C U * 365) / 1000000
$$

where

$$
\begin{aligned}
Q= & \text { annual withdrawals, in million gallons per } \\
& \text { year, } \\
W= & \text { the total number of wells representing the } \\
& \text { total number of households, } \\
= & \text { the number of users per household, and } \\
= & \text { per capita use, in gallons per day per } \\
& \text { person. }
\end{aligned}
$$

Reported statistics of the U.S. Census Bureau (2013b)

were used as the initial basis for estimating the average population of households with private wells. These statistics indicate that between 2007 and 2011 there averaged 2.54 persons per household in Elk Grove Village; however, 30.5 percent of the 13,905 residential dwellings, as determined for the 2010 Census, were multiunit structures. One might speculate that household populations of single-family homes would be greater than the populations of multifamily housing units in this predominantly middle class community. Review of the database information indicated that all of the identified private wells within the study area served single-family homes. As such, the persons (number of users) per household was adjusted upward to three. This estimate of persons per household agreed well with that later derived for the unincorporated area (fig. 3) from U.S. Census Bureau (2013a) statistics. The 382 residents in single-family homes within the 134 homes in this area (essentially each using a well) compute to 2.85 residents per home.

A per capita use coefficient of 80 gallons per day per person $(\mathrm{gal} / \mathrm{d} / \mathrm{p})$ was used. This coefficient was derived from the population $(19,000)$ and the annual public supply deliveries (566 Mgal) subsequently determined for the study area. This coefficient is in good agreement with those used by others in the region to reflect domestic water use. The same coefficient value was used for the 2010 USGS national compilation of water use (U.S. Geological Survey, 2013) to estimate domestic deliveries by public supply and self-served residential withdrawals in Illinois. That coefficient was derived from analysis of recent trends in Illinois public supply water use by using statewide data and insights of the ISWS Illinois Water Inventory Program (Mills and Sharpe, 2010). Neighboring Great Lakes states used domestic use coefficients that generally ranged from about $75 \mathrm{gal} / \mathrm{d} / \mathrm{p}$ to $85 \mathrm{gal} / \mathrm{d} / \mathrm{p}$ for the USGS national compilation. The ISWS uses coefficients of $75-80 \mathrm{gal} / \mathrm{d} / \mathrm{p}$, as dictated by the agency application (Timothy Bryant, Illinois State Water Survey, Illinois Water Inventory Program, written commun., 2012).

\section{Return Sanitary Sewer Flow}

Hydroacoustic flow monitoring within the sanitary sewershed provided the measured return flow for the waterbalance equation. An upward-looking 3.0-megahertz (MHz) acoustic Doppler current-velocity meter (ADVM) (fig. 12) was installed in the MWRD interceptor sewer that drains the sewershed near well TW1 (figs. 2; 13). This monitoring site is identified as USGS station 420120087583401, Sewer at Oakton at Elk Grove Village, Illinois. Access to the interceptor required confined space entry training and regulated safety precautions.

The ADVM was mounted to the invert of the 5 - $\mathrm{ft}$ diameter concrete interceptor pipe, about $10 \mathrm{ft}$ upstream of the manhole access location, and secured with concrete anchors. Based on prior experience and manufacturer recommendations, the minimum sewer size and stage requirements for use of the ADVM for measurements of flow within sewers is about a 3 -ft diameter pipe and about a 0.5 -ft fluid height above the meter. Typical stage within the monitored interceptor was about $1-2 \mathrm{ft}$. The pipe size and stage requirements, along with the exploratory scope of the study, limited the ADVM monitoring of sewer flow (discharge) to the single interceptor site.

The ADVM was installed in March 2012. Its power and data cable was secured with concrete anchors along the interceptor pipe. On exiting the manhole, the cable was routed through buried conduit into an adjacent instrument enclosure. The enclosure contained a 12-volt battery to power the ADVM, with a solar panel mounted above the enclosure and a voltage regulator to maintain the battery charge. The ADVM was programmed for the interceptor sewer geometry and data parameters (sewer shape and diameter and instrument height and orientation). Its setup parameters were saved into a log file and archived.

The configuration of the ADVM installed for the study uses three acoustic transducers to resolve the depth of water and a mean velocity vector (fig. 12). Upstream- and downstream-facing acoustic transducers apply Doppler technology to compute the mean water velocity. A third transducer facing directly upward is used to measure the depth of water. Internal ADVM calculations compute a wetted cross-sectional area based upon the measured depth and the pipe geometry and then use the velocity and cross-sectional area to compute a discharge. The ADVM was programmed to measure flow and output the data at 5-minute intervals. This interval for data output was selected based upon the size of the sewershed and prior experience monitoring sewer flows. The interval captures the unsteady flow characteristics of sewer flow measurement without compromising power and data storage within the ADVM. 

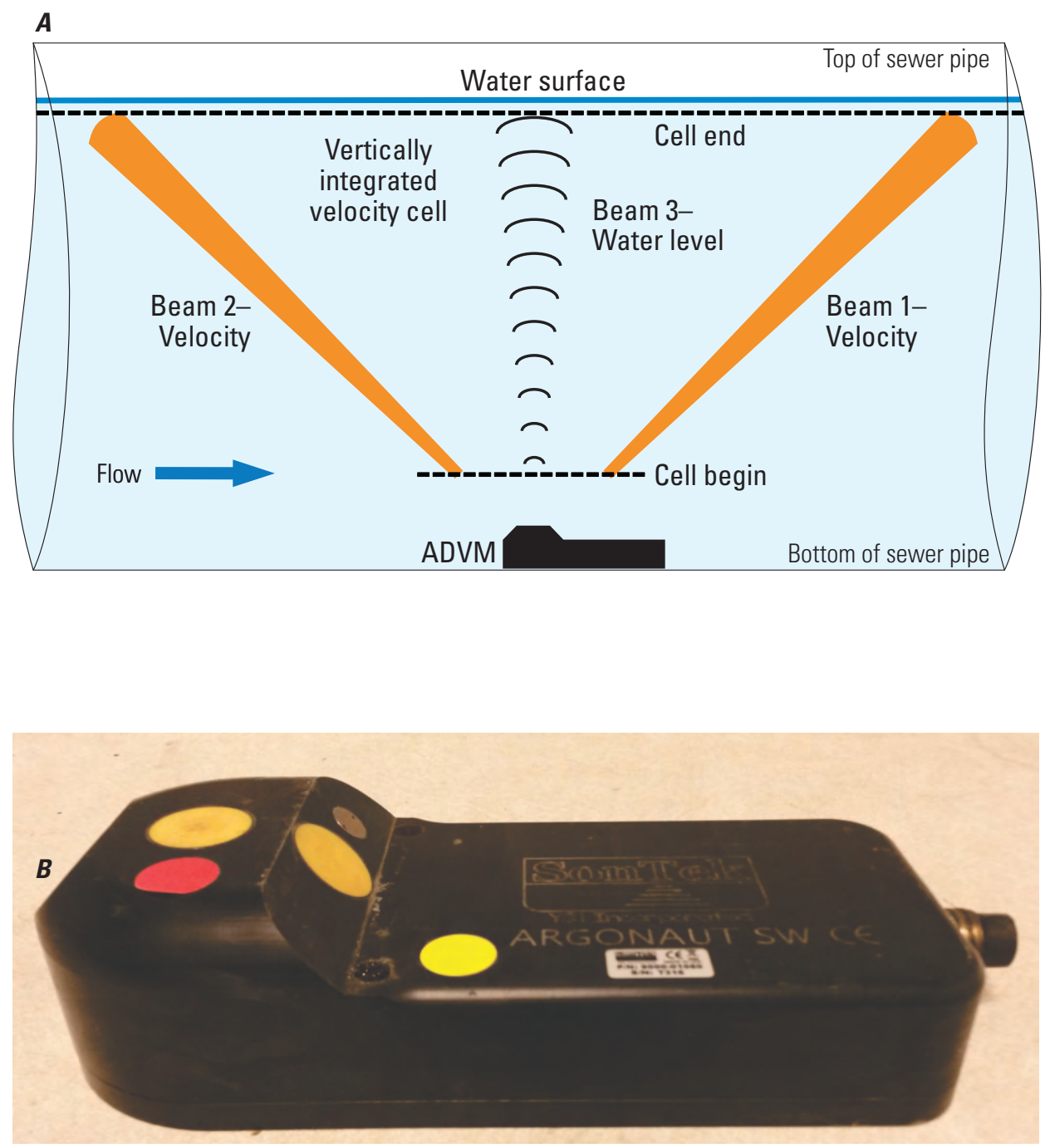

Figure 12. $A$, Principles of flow measurement with an acoustic Doppler current-velocity meter (ADVM). $B, A D V M$ used in the sanitary sewer installation. 
$\boldsymbol{A}$
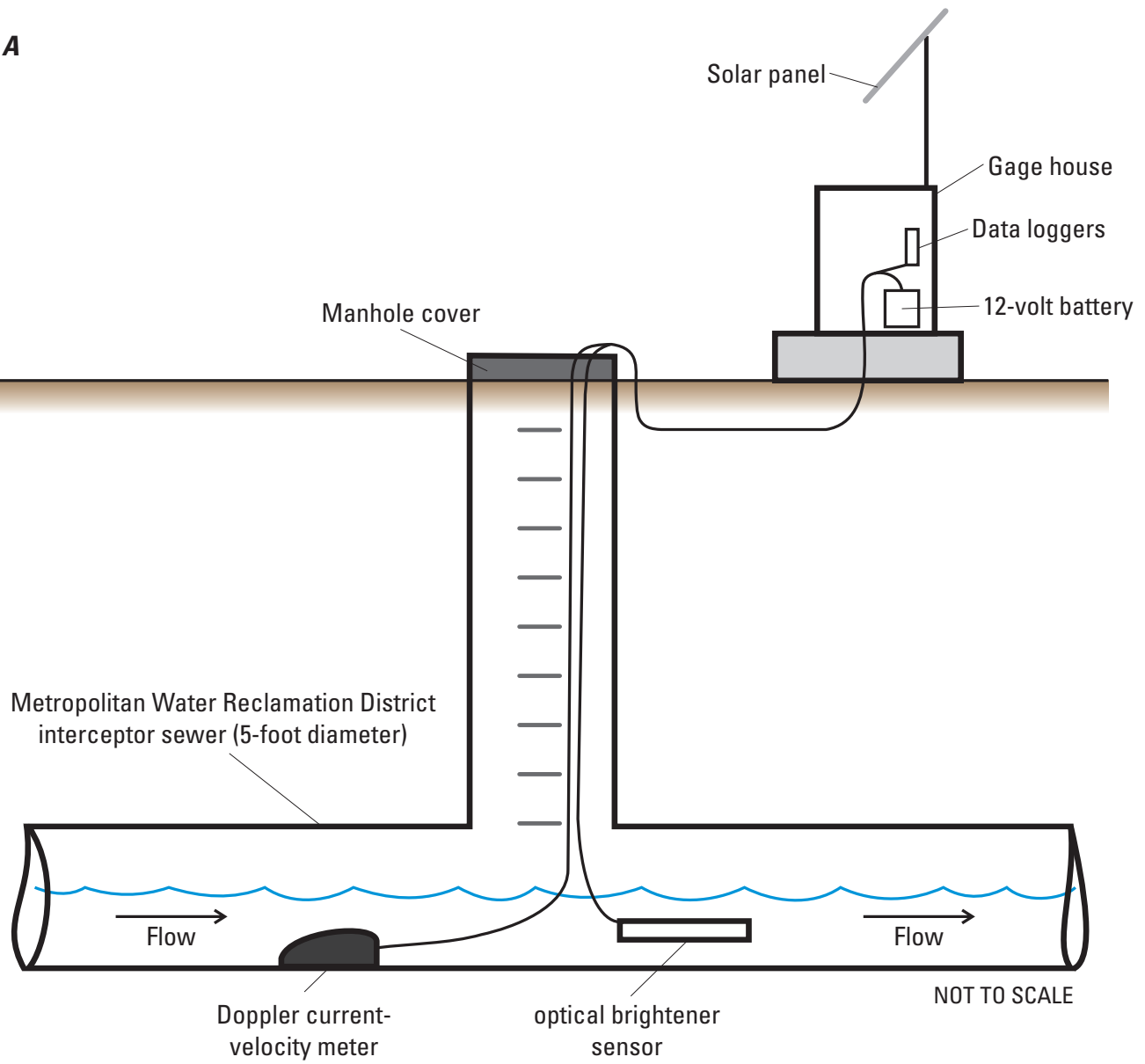

B
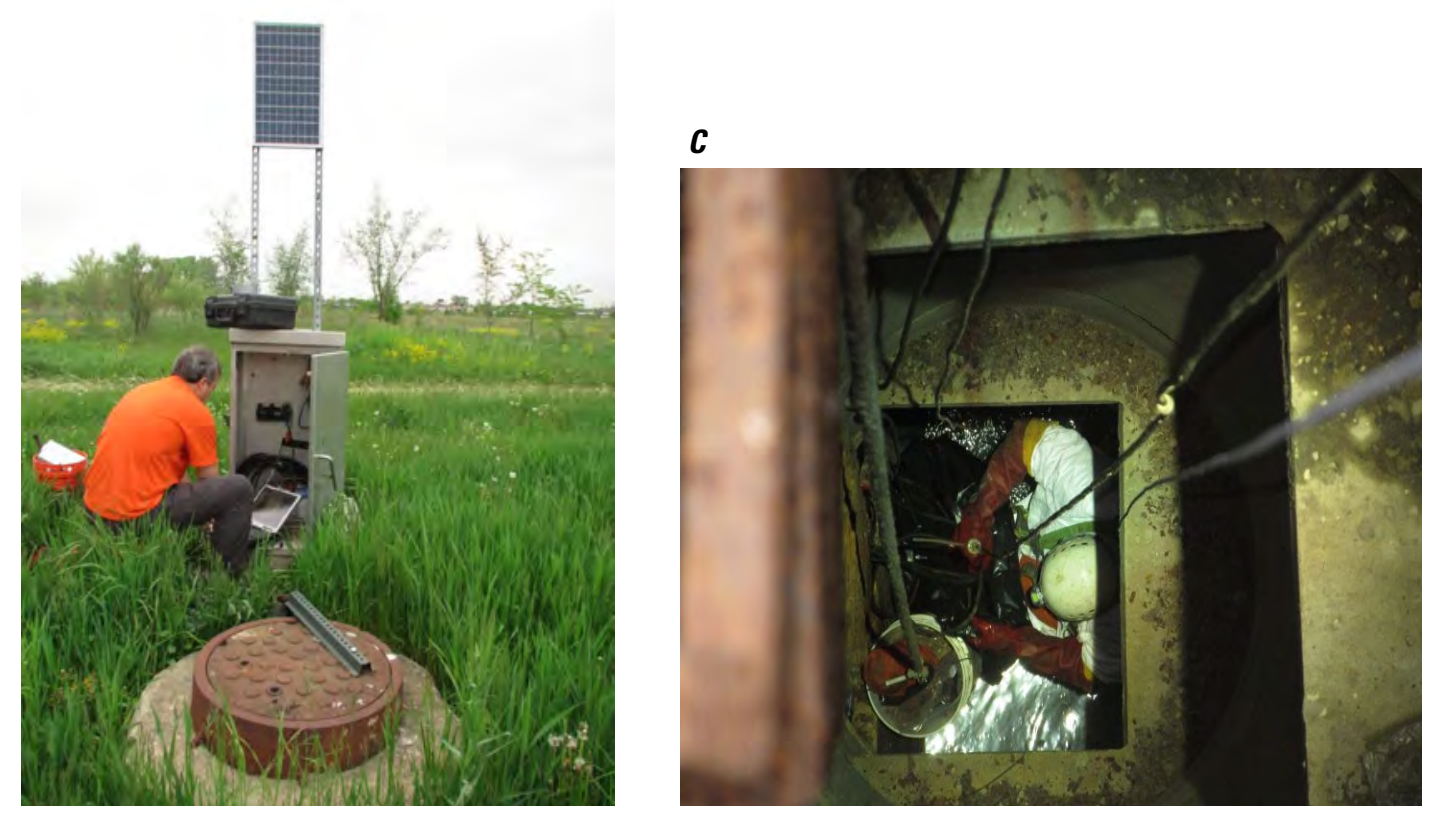

Figure 13. U.S. Geological Survey station Sewer at Oakton at Elk Grove Village, Illinois, in the interceptor near observation well TW1 (see fig. 2 for location). $A$, Instrumentation system for hydroacoustic and optical brightener sanitary sewer flow monitoring. $B$, Surface enclosure and solar panel for the monitoring instruments. $C$, In-sewer equipment installation (requiring confined space entry training, personal protective equipment, and regulated safety precautions). 
Occasional buildup of debris on or near the ADVM was evident, observed during site visits and in review of the data. Although it affected ADVM velocity measurements, the buildup generally was light. For the most part, velocity through this reach of pipe was sufficient to move particulate matter or debris past the meter; also, any observed debris was removed during site visits.

A stage-discharge rating was developed in addition to the direct computation of discharge by using velocity data of the ADVM. The rating was based, in part, on periodic lowstage wading discharge measurements made for verification of the discharge computed by the ADVM; the measurements were made within the sewer at the manhole location. The relation of discharge to higher stages represented in the rating was developed from ADVM stage-velocity data obtained during periods of record considered satisfactory. The measurements followed standard USGS methods (Rantz and others, 1982; Turnipseed and Sauer, 2010). The stage-discharge rating is independent of velocity; thus, for site conditions not affected by variable backwater or surcharge conditions, its use often provides a more consistent time series of discharge than that computed by use of the ADVM stage-velocity discharge record. Suspended debris may affect the two ADVM transducers used for measuring velocity, whereas the ADVM transducer measuring stage is unaffected. This debris effect, as well as unsteady flow, results in noisy (variable) and sometimes missing velocity data, whereas the stage record is very good with limited noise and missing data. Because of the noise and missing data in the velocity time series that resulted from the occasional debris buildup and unsteady flow in the interceptor sewer, use of the stage-discharge rating was found to provide the most reliable and consistent discharge time series. For this reason, the time-series record from this stage-discharge rating was used to compute the final discharge time series for the mass-balance analysis.

Flow data from the ADVM were downloaded during periodic site visits. Log files were generated for each site visit to record the ADVM parameters. Processing of the ADVM raw data followed standard USGS protocols. The raw data files initially were reviewed in the field by using manufacturer's software. The data downloaded from the ADVM then were temporarily stored on a field personal computer and transferred back to the USGS office. In the office, the data were exported and processed for loading into the USGS National Water Information System (NWIS) database. Within NWIS, the data were reviewed thoroughly by a USGS hydrologist experienced data collection and analysis of sewer flow. Stage, area, velocity, and discharge hydrographs similarly were reviewed and approved by USGS staff.
Final processing of the data for analysis required a number of additional measures, including estimation of missing record and accounting for components of the measured sewer flow that were not the result of sanitary discharge. The measures are described in the section "Quantification of Sanitary Sewer Flow."

\section{Other Unmeasured Return Flow}

Efforts were made to quantify two potentially significant sources of direct returns of metered (public water deliveries) and self-supplied water to surface waters that are not accounted for in the measurement of sanitary sewer flow: (1) water discharged from public and private pools in the study area (fig. 14) at the conclusion of the pool season and (2) water lost during residential carwashing. In Elk Grove Village, metered and self-supplied water used to fill public and private pools is routinely discharged to the storm sewers, not sanitary sewers (Scott Bernholdt, Department of Public Works, Elk Grove Village, Illinois, oral commun., 2013). For this study, most of the water used in residential washing of cars was considered lost to storm drains; water used in commercial carwashes typically is reported as discharged to sanitary sewers (Western Carwash Association, 2013). The methods used to used to estimate and (or) evaluate the quantities of water that might be associated with discharge to storm sewers from swimming pools and carwashing in the study area are described in detail in appendix 1. Review of National Pollutant Discharge Elimination System (NPDES) permits for Elk Grove Village (U.S. Environmental Protection Agency, 2013a) found no evidence of other more notable direct discharges to Salt Creek.

The estimate(s) of swimming pool discharge was included in the final estimate of sewershed direct returns because the estimate(s) could be quantified within a reasonable degree of uncertainty (less than about 25 percent). Although estimated, the volume of carwash discharge was not included as a direct return for determination of consumptive use; estimation uncertainty was substantial, as no study area data or related information were available as a basis for the estimation. Direct return flow from other possible routes, such as drainage from impervious surfaces (parking lots) and commercial properties during landscape irrigation, were not considered for estimation, because of their difficulty of quantification and the presumption of limited return volumes. 

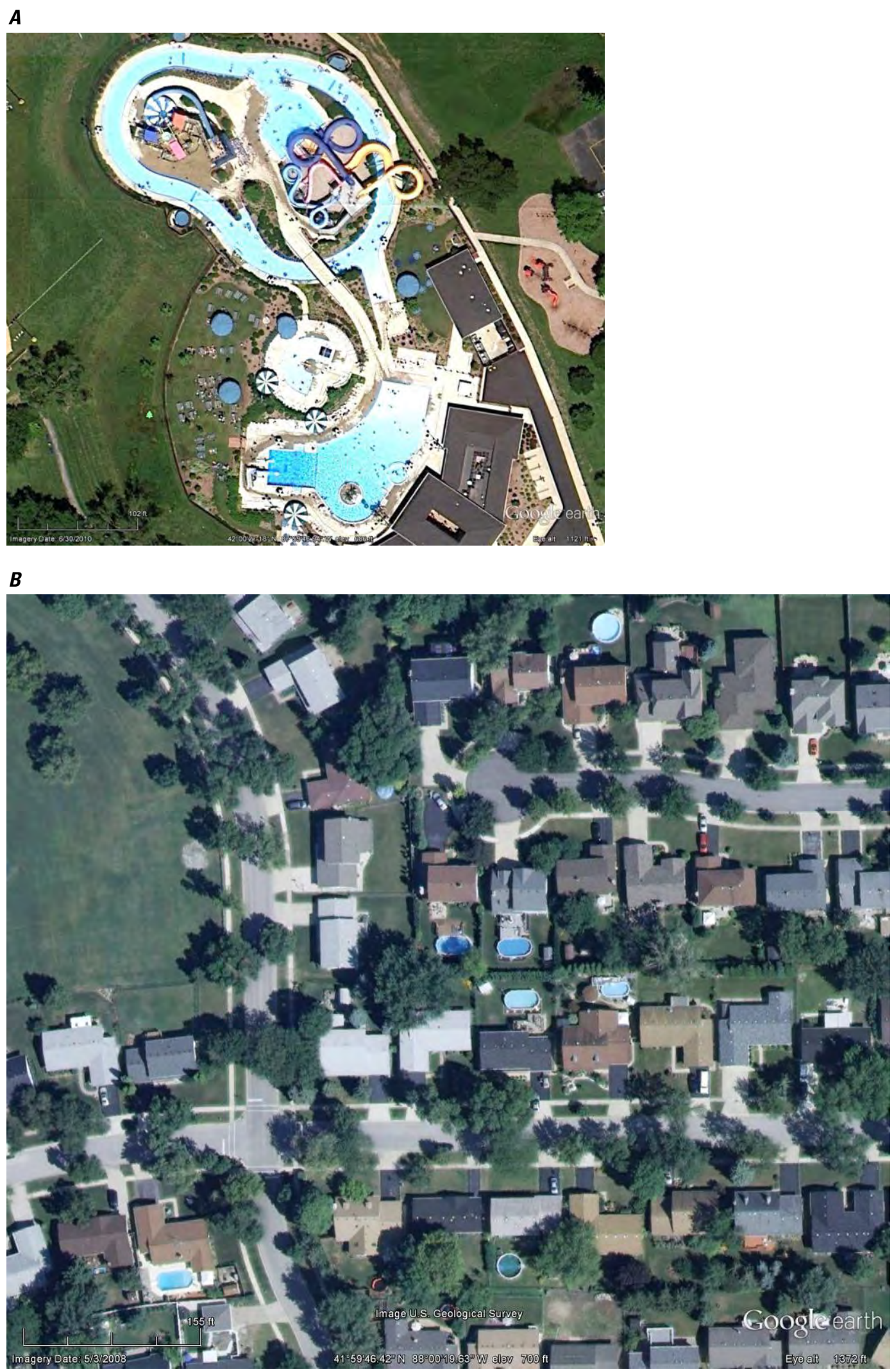

Figure 14. Examples of visual accounting of swimming pools in the study area, Elk Grove Village, Illinois. $A$, Village water park. $B$, Typical residential pools. (Imagery source and date are Google Earth, June $30,2010$. 


\section{Groundwater}

In order to reasonably address questions regarding possible IN, INF, and EXF that would need to be accounted for in the sewershed outflow measured in the interceptor sewer, it was necessary to evaluate the relation between depths to groundwater and depths of sanitary sewer inverts and the variability of that relation across the study area and through time. To evaluate this relation, 12 observation wells were installed adjacent to sewer lines of various depths (figs. 2; 15; table 1). The 1-in. diameter PVC wells with 5-ft screens (nominal length of open interval) were installed during February-March 2012 by using the Geoprobe Systems direct-push methodology (figs. 15A, B). The wells were placed in the open holes that resulted from the cores that were collected at each location to determine the natural lithologies and trench-fill materials near the sewer lines (table 2). The annulus adjacent to the wells was backfilled with medium-grained quartz sand to a height about $1 \mathrm{ft}$ above the top of the well screen, followed by fine-grained granular bentonite to near land surface. The bentonite backfill was hydrated to ensure a proper seal that restricts surface flow down the annulus to the screen interval. Backfill materials were placed by using a tremie to ensure accurate depths of placement. The tops of all but one of the wells (TW1) terminated a few tenths of a foot below land surface and were contained inside flush-mount security vaults that were cemented in place. Flush-mount wells were capped to prevent surface water leakage into the wells, should the security vault flood. The top of well TW1 terminated about $2.8 \mathrm{ft}$ above land surface, inside a 4-square inch $\left(\mathrm{in}^{2}\right)$ steel security casing. Following installation, all wells were developed to purge sediment-laden waters that, as the result of well construction, represent a mixture of depths within the groundwater system.

The wells were distributed across the site at locations that approximately represented the vertical extent of topographic relief (fig. 8). With the generally limited relief of the sewershed, the number of wells installed was considered appropriate for reasonably characterizing depths to groundwater throughout the area; depth to groundwater in shallow, unconfined systems tends to mimic land surface topography. With this area centrally bisected by the north-to-south drainage of Salt Creek (fig. 8), the lowest land surface elevations in the sewered-part of the area occur along the streets flanking the Salt Creek floodplain-about $680 \mathrm{ft}$ North American Vertical Datum of 1988 (NAVD 88). The highest land surface elevations occur in the southeasternmost part-about $720 \mathrm{ft}$ NAVD 88. In general, across the eastern half of the sewershed, the elevation drops about $25 \mathrm{ft}$ from its eastern boundary to the edge of the Salt Creek floodplain; across the western half, the elevation drops about $10 \mathrm{ft}$ from its western boundary to the floodplain. With their placement across the sewershed at approximate land surface elevations of $682-716 \mathrm{ft}$ NAVD 88 , the installed wells are considered to reasonably capture the variability in land surface relief, and thus, the assumed variability in the depth to groundwater. The depth of installed wells ranged from about 13-44 ft below land surface (table 1). Typical well construction is documented in the selected graphical logs of four representative wells (appendix 2).

Distribution of the wells across the sewershed also was planned in consideration of describing and appropriately representing the area's near-surface lithologies. As indicated from the collected cores and available construction logs for supply wells (Illinois State Geological Survey, 2013), the near-surface soils across the sewershed (within the approximate depths of the observation wells) are fine-grained, consisting of silt, clayey silt, and silty clay deposits. The supply well logs and observations from sewer line installations and repair (Scott Bernholdt, Department of Public Works, Elk Grove Village, Illinois, oral commun., 2011) indicate the presence of some very localized deposits of sandy silt, sand, and gravel. These coarser grained deposits seem to be no more than about 1-2 ft thick and typically are present at depths greater than about $10 \mathrm{ft}$. Shallower sand deposits, including saturated flowing sands, have been reported (Scott Bernholdt, Department of Public Works, Elk Grove Village, Illinois, oral commun., 2011) in areas close to Salt Creek (presumably principally within its floodplain) and in isolated locations limited to the southwestern part of the study area (fig. 8). At some of the noted locations, the soils encountered during installation of nearby wells tended to verify the limited areal extent of these course-grained deposits. General representations of the area geology, trench-fill lithologies and other materials, and summarized descriptions of cores collected during installation of four selected observation wells are included in appendix 2 .

Each well was installed near a sanitary sewer line, with all but two within 2-3 ft of a line. Well TW1 (fig. 2) was installed at a distance of about $6 \mathrm{ft}$ because of uncertainties about the lateral limits of the approximately $52-\mathrm{ft}$ deep interceptor sewer that drains the study area, and well TW7 was installed about $4 \mathrm{ft}$ topographically downgradient of the adjacent line because of the close presence of a sidewalk. The terminal depths of 10 of the wells were within about 3-9 ft of the sewer inverts, with the top of their screen intervals ranging from about $4 \mathrm{ft}$ below the sewer invert (well TW12) to about $1.5 \mathrm{ft}$ above the invert (well TW6). Positioning of the well screens relative to the sewer inverts was dictated by the following factors:

1. the necessity of some part of the screen interval to be below the invert to ensure collection of any sewer flow leakage (generally by EXF through unsaturated deposits to the water table), as indicated by the presence of OBs in the collected water samples, and

2. depth of groundwater relative to the invert, as determined from soil cores at the time of well installation. 


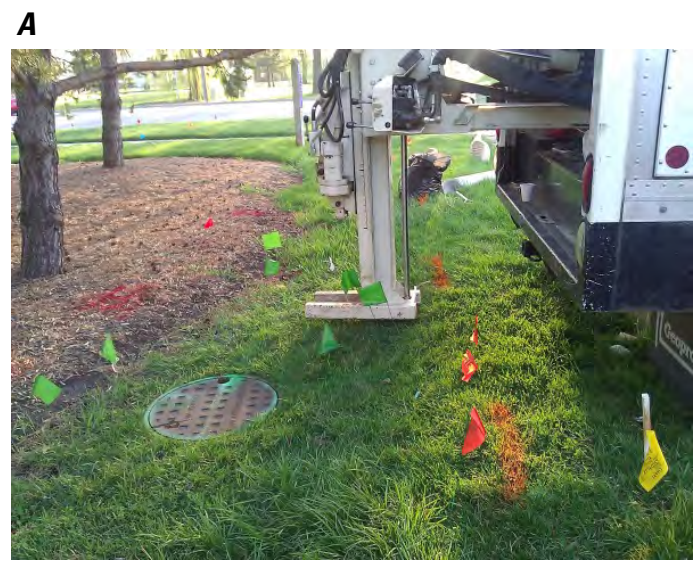

B

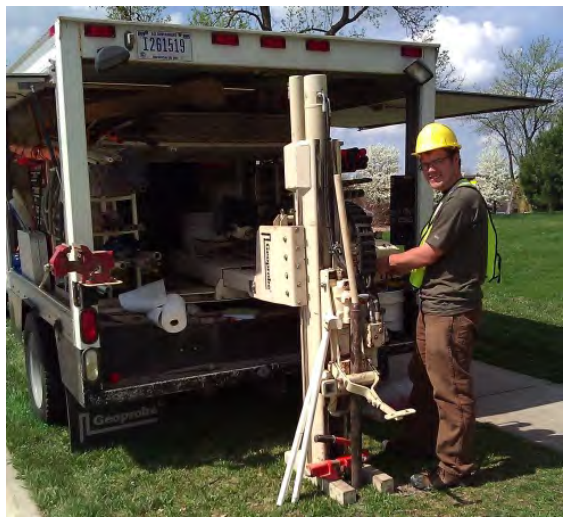

C

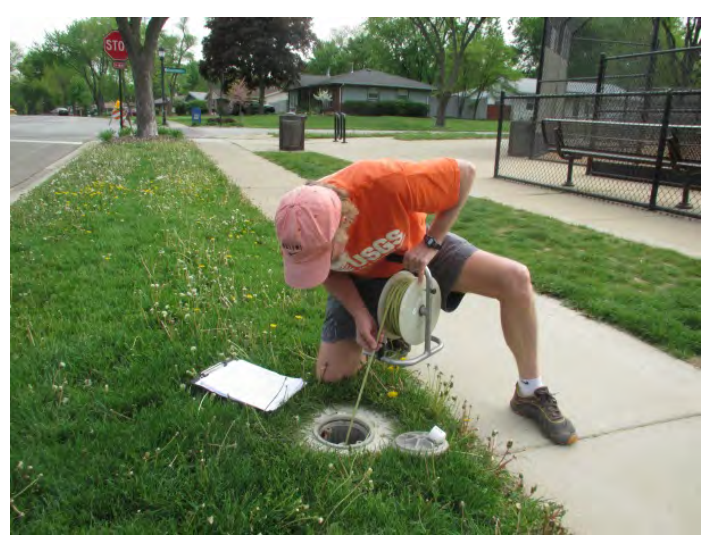

D

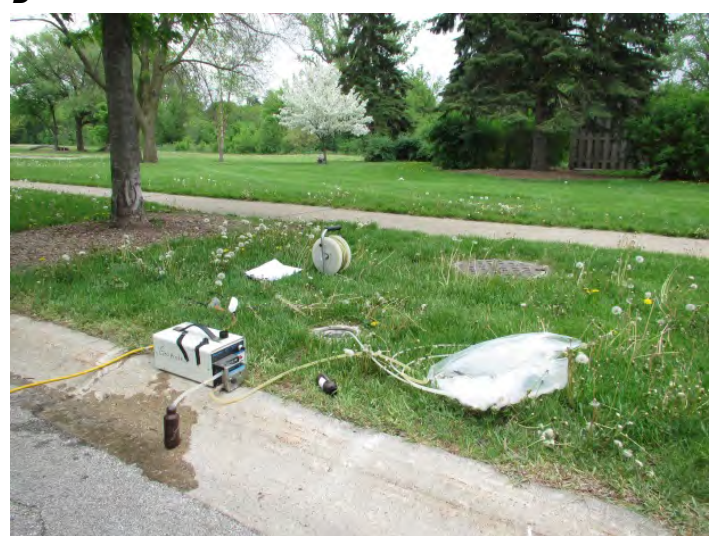

$E$

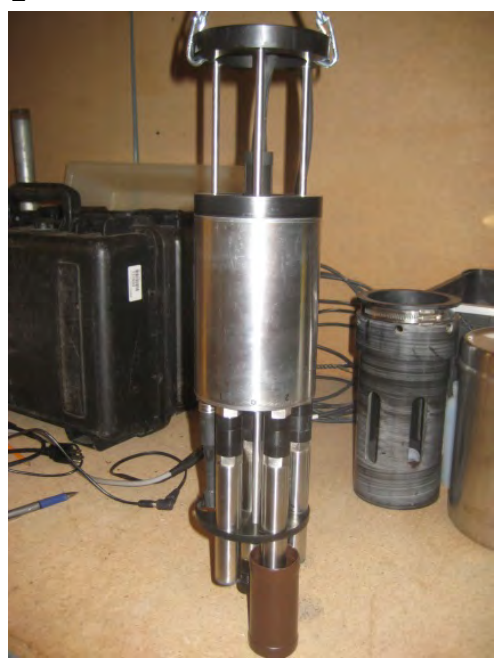

$\boldsymbol{F}$

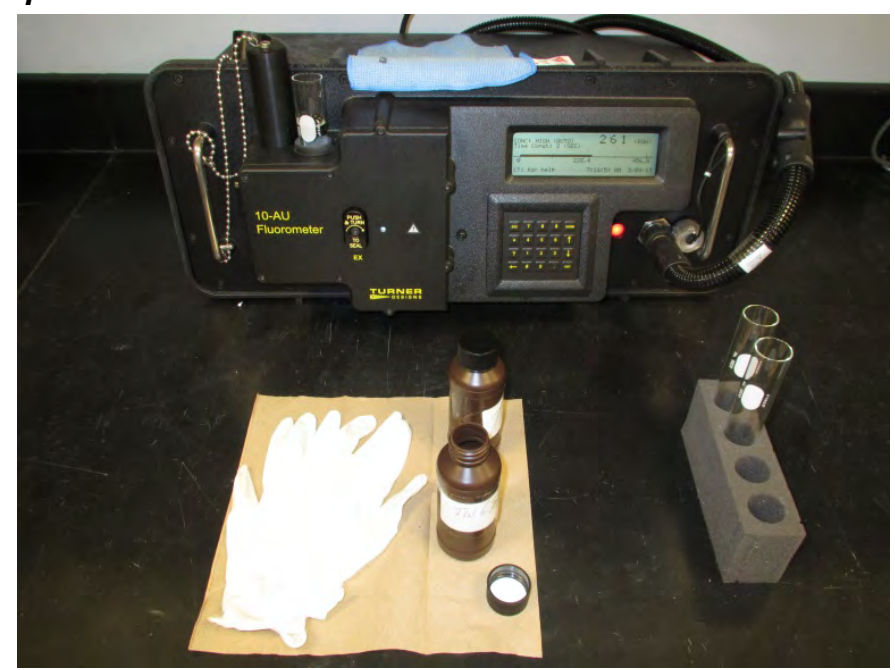

Figure 15. Field and benchtop instrumentation used in the determination of consumptive use in the study area, Elk Grove Village, Illinois. $A$, Direct-push system, prior to installation of observation well TW12 adjacent to a sanitary sewer line and manhole. $B$, Direct-push system, installation of well TW2 near the sanitary sewer lift station. $C$, Completed flush-mount well TW7 in a residential neighborhood. $D$, Completed flush-mount well TW9 in the Salt Creek floodplain. E, Fluorometer, used for in situ (field) assessment of optical brighteners. F, Fluorometer, used for benchtop assessment of optical brighteners. 
Table 2. Hydrogeologic information for observation wells installed adjacent to sanitary sewers in the study area, Elk Grove Village, Illinois, March $2012-$ May 2013.

[NWIS, U.S. Geological Survey National Water Information System; ft bls, feet below land surface; dates are expressed as month/day/year]

\begin{tabular}{|c|c|c|c|c|c|c|c|c|c|}
\hline $\begin{array}{l}\text { NWIS site } \\
\text { identification }\end{array}$ & $\begin{array}{l}\text { Local } \\
\text { name }\end{array}$ & $\begin{array}{l}\text { Open } \\
\text { interval } \\
\text { of well, } \\
\text { in ft bls }\end{array}$ & $\begin{array}{l}\text { Approximate } \\
\text { depth to } \\
\text { sewer invert, }{ }^{1} \\
\text { in ft bls }\end{array}$ & $\begin{array}{l}\text { Lithology near } \\
\text { well and sewer }\end{array}$ & $\begin{array}{l}\text { Lithology near } \\
\text { open interval } \\
\text { of well }\end{array}$ & $\begin{array}{l}\text { Minimum } \\
\text { depth to } \\
\text { groundwater, } \\
\text { in ft bls }\end{array}$ & $\begin{array}{l}\text { Date of } \\
\text { minimum } \\
\text { depth }\end{array}$ & $\begin{array}{l}\text { Maximum } \\
\text { depth to } \\
\text { groundwater, } \\
\text { in } \mathrm{ft} \text { bls }\end{array}$ & $\begin{array}{l}\text { Date of } \\
\text { maximum } \\
\text { depth }\end{array}$ \\
\hline 420121087583401 & ${ }^{2} \mathrm{TW} 1$ & $38.6-43.6$ & 52 & $\begin{array}{l}\text { Fill-clayey silt/silty clay; } \\
\text { some sand }\end{array}$ & $\begin{array}{l}\text { Pebbly, clayey silt/ } \\
\text { silty clay }\end{array}$ & 26.42 & $04 / 23 / 12$ & 28.69 & $11 / 08 / 12$ \\
\hline 420024087592101 & TW2 & $14.9-19.9$ & 22 & Fill-gravelly clayey silt & Gravelly clayey silt & 9.14 & $08 / 20 / 12$ & 13.45 & $01 / 31 / 13$ \\
\hline 415937088002101 & ${ }^{2}$ TW5 & $8.7-13.7$ & 8 & Fill-clayey silt & $\begin{array}{l}\text { Gravelly, pebbly, silty } \\
\text { sand/sandy silt }\end{array}$ & 3.7 & $03 / 01 / 12$ & 12.65 & $09 / 20 / 12$ \\
\hline 415954087594101 & TW6 & $8.2-13.2$ & 8 & $\begin{array}{l}\text { Fill-sandy, pebbly, } \\
\text { gravelly silt to clayey } \\
\text { silt }\end{array}$ & $\begin{array}{l}\text { Clayey silt to silty, } \\
\text { fine-grained sand }\end{array}$ & 3.12 & $01 / 31 / 13$ & 8.64 & $09 / 27 / 12$ \\
\hline 415956087591801 & TW7 & $13.9-18.9$ & 14 & $\begin{array}{l}\text { Fill-sandy, pebbly, } \\
\text { gravelly silt to clayey } \\
\text { silt with thin sand, } \\
\text { gravel lenses }\end{array}$ & $\begin{array}{l}\text { Silty, pebbly fine- } \\
\text { medium grained } \\
\text { sand to pebbly silty } \\
\text { clay/clayey silt }\end{array}$ & 7.45 & $01 / 31 / 13$ & 11.62 & $08 / 20 / 12$ \\
\hline 420029088000601 & ${ }^{2} \mathrm{TW} 8$ & $16.9-21.9$ & 18 & $\begin{array}{l}\text { Fill-gravelly,clayey silt } \\
\text { with decaying woody } \\
\text { debris in lower part; } \\
\text { Native?-pebbly clayey } \\
\text { silt/silty clay }\end{array}$ & $\begin{array}{l}\text { Clayey silt with } \\
\text { woody debris to } \\
\text { pebbly, clayey silt/ } \\
\text { silty clay }\end{array}$ & 12.60 & $01 / 31 / 13$ & 13.72 & $11 / 08 / 12$ \\
\hline 420001087595201 & ${ }^{2}$ TW9 & $15.1-20.1$ & 16.5 & $\begin{array}{l}\text { Fill-clayey silt to silty } \\
\text { sand/silt with clay }\end{array}$ & $\begin{array}{l}\text { Silty sand/silt with } \\
\text { clay to fine- } \\
\text { grained silty sand/ } \\
\text { sandy silt }\end{array}$ & 12.49 & $01 / 31 / 13$ & 14.02 & $09 / 20 / 12$ \\
\hline 420112087590501 & TW11 & $10.1-15.1$ & 10 & $\begin{array}{l}\text { Fill-clayey silt to silty } \\
\text { clay }\end{array}$ & $\begin{array}{l}\text { Clayey silt to silty } \\
\text { clay }\end{array}$ & 5.30 & $03 / 22 / 12$ & 10.77 & $11 / 07 / 12$ \\
\hline 415941087584601 & TW12 & $11.0-16.0$ & 7 & $\begin{array}{l}\text { Fill-silt with sand; } \\
\text { Native?-silt with clay }\end{array}$ & $\begin{array}{l}\text { Silt with sand to silt } \\
\text { with clay }\end{array}$ & 6.92 & $08 / 20 / 12$ & 7.40 & $11 / 07 / 12$ \\
\hline 420053087592201 & TW13 & $10.0-15.0$ & 10.5 & $\begin{array}{l}\text { Fill-silt with minor clay; } \\
\text { Native?-silt with minor } \\
\text { clay to clayey silt }\end{array}$ & $\begin{array}{l}\text { Silt with minor clay } \\
\text { to clayey silt }\end{array}$ & 6.64 & $01 / 31 / 13$ & 9.91 & $11 / 07 / 12$ \\
\hline 420133087590901 & TW14 & $8.2-13.2$ & 9 & $\begin{array}{l}\text { Fill-gravelly, pebbly, } \\
\text { sandy silt; } \\
\text { Native?-clayey silt }\end{array}$ & $\begin{array}{l}\text { Gravelly, pebbly, } \\
\text { sandy silt to clayey } \\
\text { silt }\end{array}$ & 5.80 & $01 / 31 / 13$ & 8.67 & $09 / 20 / 12$ \\
\hline 420029088004401 & TW15 & $14.9-19.9$ & 16 & $\begin{array}{l}\text { Fill-silt with minor clay } \\
\text { to clayey silt }\end{array}$ & $\begin{array}{l}\text { Silt with minor clay } \\
\text { to clayey silt }\end{array}$ & 11.50 & $03 / 22 / 12$ & 13.71 & $11 / 08 / 12$ \\
\hline
\end{tabular}

${ }^{1}$ The level (depth) of the inside bottom of a sewer pipe.

${ }^{2}$ Construction and lithologic logs included in appendix 2 . 
Well TW1 was installed to a depth about $8 \mathrm{ft}$ above the interceptor sewer (and about $6 \mathrm{ft}$ above its base level of sewer flow). Drilling conditions, possibly the result of encountering gravel fill from trench construction, prevented deeper installation. The 22-ft deep well TW2 was installed to a depth assumed to be about $2 \mathrm{ft}$ above an underlying trunk line, which within about $50 \mathrm{ft}$ connects to the sanitary sewer lift station. Drilling conditions, possibly the result of encountering the top of the concrete sewer line or trench-fill gravel, prevented deeper installation. At well TW12, the depth to groundwater was greater than $4 \mathrm{ft}$ below the sewer invert at time of well installation, thus dictating the comparatively deep placement of its screen relative to the depth of the sewer invert.

Groundwater levels at the network of wells were measured manually during nine visits to the study area during April 2012-March 2013. The interval between visits ranged from 1 week to almost 3 months. An additional visit was made in May 2013 for selected measurement of water levels in six wells (TW1, TW2, TW6, TW7, TW9, and TW14). Prior to water level measurement, the cap of each flush-mount well was removed and the water level in the open well was allowed to stabilize to its atmospherically static level; check measurements were made to ensure the water levels were static. Measurements were made with a calibrated electric tape accurate to $0.01 \mathrm{ft}$. All groundwater level data were reviewed for accuracy and archived in the USGS NWIS database.

To gain a better understanding of the short-term variability of groundwater levels immediately adjacent to sewer lines, two of the wells (TW5, TW9) (fig. 2) temporarily were outfitted with 5-15 lb/in ${ }^{2}$ (PSI) continuously data-recording (logging) pressure transducer. Automatic logging of water levels was conducted during August 21-September 20, 2012, for well TW5; and June 7-September 20, 2012, for well TW9. Measurements were made and recorded at 15-minute intervals. During site visits, data were downloaded from the logger and a check measurement was made for quality assurance of the accuracy of the water level sensor. All continuously measured groundwater-level data were reviewed for accuracy, corrected for sensor drift when necessary, and archived in the USGS NWIS database.

\section{Optical Brighteners}

Water samples for analysis of OBs associated with sanitary discharge were collected at observation wells installed adjacent to sewer lines and other area locations, including Salt Creek, and the sewer interceptor (fig. 16). The presence of OBs is commonly associated with domestic and commercial use wastewaters, as they are found in laundry soaps and detergents. Their detection and variability of their concentrations in sewer flow and groundwater can be indicative of EXF and INF, and thus, suggestive of deteriorating sanitary sewer infrastructure. The variability of concentrations in sewer flow also can be useful for gaining insight into trends in water use and its return for treatment, and may be indicative of undesirable stormwater discharge (IN), as suggested by periodic freshwater dilution of OB concentrations. OB dyes absorb ultraviolet (UV) wavelength light and fluoresce (reemit or reflect) in the blue region of the visible spectrum, and thus they are detected readily by use of a long-wavelength fluorescent UV light. OBs are subject to adsorption to soil particles, and degradation by exposure to ultraviolet [UV] light for a long period (photic decay), and to gases, including oxygen, and microbes (Alhajjar and others, 1990; Sargent and Castonguay, 1998), so their use in assessing past contamination of groundwater might be increasingly infeasible as time passes. In addition, should naturally fluorescing organic compounds (such as fulvic and humic acids) be present in study area soils, they could hamper identification of OB compounds present at low concentrations. Given the source concentrations of sewer discharge and the OB-specific configuration of the fluorometers used in the study, this potentiality was not considered conflictive with the objectives of the study's OB investigation.

Identification of specific areas that might be contributing substantial volumes of IN, INF, and EXF and quantification of these volumes was beyond the scope of the study. Identification of the principal contributing locations or areas and determination of quantities, whether at the local or sewershed scale, would require substantial additional effort. This effort would not be limited to compiling and evaluating necessary system construction and performance information, identifying or developing proper measurement or estimation approaches, and applying those technical and (or) analytical approaches.

Although almost half of the sewer lines in the sewershed are considered sealed for preventing extraneous INF of groundwater into the lines or EXF of sewer flow from the lines, all sewer systems should be considered suspect of INF and EXF. Such systems age, as damp conditions can decay the piping, manhole, and mortar materials, and tree roots and settlement or compaction of the trench-fill materials can disrupt pipe connections or structurally damage the pipes.

In addition to routine collection of groundwater samples for $\mathrm{OB}$ analysis at the distributed observation wells, a few additional sewer flow, surface water, and groundwater samples were collected at:

1. the sewershed interceptor site near well TW1 (TW1-IN),

2. upstream and downstream locations in Salt Creek along the northern and southern boundaries of the study area (sites SC-U and SC-D), and

3. two background concentration locations (BG7 and BG14), and a site near well TW9 where elevated concentrations of OBs were detected (9DG1, 9DG2) (fig. 2). 

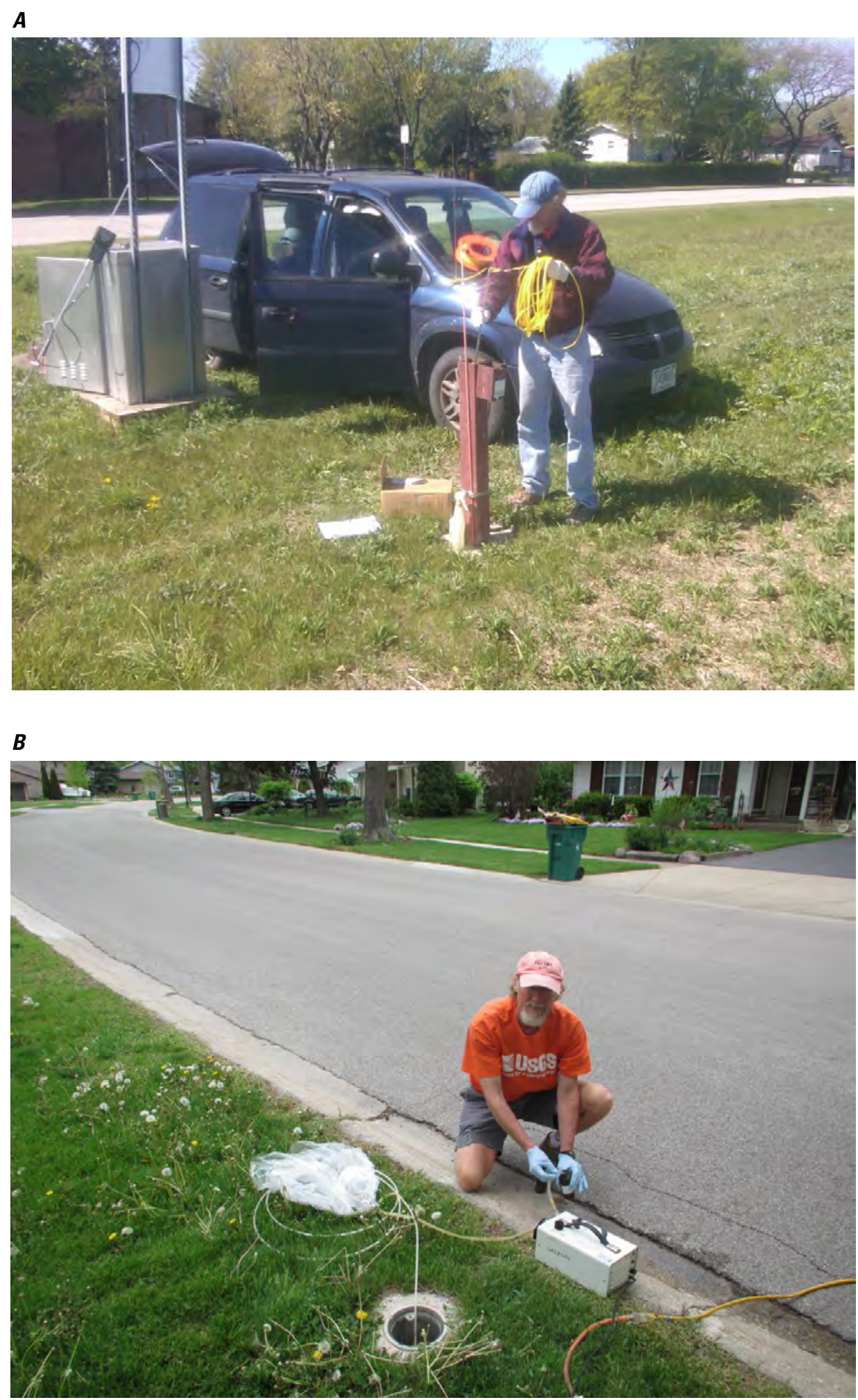

Figure 16. Collection of groundwater samples for analysis of optical brighteners in the study area, Elk Grove Village, Illinois. $A$, By bailer in observation well TW1. $B$, By peristaltic pump in well TW9. 
Two fluorometer models were deployed for analysis of OB concentrations: a portable, multisensor platform fluorometer (Turner Designs C6, hereafter referred to as the field fluorometer) (fig. 15E) and a benchtop fluorometer (Turner Designs 10AU) (fig. 15F). Both models are configured to detect and measure fluorescence specifically associated with OBs. Details regarding their configuration are available from the manufacturer. The field fluorometer was used in a benchtop application (fig. 15F) during April-June 2012; following that, it was deployed for continuous measurement of OB concentrations of sewer outflow within the interceptor near well TW1 (fig. 13A).

Various quality assurance measures were taken in regards to sample collection and analysis to ensure that in situ OB concentrations were as reasonably representative as possible, given the constraints of hydrogeology, well construction, and analytical instrumentation design. The measures, including determination of background concentrations, and methods of sample collection are described in detail in appendix 3 . The measures resulted in the following concentration guidelines for determination of OB-affected sewer flow, groundwater, and surface water.

- concentrations less than 50 micrograms per liter $(\mu \mathrm{g} / \mathrm{L})$ are considered representative of background concentrations and generally unaffected by sewer-sourced OBs,
- concentrations greater than about $50 \mu \mathrm{g} / \mathrm{L}$ are considered minimally, but measurably, indicative of sewer flow or natural waters affected by OBs,

- concentrations of about $100-200 \mu \mathrm{g} / \mathrm{L}$ are considered moderately indicative of sewer flow or natural waters affected by OBs, and

- concentrations greater than $200 \mu \mathrm{g} / \mathrm{L}$ are considered strongly indicative of sewer flow or natural waters affected by OBs.

Groundwater samples were collected from the network of observation wells during five site visits from April 2012March 2013; an additional collection was made from three wells (TW1, TW6, TW9) in May 2013 (table 3). Intervals between sample collection ranged from about 1.5 to 5 months, and sample dates were intended to capture concentrations during the seasonal cycle in groundwater levels, from higher levels typically in spring and lower levels typically in summer through winter. The small number of samples (four) collected from the sewer interceptor (TW1-IN) during April 2012-May 2013 was intended to complement the anticipated continuously measured $\mathrm{OB}$ concentrations by using the field fluorometer and to provide a general understanding of the variability of these concentrations in sewer flow.

Table 3. Optical brightener concentrations in sanitary sewer flow and groundwater from observation wells in the study area, Elk Grove Village, Illinois, April 2012-May 2013.

[NWIS, U.S. Geological Survey National Water Information System; concentrations in micrograms per liter; nd, no data]

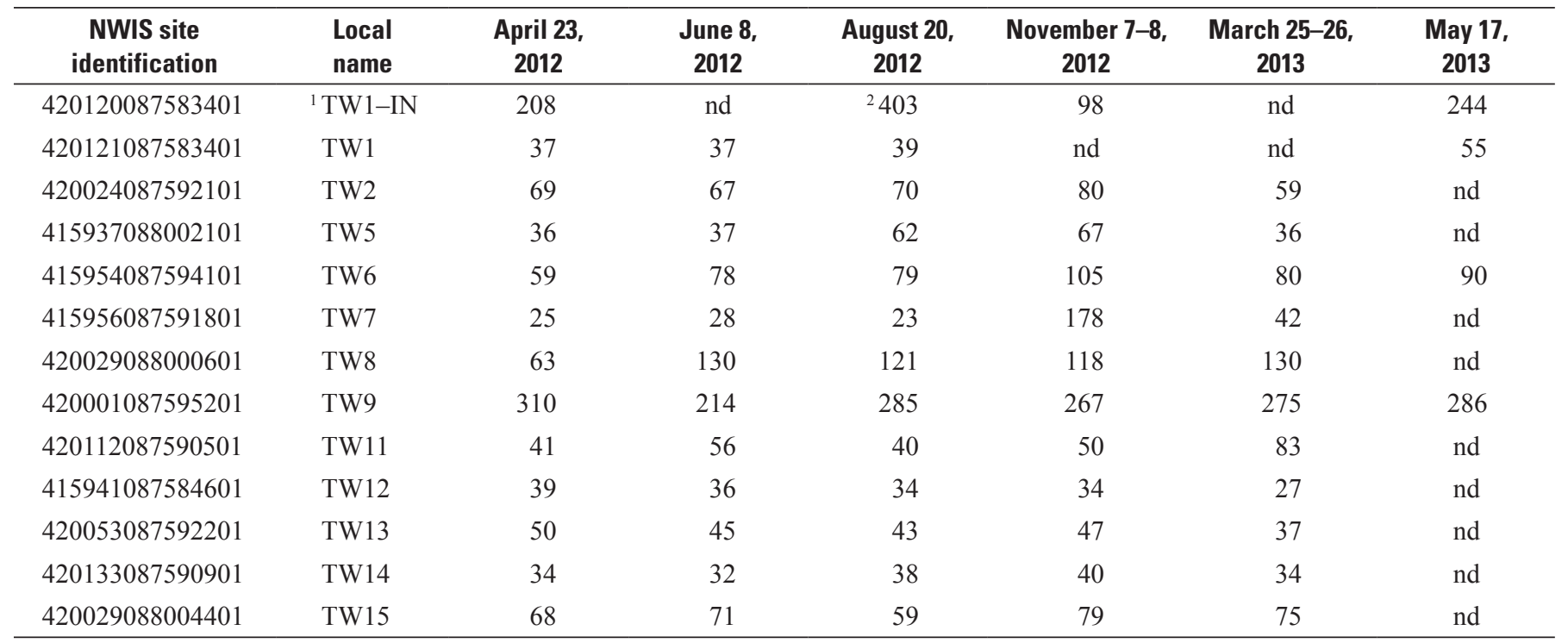

${ }^{1}$ U.S. Geological Survey station Sewer at Oakton at Elk Grove Village, Illinois.

${ }^{2}$ Sample collected August 23, 2012. 
The collection of samples from Salt Creek for assessment of the potential extent of EXF throughout the watershed is described in detail in appendix 5 ("Concentrations of Optical Brighteners in Salt Creek"). Samples were collected in June and September 2012, during the height of the 2012 drought. The samples were intended to characterize $\mathrm{OB}$ concentrations in base flow that, in part, represents study area-wide groundwater discharge to the stream. A followup collection was made in March 2013, after the return to more typical seasonal precipitation patterns. A detected increase in $\mathrm{OB}$ concentrations from the upstream limits to the downstream limits of the study area would suggest an addition of OBs to the stream from groundwater in the study area. With the lack of supporting data, it must be assumed that any such groundwater contribution of OBs represent areawide, nonpoint source contribution.

Deployment of the field fluorometer in the sewer interceptor was intended to provide a means for continuous, unattended measurement of OB concentrations in the sewer flow discharge. Following deployment of the fluorometer in the interceptor sewer, technical difficulties were experienced with the continuous logging component of the unit. Therefore, monitoring of $\mathrm{OB}$ concentrations in the sewer flow with the unit was limited to short-term synoptic measurements during periodic site visits. The continuous measurement of OBs was expected to provide the means to improve understanding of the variability of concentrations, which might be related to groundwater level or storm-associated variability. Observed variability in $\mathrm{OB}$ concentrations also was expected to provide insight into behavioral water use and water return patterns, including diurnal-to-seasonal trends. For example, one might expect decreases in $\mathrm{OB}$ concentration in sewer flow from baseline concentrations by freshwater dilution with:

1. increased INF of groundwater with rising seasonal groundwater levels (late winter-spring);

2. increased INF of groundwater with periodic storminduced perched water within trench-fill materials (possibly interflow) adjacent to sewer lines; and

3. IN of stormwater to sanitary sewers, through undesirable discharges from basement sump pumps and guttering systems at residences and (or) commercial facilities.

It was envisioned that such information obtained on the variability of OB concentrations in sewer flow might allow better insight into contributing sources of freshwater to sanitary sewer flow and quantification of those contributions.

\section{Other Data}

Precipitation data were used in the study principally for evaluation of anomalous increases in sewer flows, particularly to discriminate between increases resulting from storm-associated IN and those from short-term lodging of debris around the
ADVM or its malfunction. For the evaluation, the daily precipitation record was plotted against the hydrograph of sewer discharge. Precipitation data also were used in the evaluation of missing records of sewer flow discharge for subsequent estimation of these missing data.

Precipitation data were available from two collection stations close to the study area: USGS station 420057088001700 Busse Woods near Elk Grove Village, Illinois, located near the north-central boundary of the sewershed, and the nearby NOAA weather station at Chicago O'Hare Airport (fig. 1). Because a portion of the USGS data available for this study were provisional and subject to revision, all precipitation data used in study analysis and presented in this report are from the NOAA weather station. The USGS data primarily were used solely to verify the appropriate use of the NOAA data for representation of study area meteorological conditions; the data also were used to improve understanding of the variability of precipitation occurrence and intensity in the area.

Evaporation data were used in the estimation of evaporative loss from the areas' public, outdoor swimming pools, as means for improved accounting of their direct returns of metered water deliveries ultimately discharged to Salt Creek. Information regarding the sources of evaporation data and how these data were used to estimate evaporation loss from pools is presented in detail in the appendix 1.

\section{Determination of Consumptive Water Use}

The approach for this study uses direct measurement, data records, and estimations to resolve the individual components of the water balance equation, as applied to a welldefined water supply and sewershed. Estimate results were considered against several factors as a means of quality assurance and analysis of their relative uncertainty and limitations.

In a general expression, components of the water balance equation for determining consumptive use include:

\section{(Deliveries + Self-supplied withdrawals) - \\ (Returns to sewage treatment plants +}

Direct returns to surface water and groundwater sources).

For the predominantly residential Elk Grove Village study area, the water use component is represented primarily by public supply deliveries by the Elk Grove Village DPW, and to a minor extent, self-supplied groundwater withdrawals in the unincorporated neighborhood served by the public sanitary sewer system. The water return component is represented primarily by the sewer return flows though the MWRD interceptor sewer, and to a minor extent, direct returns to Salt Creek through dedicated discharge pipes and (or) through the storm sewer system by way of storm drains. Direct returns to groundwater can be discounted (considered negligible), as 
there is no evidence of these returns in the sewershed. Some estimation was necessary for each of the water volumes representing the components of use. These volumes included the directly measured sewer flows; the reported metered public water deliveries; the self-supplied withdrawals; and the direct returns of delivered and self-supplied waters to Salt Creek. Although undesirable storm-associated IN, groundwater INF, and sewer flow EXF could not be quantified, their relative contribution to error and uncertainty in accounting for sanitary sewer return flow required consideration.

\section{Quantification of Water Use}

Results of the compilation and estimation of the components of water use are presented below. These components include public supply water deliveries from Elk Grove Village and self-supplied water withdrawals from private wells.

\section{Public Supply Deliveries}

Each water meter in the Elk Grove Village DPW service area is read bimonthly, but the service area is split into approximate halves in which one half of the meters are read in odd months and the other half in even months. Thus, some estimation of water deliveries was necessary to provide a "continuous," study area-wide record of daily water use. The bimonthly collection of water meter readings also made necessary the use of meter readings that extended to at least 2 months before the start (March 1, 2012) and end (February 28, 2013) of the designated 12-month estimation period. Because of the bimonthly offset, the number of meters having readings during the study period fluctuated, but it was approximately 5,900 during the middle portion of the study period when data were available for all the meters (fig. 17).

In the geodatabase table provided by the Elk Grove Village DPW, a column labeled "consumption" indicated the delivered water supply volume in gallons, which was usually the difference between the current and previous readings of a meter. These delivered water supply volumes were used to create a preliminary estimate of the daily-metered water supply at each meter over the full study period, as determined by dividing the delivered water for each meter-reading period by the number of days between readings. In the data provided, almost all meters in the study area were represented at the beginning date of the study period. However, the last reading of about one-third of the meters occurred a few days short of the extended readings date necessary to estimate deliveries fully during the study period (fig. 17). These few days of missing data were filled (estimated) by repeating the last determined daily-metered water supply value. Negative "consumption" values provided in the geodatabase table were assumed to reflect a necessary correction to a prior false reading, and they were a very small fraction of the total readings and the total metered water supply (figs. 18A, B). As such, these negative values were retained in the computational dataset.

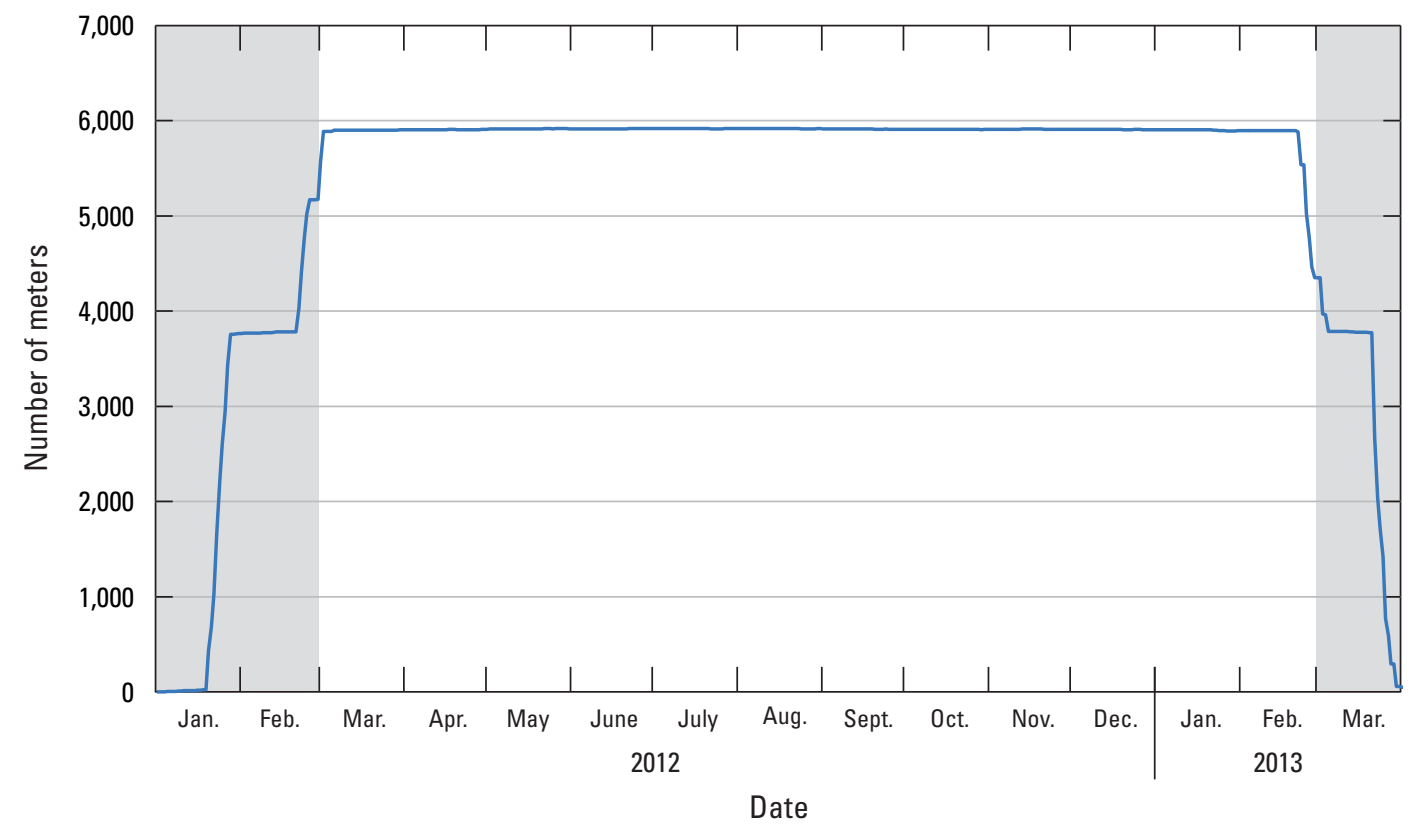

Figure 17. Number of water meters, by date, contributing to the daily total metered water supply in the study area, Elk Grove Village, Illinois, March 2012-February 2013. (Shading represents the period outside that designated for estimation of daily totals of water supply deliveries and annual consumptive use; partial datasets from outside the designated period were required for these estimations.) 

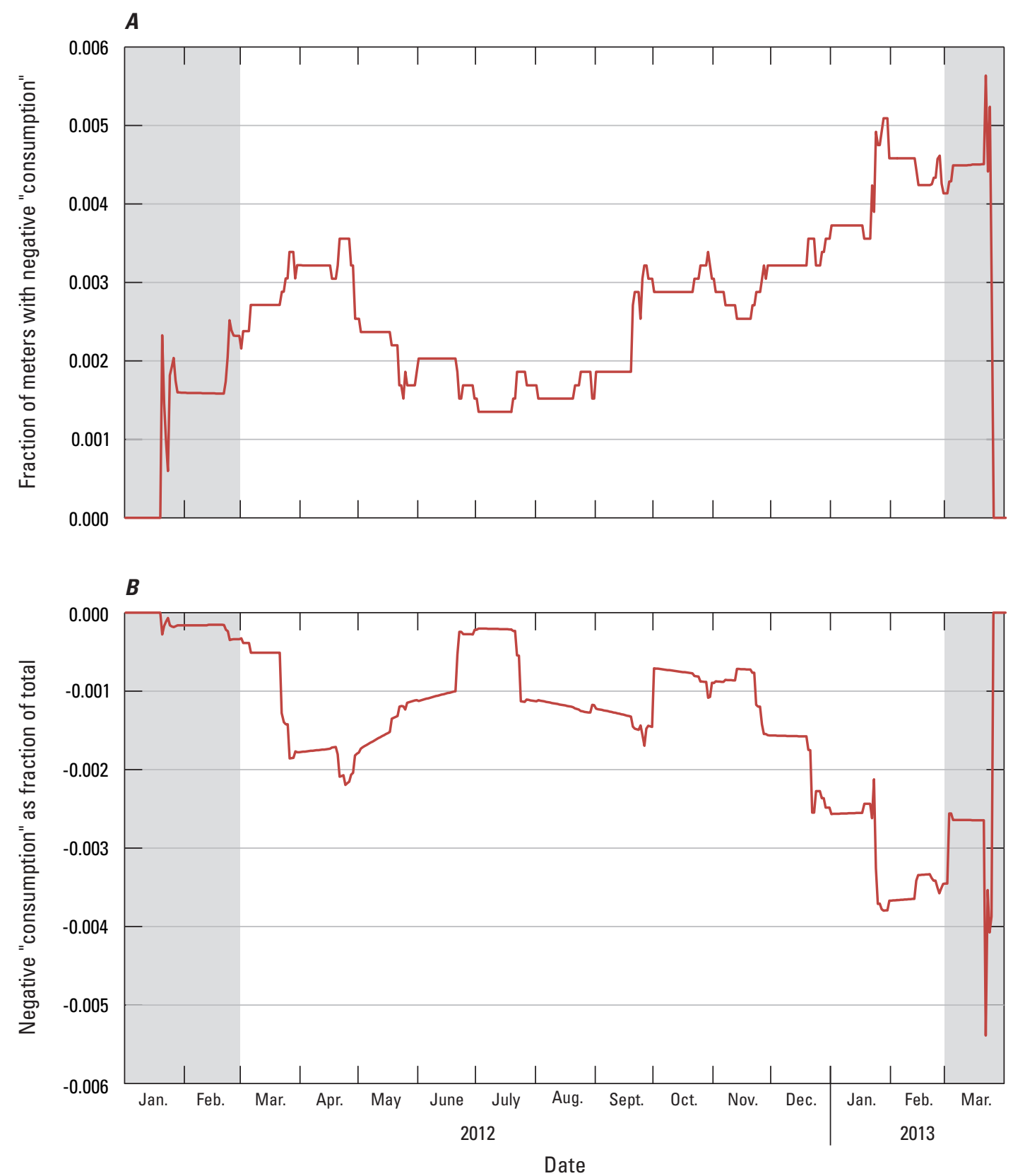

Figure 18. Relative impact of negative water supply ("consumption") values on estimation of dailymetered water supply deliveries. $A$, Fraction of meters with negative values. $B$, Daily total negative "consumption" as a fraction of the daily total metered supply, March 2012-February 2013. (Shading represents the period outside that designated for estimation of daily totals of water supply deliveries and annual consumptive use; partial datasets from outside the designated period were required for these estimations.) 
The preliminary daily-metered supply estimate at each meter was calculated from bimonthly readings that jump from one bimonthly average to another. Therefore, a daily time step is not truly represented. To provide a better estimate of daily water use, the estimate was disaggregated by applying a linear mass-conserving interpolation technique, as described in Straub and Over (2010, appendix A). Summing over the resulting disaggregated daily supply at each meter in the study area provides an estimate of the total daily-metered supply. A comparison between the preliminary and disaggregated daily total metered supply estimates is graphically presented in figure 19, with the blue line representing the disaggregated estimates. Corresponding monthly supply estimates are provided in table 4 and figure 20. During the 12-month study period, water supply deliveries in the Elk Grove Village sewershed study area totaled about $555.90 \mathrm{Mgal}$ (or 1.52 million gallons per day $[\mathrm{Mgal} / \mathrm{d}])$. Monthly deliveries ranged from about 1.25 to $2.07 \mathrm{Mgal} / \mathrm{d}$. Deliveries were greatest during the late spring through summer months of May-August (about 1.70$2.07 \mathrm{Mgal} / \mathrm{d}$ ) and peaked in June and July. Deliveries were least during fall through winter months of November-February (about 1.25-1.28 Mgal/d). Seasonal use of water primarily for filling swimming pools and landscape irrigation accounts for the high demand for water during summer months.

The annual total water supply volumes at each metered location in the study area during the study period are shown in figure 21 . The annual total water supply data by meter shown for the study period are evidently quite similar to those for calendar year 2010 (fig. 4).

Table 4. Estimated monthly metered water supply deliveries in the study area, Elk Grove Village, Illinois, March 2012February 2013.

[gal, gallons; gal/d, gallons per day; Mgal/d, million gallons per day]

\begin{tabular}{lccc}
\hline Month and year & $\begin{array}{c}\text { Metered } \\
\text { water supply, }{ }^{1} \\
\text { in gal }\end{array}$ & $\begin{array}{c}\text { Daily } \\
\text { average, } \\
\text { in gal/d }\end{array}$ & $\begin{array}{c}\text { Daily } \\
\text { average, } \\
\text { in Mgal/d }\end{array}$ \\
\hline March 2012 & $40,652,850$ & $1,311,382$ & 1.31 \\
April 2012 & $40,998,030$ & $1,366,601$ & 1.37 \\
May 2012 & $52,577,360$ & $1,696,044$ & 1.70 \\
June 2012 & $62,007,420$ & $2,066,914$ & 2.07 \\
July 2012 & $62,593,920$ & $2,019,159$ & 2.02 \\
August 2012 & $55,560,080$ & $1,792,261$ & 1.79 \\
September 2012 & $47,435,030$ & $1,581,168$ & 1.58 \\
October 2012 & $42,905,590$ & $1,384,051$ & 1.38 \\
November 2012 & $38,368,730$ & $1,278,958$ & 1.28 \\
December 2012 & $38,612,340$ & $1,245,559$ & 1.25 \\
January 2013 & $38,721,780$ & $1,249,090$ & 1.25 \\
February 2013 & $35,465,180$ & $1,266,614$ & 1.27 \\
\hline
\end{tabular}

${ }^{1}$ Estimated from interpolated meter data.
Review of the ISGS ILWATER database identified four public high-capacity wells (depths greater than 1,000 ft) that previously had been installed within the boundary of the currently defined sewershed (fig. 22); three wells (with depths between 1,400 and 1,415 ft) were determined to be legally abandoned and one well was maintained for emergency use (1,390-ft well at the southwestern edge of the sewershed). Withdrawals from the emergency well totaled $1.7 \mathrm{Mgal}$ in 2012, but as previously noted these withdrawals were not used in the estimation of consumptive use because they were discharged directly to the nearby storm sewer system (Scott Bernholdt, Department of Public Works, Elk Grove Village, Illinois, written commun., 2013).

\section{Self-Supplied Withdrawals}

Further review of the ISGS ILWATER database identified about two dozen private supply wells that previously had been installed in the sewershed (fig. 22); about half of these were determined or assumed to be no longer in use or actually located outside of the sewershed. The wells assumed to be out of use typically were older wells in areas where there has been recent construction of homes and commercial facilities.

About a dozen wells were identified in and near the unincorporated area in the northeastern part of the sewershed (figs. 3 ; 22). On the basis of driveby inspection and provided information (Scott Bernholdt, Department of Public Works, Elk Grove Village, Illinois, oral commun., 2011), it was concluded that essentially all of these mapped wells actually were installed in the unincorporated area. Review of public water delivery data (fig. 21) in conjunction with the available information on private well use in the unincorporated area and Census data (2013a) indicated that all but 10 of the 134 homes in this area have an operating well without a service connection to the village's water supply system; the 10 homes receive municipality provided water. As such, the number of mapped wells in the unincorporated area greatly underrepresents (by about 90 percent) the actual number of wells in this area.

Estimation of water withdrawals from the private wells in the unincorporated area was necessary because of the relatively large number of homes in the unincorporated area also connected to and using the village's sanitary sewer system. By applying the per capita use coefficient of $80 \mathrm{gal} / \mathrm{d} / \mathrm{p}$ to the estimated resident population of 352 (2010 U.S. Census-based estimate of 382 residents adjusted for the small population supplied by public water [ 10 homes at 3 residents per home]), annual self-supplied water withdrawals of about $10.28 \mathrm{Mgal}$ (or $0.03 \mathrm{Mgal} / \mathrm{d}$ ) are indicated. 


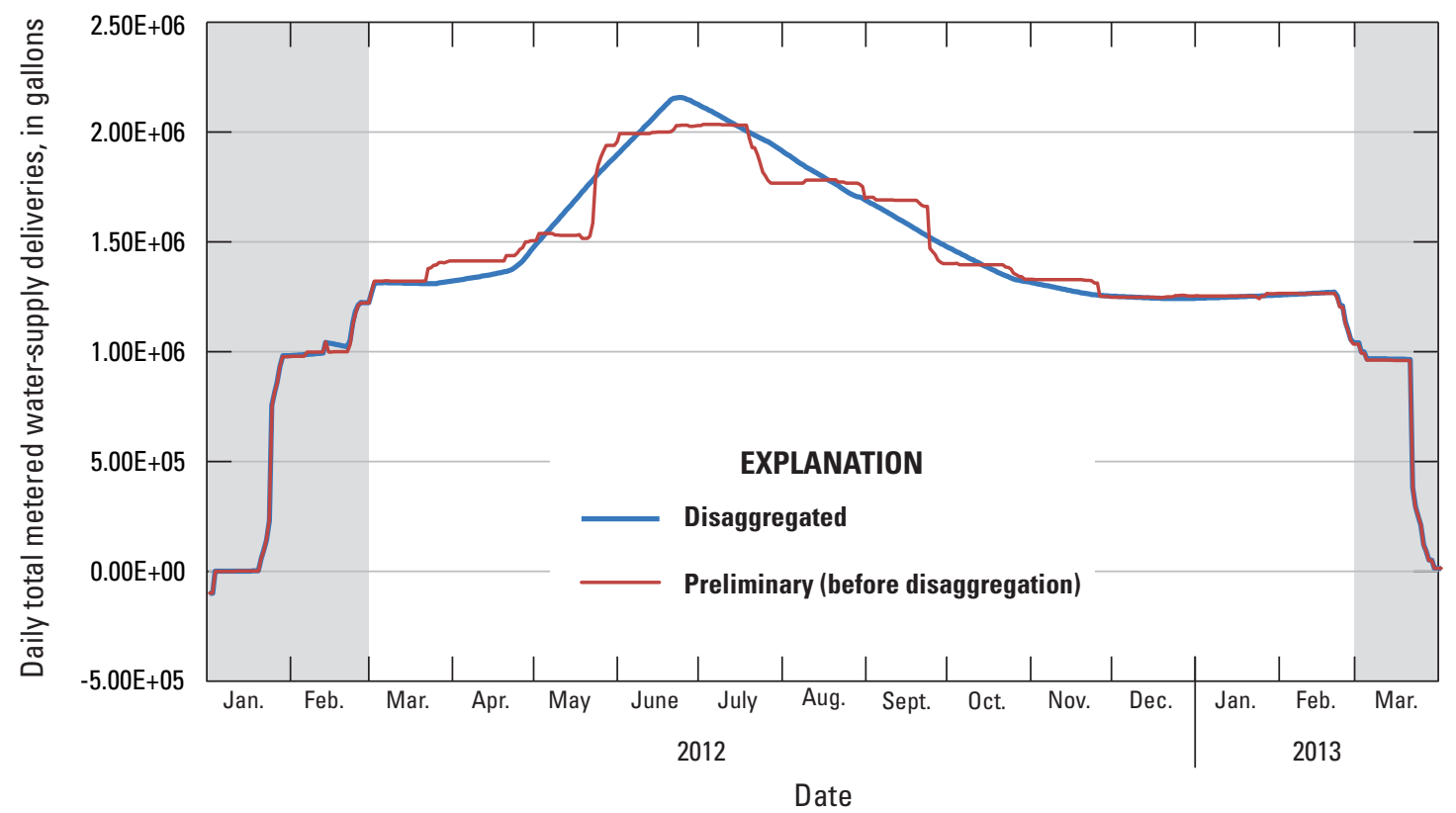

Figure 19. Estimated daily total metered water supply deliveries in the study area, Elk Grove Village, Illinois, March 2012-February 2013. (Shading represents the period outside that designated for estimation of daily totals of water supply deliveries and annual consumptive use; partial datasets from outside the designated period were required for these estimations.)

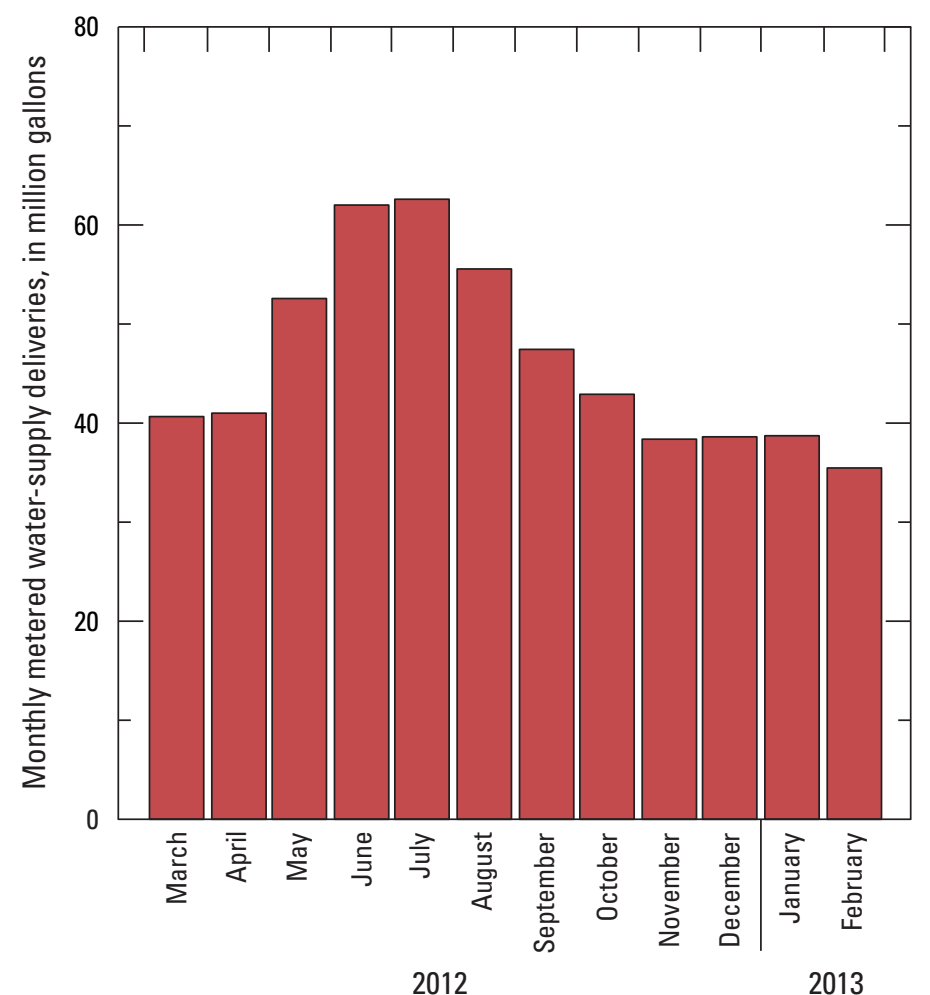

Figure 20. Estimated monthly metered water supply deliveries in the study area, Elk Grove Village, Illinois, March 2012-

February 2013. 


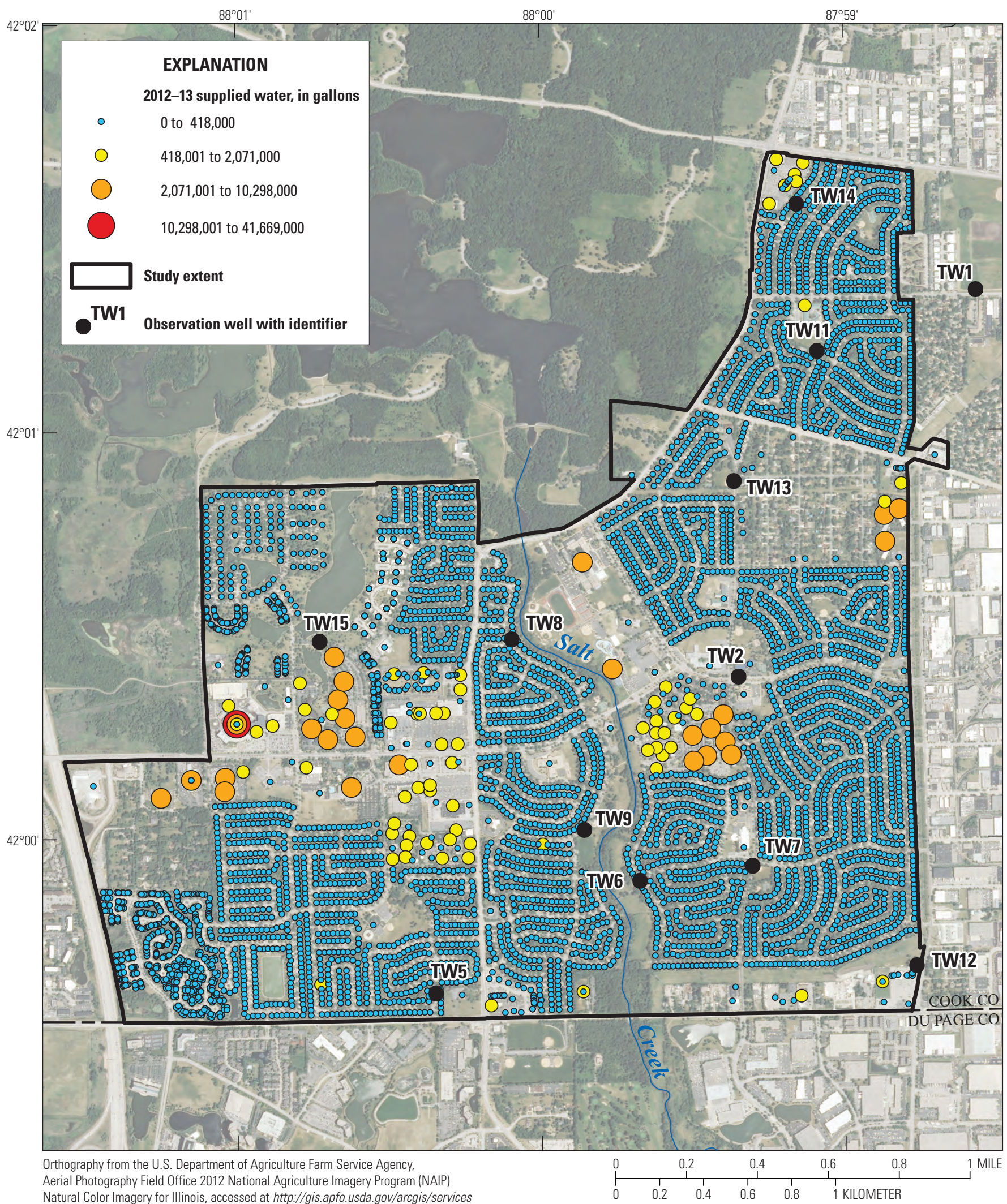

Figure 21. Approximate volume of public water supplied at metered locations in the study area, Elk Grove Village, Illinois, March 2012February 2013. 


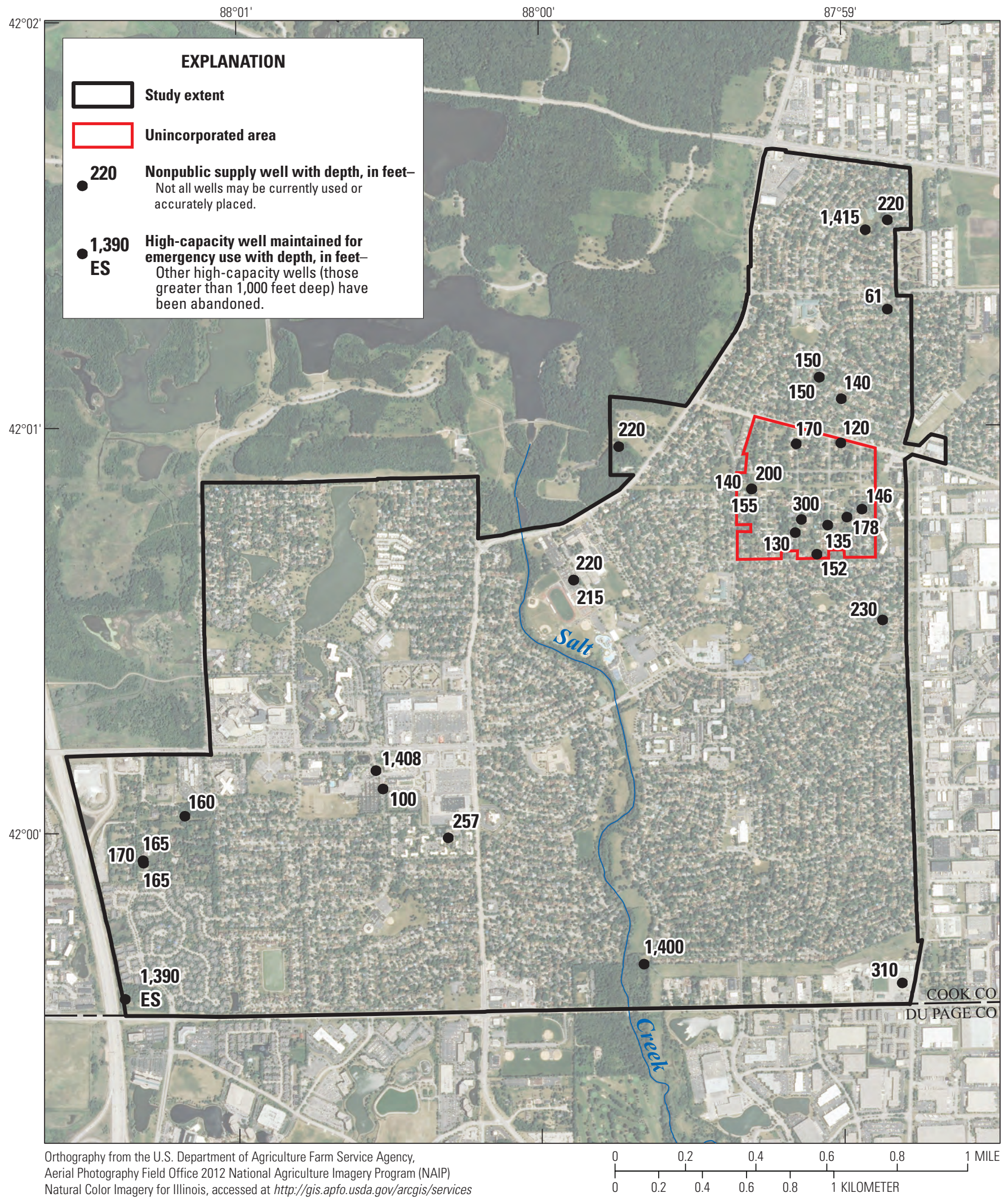

Figure 22. Approximate locations of supply wells and their depths in the study area, Elk Grove Village, Illinois, March 2013. 
With annual public supply deliveries of 555.90 Mgal and self-supplied, private well withdrawals of $10.28 \mathrm{Mgal}$, supplied water in the sewershed for the designated annual period totaled $566.18 \mathrm{Mgal}$ (or $1.55 \mathrm{Mgal} / \mathrm{d}$ ). These volumes are considered to represent the bulk of supplied water in the study area, which is necessary for resolving the water balance equation for determination of consumptive use. Given the relatively small fraction of supplied water represented by the self-supplied withdrawals (about 2 percent), then the estimates of monthly metered water supply deliveries (fig. 20; table 4) can be considered to adequately represent monthly totals of supplied water from all sources.

As a "worse-case" scenario to evaluate the effect of error in determination of number of operating supply wells on the estimate of self-supplied water in the study area, the possibility of a dozen additional operating wells in the study area was considered. Because this represents a dozen homes, with an estimated three residents per household and a per capita use rate of $80 \mathrm{gal} / \mathrm{d} / \mathrm{p}$, the present accounting of water use within the study area might be underestimated by about $1 \mathrm{Mgal}$, or less than 0.2 percent, of the total estimated use. As such, this small volume of possible additional water supply use reasonably can be ignored in the present estimation of consumptive use.

\section{Quantification of Sanitary Sewer Flow}

The ADVM provided satisfactory flow data within the sanitary sewer throughout most of the period of the study (appendix 4). That is, measured discharge was within $2-5$ percent of actual discharge, as determined by qualitative evaluation (Turnipseed and Sauer, 2010, p. 79). There were, however, several periods of missing record and poor record (measured discharge greater than 8 percent of actual discharge). Additionally, several periods were determined to have been affected by stormwater-associated IN (appendix 4; table 5), yet their measured discharge records were considered satisfactory.

Missing record and poor quality record are common in flow monitoring of sanitary sewers. Large amounts of floating debris and suspended sediment make flow monitoring in sewers a challenging task. A continuous record of sanitary sewer flows is optimal for the computation of consumptive use by using the mass-balance equation. For the most part, the ADVM installed in the Elk Grove Village sewershed provided a continuous time series of sewer flow. The exception was an extended period of missing record during August 6-29, 2012 (appendix 4). Periods of missing record were estimated based upon the observed trends in sewer flow records before and after the missing record. Precipitation records also were used to evaluate periods of missing sewer flow records. Daily mean sewer flows during dry weather before and after periods of missing record were reviewed to ensure continuity (no sudden increases or decreases in flow) in the sewer flow hydrograph.
Table 5. Periods of missing record, poor-quality record, and satisfactory record influenced by stormwater runoff, from measurements at the U.S. Geological Survey station Sewer at Oakton at Elk Grove Village, Illinois, in the Metropolitan Water Reclamation District of Greater Chicago interceptor near observation well TW1, Elk Grove Village, Illinois, March 2012February 2013.

\begin{tabular}{ll}
\multicolumn{1}{c}{ Date } & \multicolumn{1}{c}{ Status } \\
\hline March 22-23, 2012 & Stormwater influence \\
March 24, 2012 & Missing or poor record \\
March 26-30, 2012 & Missing or poor record \\
April 14-15, 2012 & Stormwater influence \\
May 3-4, 2012 & Stormwater influence \\
May 6-7, 2012 & \\
May 31, 2012 & Stormwater influence \\
June 29, 2102 & Stormwater influence \\
July 13-14, 2012 & Stormwater influence \\
July 18, 2012 & Missing or poor record \\
July 24, 2012 & Missing or poor record \\
July 26, 2012 & \\
August 4, 2012 & Stormwater influence \\
August 6-29, 2012 & Stormwater influence \\
September 4, 2012 & Stormwater influence \\
October 22-23, 2012 & Missing or poor record \\
December 20-24, 2012 & Stormwater influence \\
January 10, 2013 & Stormwater influence \\
February 7-13, 2013-February 2, 2103 & Stormwater influence \\
\hline & Stormwater influence \\
\hline
\end{tabular}

On occasion, the stage record showed a sharp rise followed by a decline that differed from the regular dry-weather diurnal pattern. These short-term fluctuations correlated with fluctuations in the velocity record and were interpreted as short-term buildup of debris near the ADVM and subsequent washoff or removal by the flow. As such, these short-term fluctuations in stage, velocity, and discharge were considered valid conditions of flow and were left in the continuous sewer discharge record. Examples of these occurrences can be found in the monthly discharge hydrographs for the 2012 dates November, 6, 15, 28 and December 6, 17, and the 2013 dates January 3 and February 13, 14 (appendix 4).

Although floating debris and suspended sediment occasionally affected the ADVM measurement of sewer flow discharge, in summary, the final computed discharge used in the consumptive use was considered minimally affected and validates the use of the stage discharge rating to compute 
discharge. Contributing factors that limited the potentially detrimental affects of floating debris and suspended sediment on the computed discharge were the relatively light debris load typical of the sewer flow, flow velocities that tended to limit or flush out buildup on and near the ADVM, and routine inspection and cleaning of the ADVM and vicinity.

Analysis of the hydrographs of return sewer flow shows typical diurnal patterns associated with sanitary sewer flows during periods of dry weather. Daily patterns for weekdays and the weekend are evident in the dry-weather sewer flow hydrographs (fig. 23A), as residential water use on weekdays differs from that on weekends. On weekdays, there usually are two peaks in flow-a morning peak and an early evening peak. The morning peak usually is slightly greater than the evening peak. On Saturdays, flow usually peaks once in late morning; on Sundays, flow often peaks twice, but the difference between the morning and evening peaks is more pronounced than those during weekdays. Peak flows tend to be greatest on weekends. Given the objectives and exploratory scope of the study, the sewer flow hydrographs were not further examined to provide more detailed understanding of trends in residential water use.

Increased sewer flows during periods of wet weather generally associated with large or persistent storms indicate the influence of stormwater IN from undesirable connections to the sanitary sewer system; also indicated is the possible influence of INF resulting from storm-induced groundwater recharge. Some portion of the increased sewer flow attributed to INF may represent slow drainage into building substructures (basements) following storms, which was subsequently discharged by way of basement sump pumps to the sanitary sewer system as direct IN. Increased flows during wet weather typically were relatively short-lived pulses lasting about 1-2 days before the flows returned to the more typical dryweather diurnal pattern (fig. 23B). Examples of these occurrences can be found in the monthly discharge hydrographs for June 2012, October 2012, and December 2012 (appendix 4). Although flows return to a diurnal pattern of discharge, the level of flow sometimes is elevated when compared to the diurnal level before the storm event.

Analysis of the sewer flow hydrograph for the October 23, 2012, storm event (fig. 23B), shows the daily mean sewer flow in the 5 days prior to the storm event (October 18-22) averaged just over $2.4 \mathrm{Mgal} / \mathrm{d}$. On the day of the storm, the daily mean sewer discharge increased sharply to over $3.5 \mathrm{Mgal} / \mathrm{d}$. This direct stormwater IN (1.1 Mgal/d) to the sewer system drained rapidly and the daily mean sewer discharge for the 5 days after the storm event (October 24-28) returned to $2.4 \mathrm{Mgal} / \mathrm{d}$. The sharp increase in sewer discharge correlates directly with measured precipitation and is indicative of stormwater-associated IN to the sanitary sewer system.

The measured instantaneous sewer discharge during the study period ranged from $0.65-10.34 \mathrm{Mgal} / \mathrm{d}$. The minimum instantaneous sewer discharge occurred on numerous occasions during early fall dry-weather periods, typically in the early morning hours at the low portion of the diurnal sewer flow hydrograph. The maximum instantaneous sewer discharge occurred over several hours at the peak of the sewer flow hydrograph associated with a storm event on January 30, 2013 (appendix 4L). The range of instantaneous discharge, as measured at 5-minute intervals, is shown in part in figure 24 and fully in appendix 4. As explained later in this section of the report, discharge associated with storm events was removed from the data record for final processing to estimate sanitary sewer discharge and to calculate consumptive use. As such, the discharge hydrograph presented as figure 24 does not include the records of identifiable storm events, including that of January 30, 2014.

The measured daily mean sewer discharge ranged from 2.00-9.05 Mgal/d. The minimum daily mean discharge occurred on several days in September-October 2012 and one day in December 2012. The maximum daily mean sewer discharge occurred on January 30, 2013, and it was strongly influenced by apparent stormwater IN to the sewer system.

The measured daily mean sewer discharge during dry-weather spring months was typically in the range of 3-4 Mgal/d, whereas measured daily mean sewer discharge during similar dry-weather summer months was in the range of 2-2.5 Mgal/d. Seasonal variation in daily mean and monthly mean flows of the sanitary sewer hydrograph during dry weather is assumed to be the result of variation in the natural and storm-associated groundwater INF to the sewer system, as it seems unlikely that water use patterns would appreciably affect sewer discharge in a seasonal manner. The seasonal (summer) increase in water use that has been noted (refer to the section "Public Supply Deliveries"), principally is associated with filling swimming pools and landscape irrigation, neither of which result in notable sanitary sewer discharge in the sewershed (refer to the section "Other Unmeasured Return Flow").

After a thorough review of all of the ADVM data and computation of discharge, monthly mean total flow in the sanitary sewer was compiled for the designated annual estimation period of March 2012-February 2013 (table 6). Discharge hydrographs and precipitation data were reviewed to identify periods affected by stormwater-associated IN (including the delayed INF and (or) IN) to the sewer system. These periods were identified by trending slopes in the monthly discharge hydrographs (sections B and C in fig. 23B; appendix 4). The associated volumes of IN from these periods were estimated by using the hydrographs to isolate and total those rates that were greater than the baseline flow rate(s) that prevailed before and after the stormwater-affected period (section A in fig. 23B). By using this hydrographic separation method, the estimated annual stormwater-associated IN contributed to sanitary sewer system discharge was $19.5 \mathrm{Mgal}$. This volume was removed from the sanitary sewer discharge record that subsequently was further processed. 


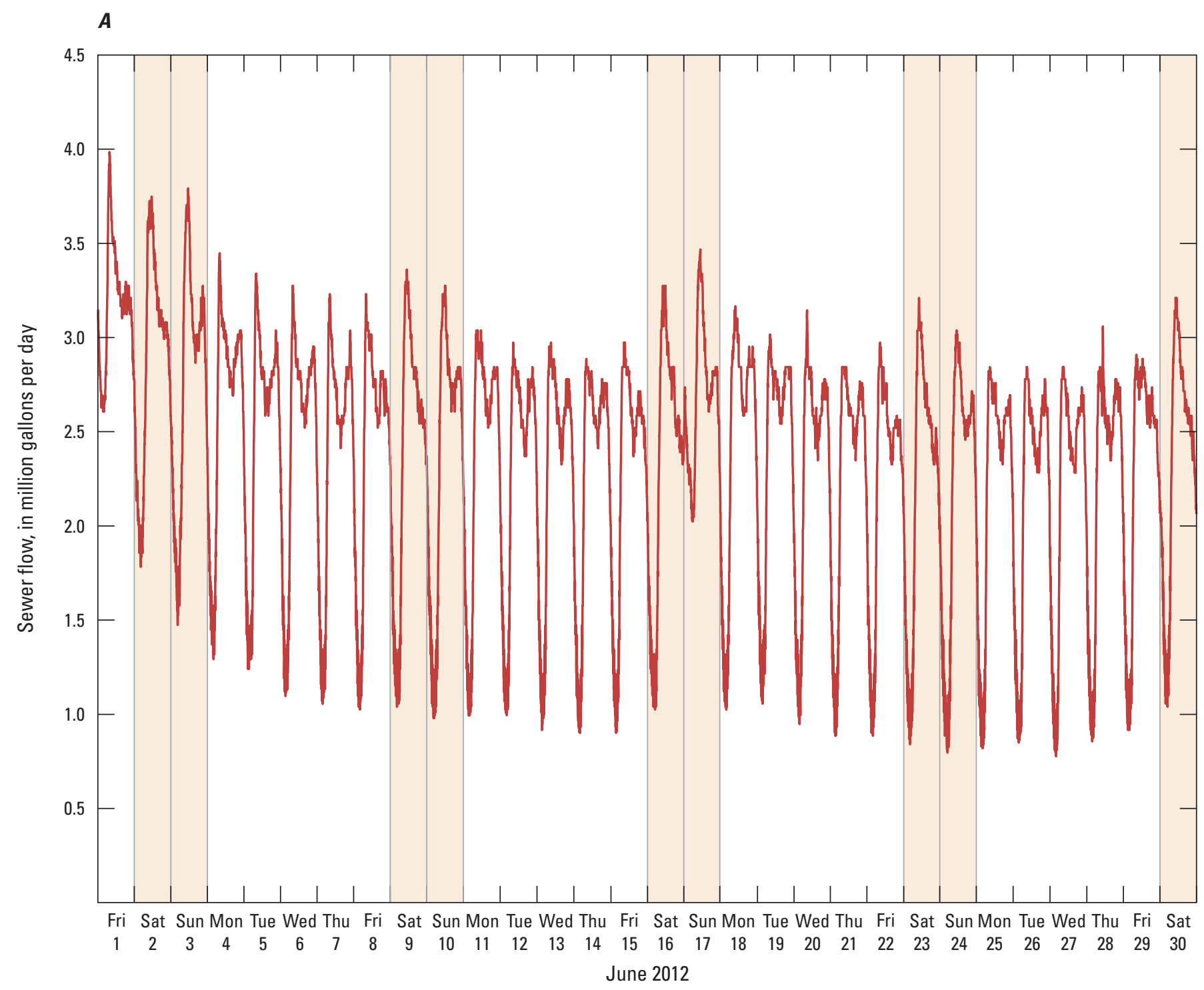

Figure 23. Sanitary sewer flow at the U.S. Geological Survey station Sewer at Oakton at Elk Grove Village, Illinois. A, Dry-weather conditions showing weekday pattern (double peak) and weekend pattern (Saturday-Sunday sloping peak), June 2012. 


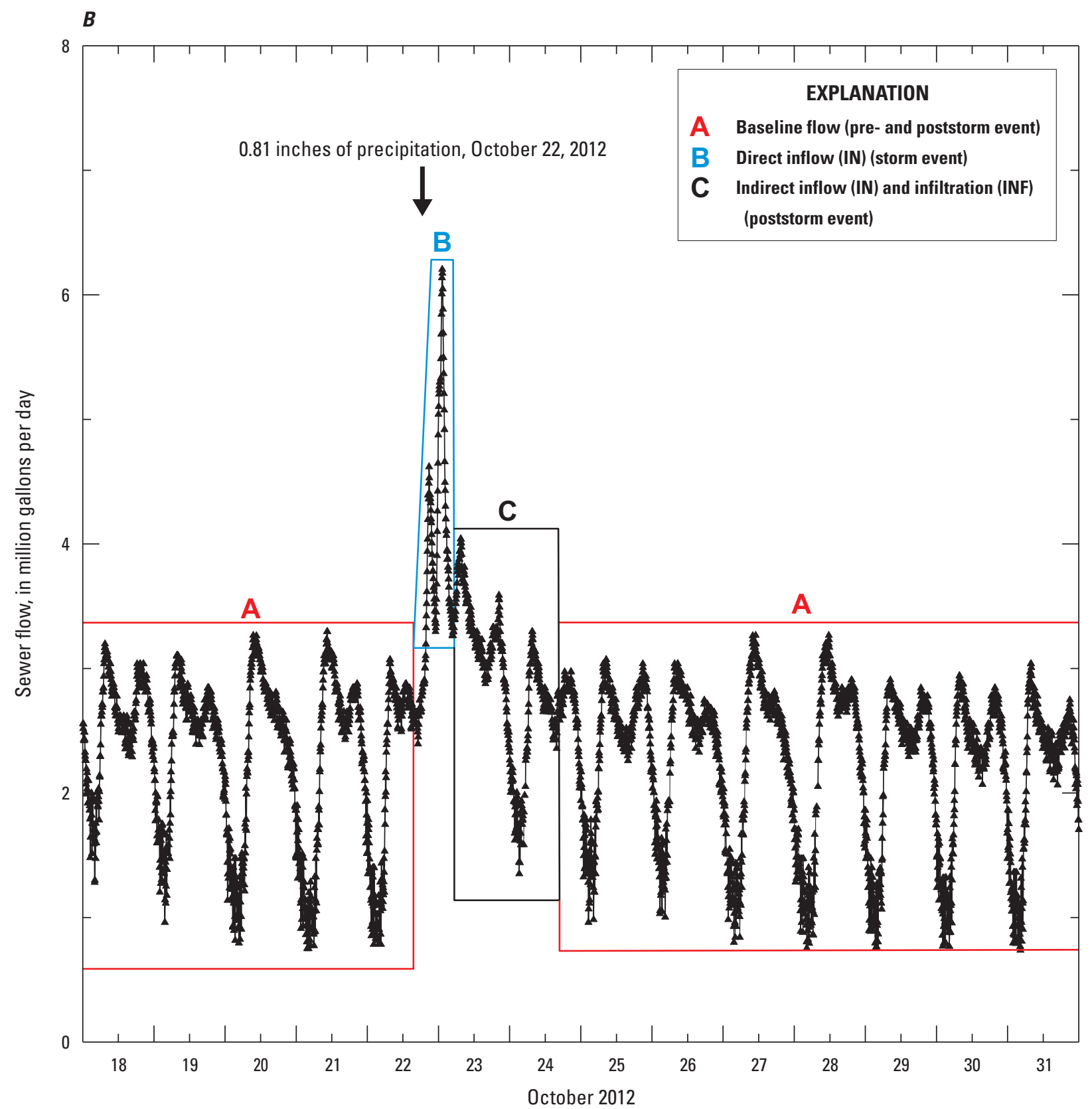

Figure 23. Sanitary sewer flow at the U.S. Geological Survey station Sewer at Oakton at Elk Grove Village, Illinois. B, Wet-weather conditions with stormwater-affected period, October 18-31, 2012. 


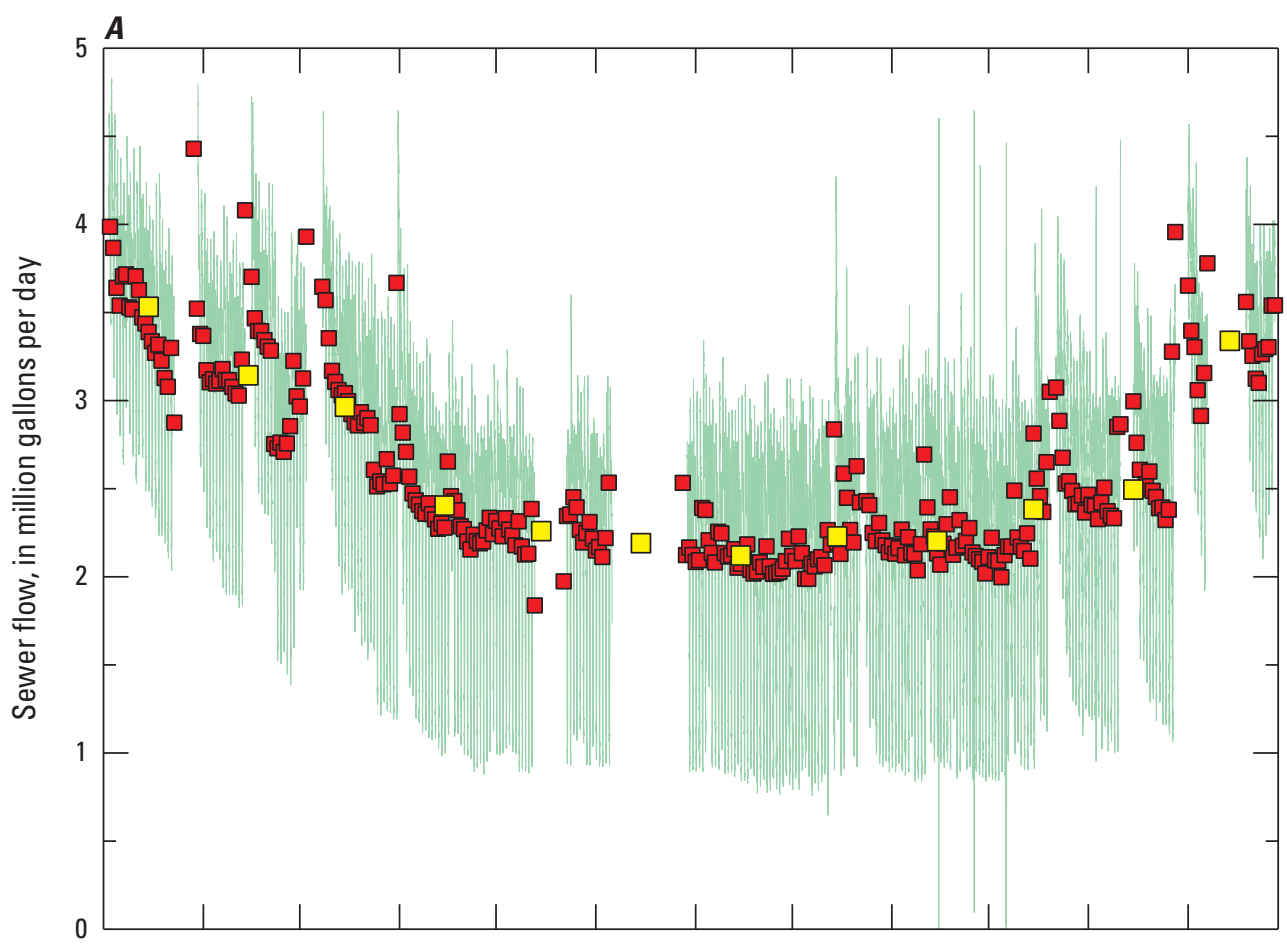

\section{EXPLANATION}

Measured 5-minute sewer discharge

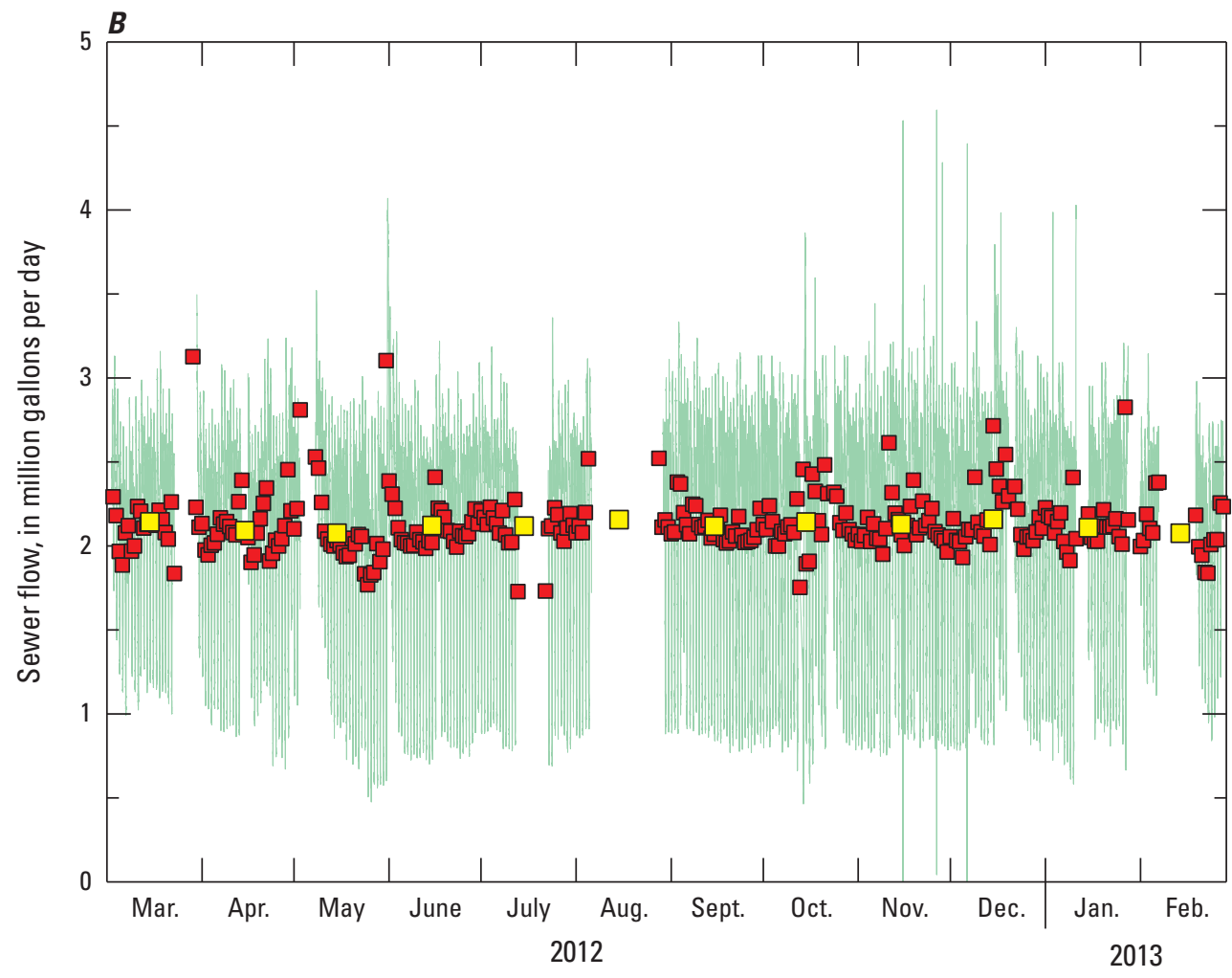

$\square \quad$ Daily mean sewer discharge

$\square \quad$ Monthly mean sewer discharge

Figure 24. Sanitary sewer flow at the U.S. Geological Survey sewer flow monitoring station Sewer at Oakton at Elk Grove Village, Illinois, March 2012-February 2013. A, Measured 5-minute, daily mean, and monthly mean discharge. $B$, detrended and offset 5-minute, daily mean, and monthly mean sewer discharge. 
Table 6. Monthly mean monthly sanitary sewer flow, as measured at the U.S. Geological Survey station Sewer at Oakton at Elk Grove Village, Illinois, March 2012-February 2013.

\begin{tabular}{|c|c|c|c|c|}
\hline Month and year & $\begin{array}{l}\text { Measured monthly } \\
\text { mean total flow, } \\
\text { in } \mathrm{ft}^{3} / \mathrm{s}\end{array}$ & $\begin{array}{l}\text { Measured monthly } \\
\text { mean total flow, } \\
\text { in Mgal/d }\end{array}$ & $\begin{array}{c}\text { Detrended and offset } \\
\text { estimated monthly } \\
\text { mean flow, } \\
\text { in } \mathrm{ft}^{3} / \mathrm{s}\end{array}$ & $\begin{array}{l}\text { Detrended and offset } \\
\text { estimated monthly } \\
\text { mean flow, } \\
\text { in Mgal/d }\end{array}$ \\
\hline March 2012 & 5.49 & 3.55 & 3.33 & 2.15 \\
\hline April 2012 & 4.90 & 3.17 & 3.25 & 2.10 \\
\hline May 2012 & 4.78 & 3.09 & 3.26 & 2.11 \\
\hline June 2012 & 3.72 & 2.40 & 3.26 & 2.11 \\
\hline July 2012 & 3.49 & 2.26 & 3.25 & 2.10 \\
\hline August 2012 & 3.36 & 2.17 & 3.42 & 2.21 \\
\hline September 2012 & 3.28 & 2.12 & 3.28 & 2.12 \\
\hline October 2012 & 3.52 & 2.28 & 3.33 & 2.15 \\
\hline November 2012 & 3.41 & 2.20 & 3.30 & 2.13 \\
\hline December 2012 & 3.88 & 2.51 & 3.36 & 2.17 \\
\hline January 2013 & 4.75 & 3.07 & 3.31 & 2.14 \\
\hline February 2013 & 5.78 & 3.74 & 3.23 & 2.09 \\
\hline
\end{tabular}

The measured sewer discharge data were further analyzed and adjusted by using numerical signal methods to estimate a sanitary discharge time series for the designated annual estimation period. For this estimation method, the following adjustments were made:

1. the sewer discharge data were analyzed to remove the seasonally variable contribution of groundwater INF to estimated sanitary sewer flow, and

2. the resulting time series of sanitary sewer discharge was offset to the sewer discharge record when groundwater INF to the sewer was at a likely minimum.

The data were analyzed and adjusted by using the Hilbert-Huang transform (HHT) (Huang and others, 1998), a signal processing technique that is adaptive and valid for nonlinear and nonstationary data. The HHT analysis consists of decomposing a time series into multiple modes, called intrinsic mode functions (IMF), and a residual trend (Huang and others, 1998). Each IMF and the residual trend are then Hilbert transformed to create time-frequency spectra. The first IMF represents system noise, and it can be subtracted from the overall signal as a noise-filtration technique (Kanani and others, 2010). The last IMF represents the large-scale system variation (low-frequency cyclic pattern). Subtracting the residual removes any nonstationarity in the signal, effectively subtracting seasonal variation. The detrended data were then offset by the mean sanitary sewer discharge from the likely minimum indicated as September 2012.

The additional adjustment of the measured sewer discharge was considered to provide a more representative estimation of specifically sanitary discharge to the sanitary sewer system for determination of consumptive use than that of the raw measurements. The method attributes no source to the subtracted water volume that represents seasonal variability. For the purposes of this estimation effort, the $210 \mathrm{Mgal}$ of water volume removed by this approach is considered to represent primarily the INF contribution to sanitary sewer return flow. As expected, the detrending and offsetting process results in a more consistent estimate of the sanitary sewer discharge; however, this process also removes the additional contribution of possibly valid seasonal variation in water use and resulting water return.

As estimated from the detrended and offset (adjusted) data, monthly mean sanitary sewer discharge ranged from 2.09 to $2.21 \mathrm{Mgal} / \mathrm{d}$ (table 6 ). The estimated annual mean sanitary sewer discharge was $778.25 \mathrm{Mgal}(2.13 \mathrm{Mgal} / \mathrm{d})$, which is greater than the estimated supplied water in the sewershed of $556.18 \mathrm{Mgal}(1.55 \mathrm{Mgal} / \mathrm{d})$. The excess in sewer discharge is attributed primarily to INF from groundwater into the sewers. This is discussed in detail in the section "Groundwater Relation to Sanitary Sewer Flow."

\section{Other Aspects of Return Flow}

Return flow in the sewershed primarily consists of sanitary sewer returns; however, to gain a more complete understanding of the actual volume of returns, several other aspects to the accounting of return flow must be considered. These considerations are discussed in the following sections and include (1) the relation of groundwater level to the depth of the sewer inverts and its possible significance to how well the measured sewer flows represented sanitary sewer return flows, and (2) the direct returns of swimming pool and carwash discharge to Salt Creek. 


\section{Groundwater Relation to Sanitary Sewer Flow}

The periodic measurements of groundwater levels at the 12 wells installed adjacent to select sanitary sewer lines (fig. 2) indicated that, for the most part, the nearby groundwater surface at these locations was at a shallower depth than the nearby sewer invert (figs. 11;25). This relation between groundwater and sewer depth, which is presumed to persist throughout most of the sewershed, appears to account for the substantial volume of groundwater INF into the sewers and overestimation of sewershed outflow.

Depth to groundwater in the sewershed ranged from $3.12 \mathrm{ft}$ (well TW6) to $28.69 \mathrm{ft}$ (well TW1) (table 2; fig. 2). Minimum depths to groundwater at the wells ranged from $3.12 \mathrm{ft}$ (well TW6) to $26.42 \mathrm{ft}$ (well TW1) and maximum depths from $7.40 \mathrm{ft}$ (well TW12) to $28.69 \mathrm{ft}$ (well TW1). The vertical change in groundwater depths at individual wells ranged from $0.48 \mathrm{ft}$ (well TW12) to $8.95 \mathrm{ft}$ (well TW5). The minimum depths to water were less than (above) the depths of the sewer inverts at all of the well locations, and the maximum depths to water were greater than (below) the depths of the sewer inverts at only four locations (wells TW5, TW6, TW11, TW12). At each of these locations where the deepest measured water levels were below the sewer invert, the depth of the sewer invert was among the shallowest of those inspected in the sewershed $(8,8,10$, and $7 \mathrm{ft}$, respectively). For all but one well (TW12), the period when the groundwater level fell below the sewer invert was late summer 2012 to early winter 2013, when the effect of the 2012 drought on groundwater resources in this region of the State was most evident.

For the most part, the range of periodically measured groundwater levels varied over a typical range for shallow groundwater and tracked seasonal climatic and precipitation patterns. To gain a better understanding of the short-term variability of groundwater levels adjacent to and near sewer lines, three wells (TW1, TW5, and TW9) were outfitted temporarily with pressure transducer-data loggers that recorded levels at 15-minute intervals.

Short-term variability, as indicated by observation well hydrographs, might be in response to various factors, including:

1. undesirable stormwater discharges to the sewer system (IN), with leakage to the groundwater system (EXF),

2. fluctuating sewer discharge during high-usage periods, with EXF to the groundwater system, and (or)

3. rapid percolation of rainfall into the shallow trenchfill materials enveloping the sewer lines, with the percolation occurring at or near the location monitored by an observation well or a remote location(s).
Preferential downgradient transport of remotely infiltrated water is possible along the sewer line within comparatively permeable trench-fill materials (Lung and Nice, 2003). Newer reaches of the network are reported to include a gravel pack as part of the trench fill (Scott Bernholdt, Department of Public Works, Elk Grove Village, Illinois, oral commun., 2011).

Groundwater levels monitored at well TW1 during early November 2012-late March 2013 showed no response to individual storm events, as anticipated. This well is the deepest in the study, about $44 \mathrm{ft}$ (table 1; figs. 25A; 2), and terminates about $8 \mathrm{ft}$ above the adjacent interceptor sewer invert. Similarly, no water level response to individual storms was evidenced at well TW9, with monitoring conducted during early June-late September 2012. At this 20-ft deep well (table 1), OBs were detected at elevated concentrations, suggesting past or present leakage of sewer flow to groundwater. The detected presence of OBs in groundwater at well TW9 is discussed in detail later in this section and in the section, "Findings of Related Assessments."

Continuous groundwater level monitoring at well TW5 (figs. 26; 2) during about mid-August to mid-September 2012 indicated groundwater levels at this location respond very rapidly to storm events that exceed about 0.2 inches per day (in/d). Four of these events are noted in the precipitation records of the NOAA weather station at Chicago O'Hare Airport (Angel, 2013b). In response to these storms, water levels rose about $2-3 \mathrm{ft}$ and within about 24 hours fell to near prestorm levels. The open interval of this well is about $8.7-13.7 \mathrm{ft}$ below land surface, with the depth of the adjacent sewer invert about $8 \mathrm{ft}$. Interestingly, the greatest range in water level depths $(8.95 \mathrm{ft})$ was evidenced in this well. This wide range of fluctuation seemingly was not in response to individual storm events, but represented climatic and precipitation trends in groundwater levels as typified at the other study wells. The shallow depth of this well and the exposure of its open interval to pebbly, silty sand at a depth of about 12.0-13.3 ft (appendix 2B) certainly contribute to the observed rapid response of groundwater levels to storm events. Whether that response reflects rapidly infiltrating precipitation through the somewhat permeable clayey silt fill overlying the coarse-grained deposits, lateral transport of groundwater from storm infiltration into nearby shallow sand deposits (fig. 8), or leakage (EXF) from the overlying sewer line that may be receiving stormwater IN is uncertain. Results from OB sampling discussed in the section "Potential for Exfiltration" do not appear to implicate EXF induced by stormwater IN as a causal factor in the rapid rise in groundwater level at well TW5. The period of continuous monitoring of groundwater levels coincided with the period of about 6 months when groundwater levels, as measured at well TW5, were as much as $4 \mathrm{ft}$ below the sewer invert. 

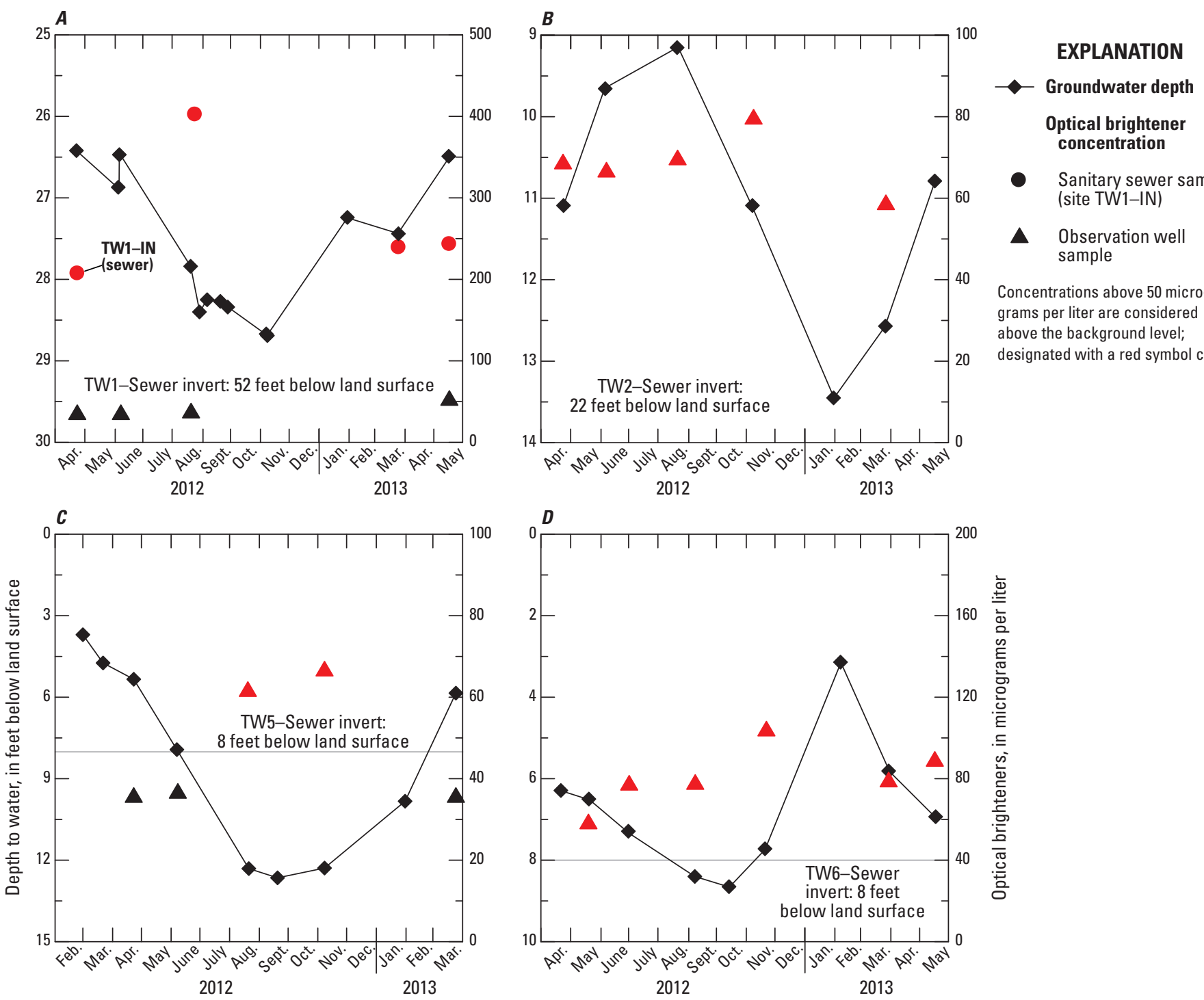

- Sanitary sewer sample (site TW1-IN)

A Observation well sample

Concentrations above 50 micrograms per liter are considered above the background level; designated with a red symbol color.
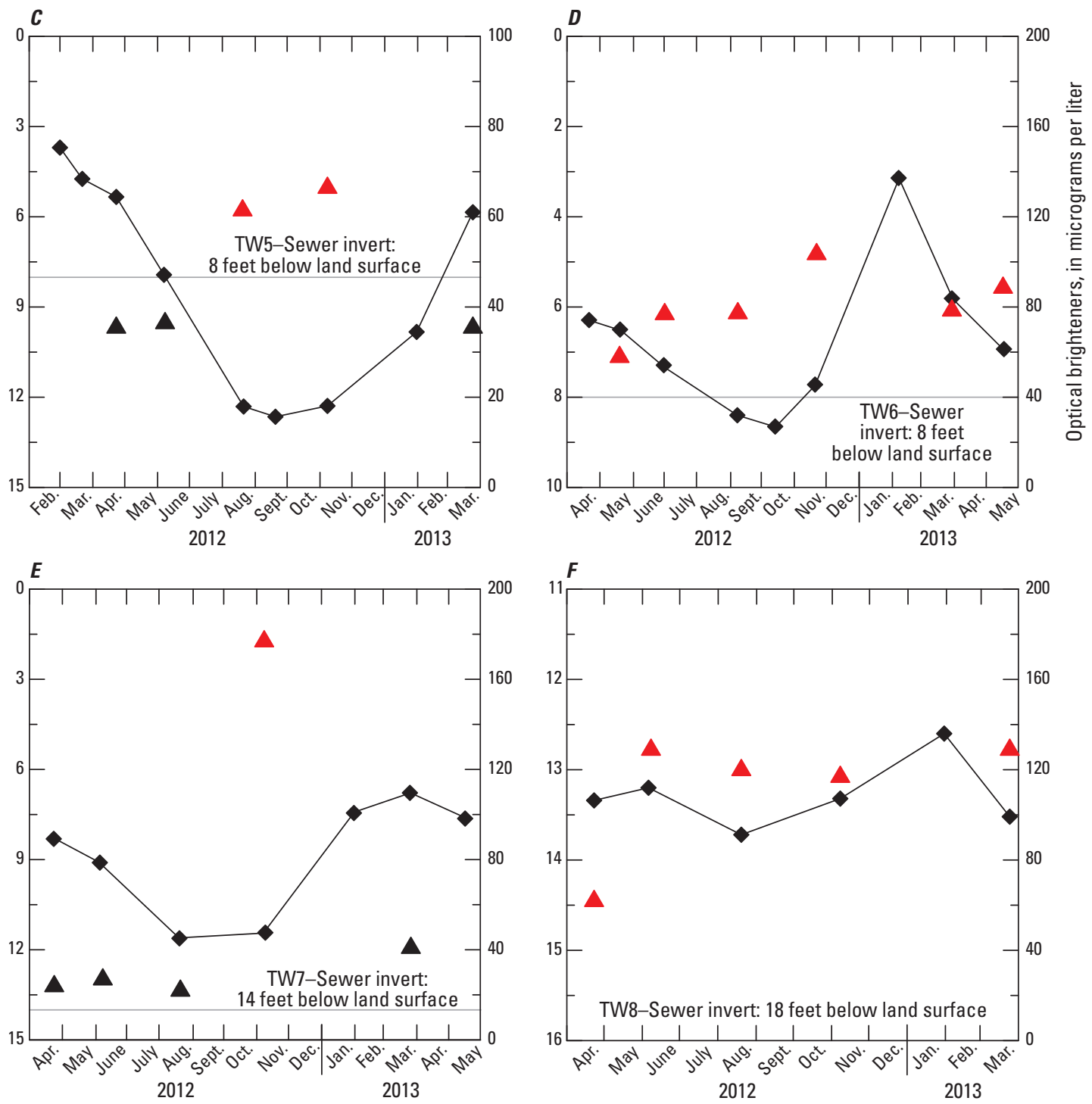

Figure 25. Groundwater and sanitary sewer invert depths and concentrations of optical brighteners at observation wells installed adjacent to sanitary sewers in the study area, Elk Grove Village, Illinois, April 2012-May 2013. A, Well TW1 and within sewer at site TW1-IN. B, Well TW2. C, Well TW5. D, Well TW6. E, Well TW7. F, Well TW8. 

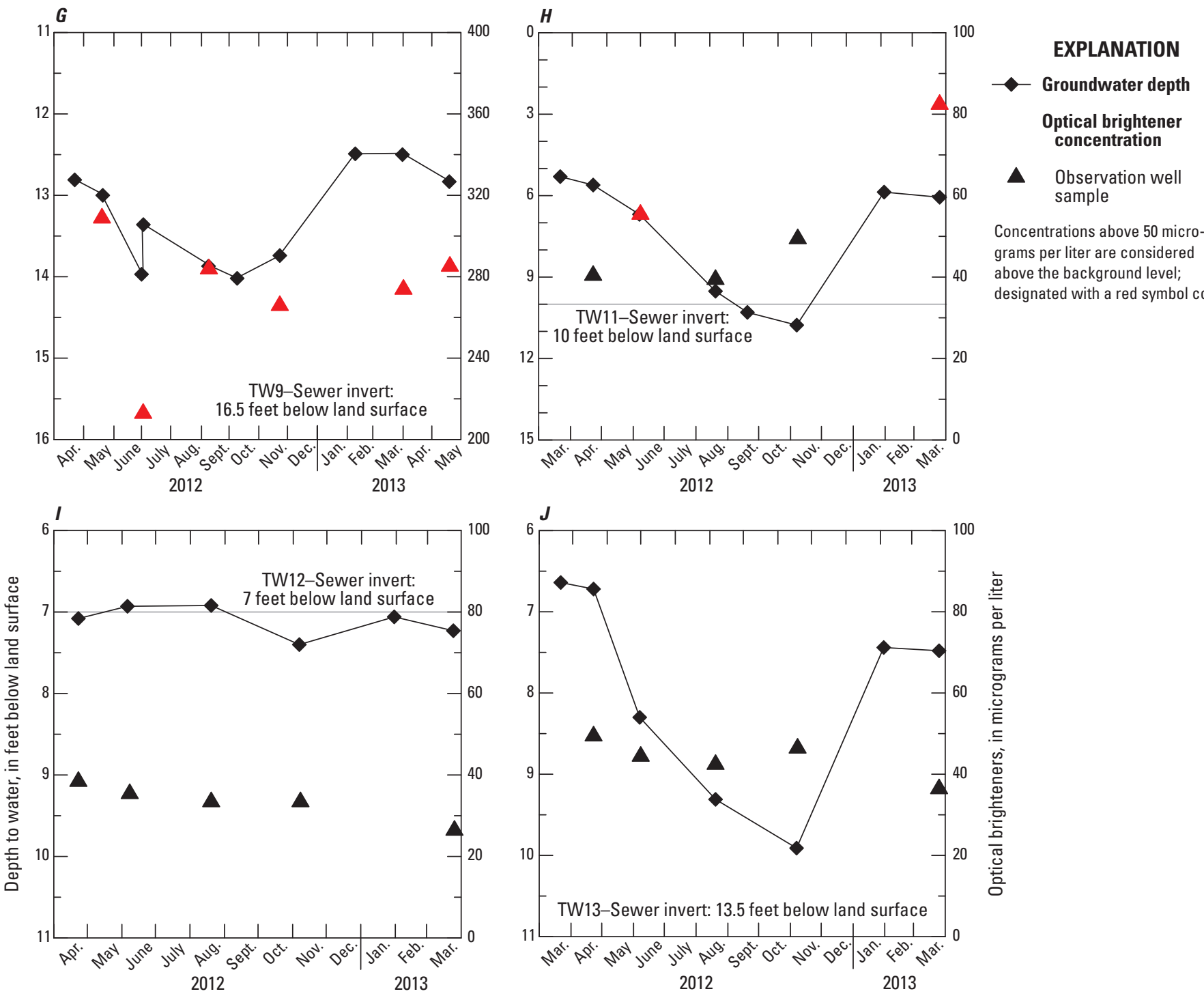

Concentrations above 50 micrograms per liter are considered above the background level; designated with a red symbol color.
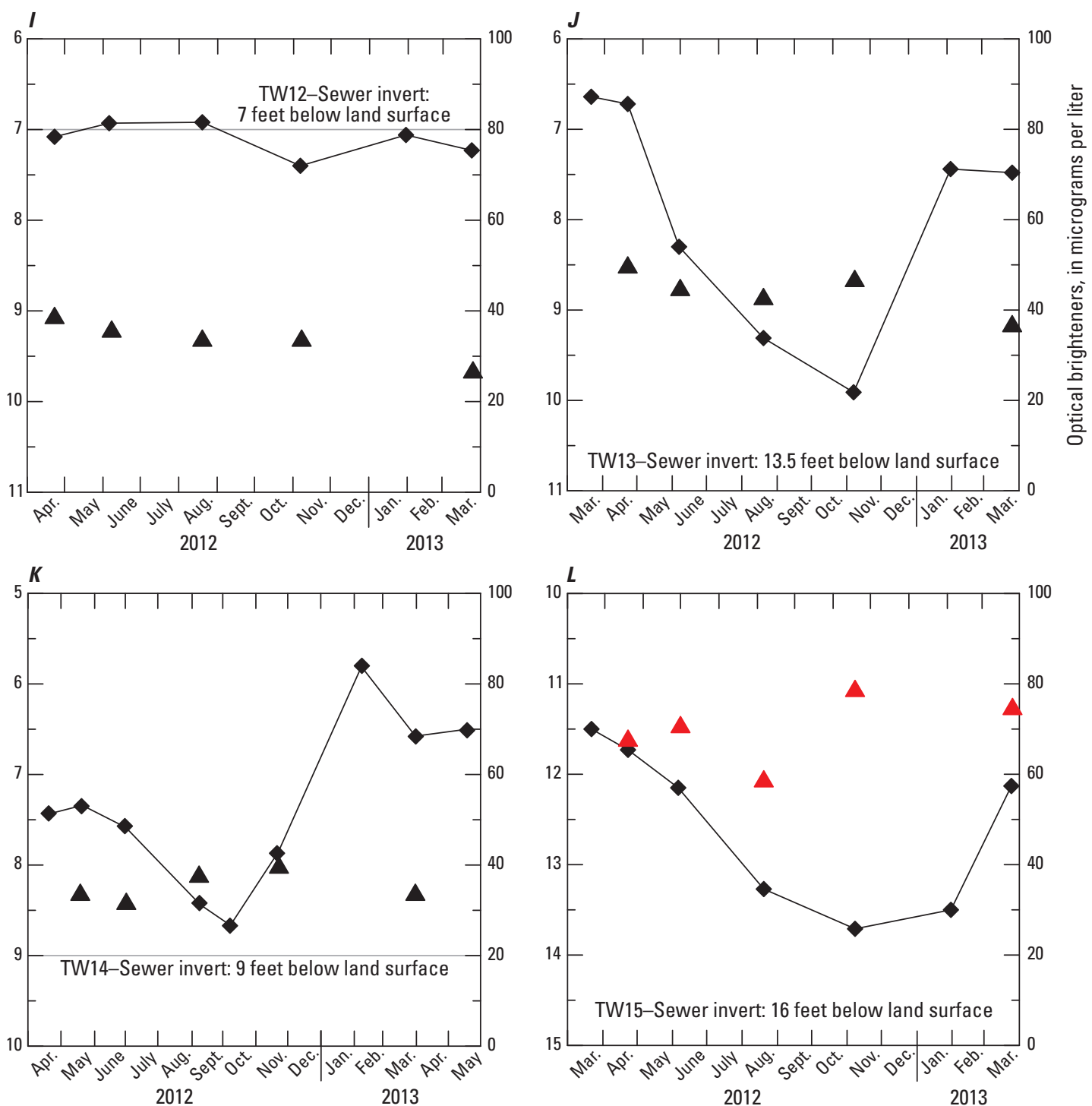

Figure 25. Groundwater and sanitary sewer invert depths and concentrations of optical brighteners at observation wells installed adjacent to sanitary sewers in the study area, Elk Grove Village, Illinois, April 2012-May 2013. G, Well TW9. H, Well TW11. I, Well TW12. J, Well TW13. K, Well TW14. L, Well TW15. 


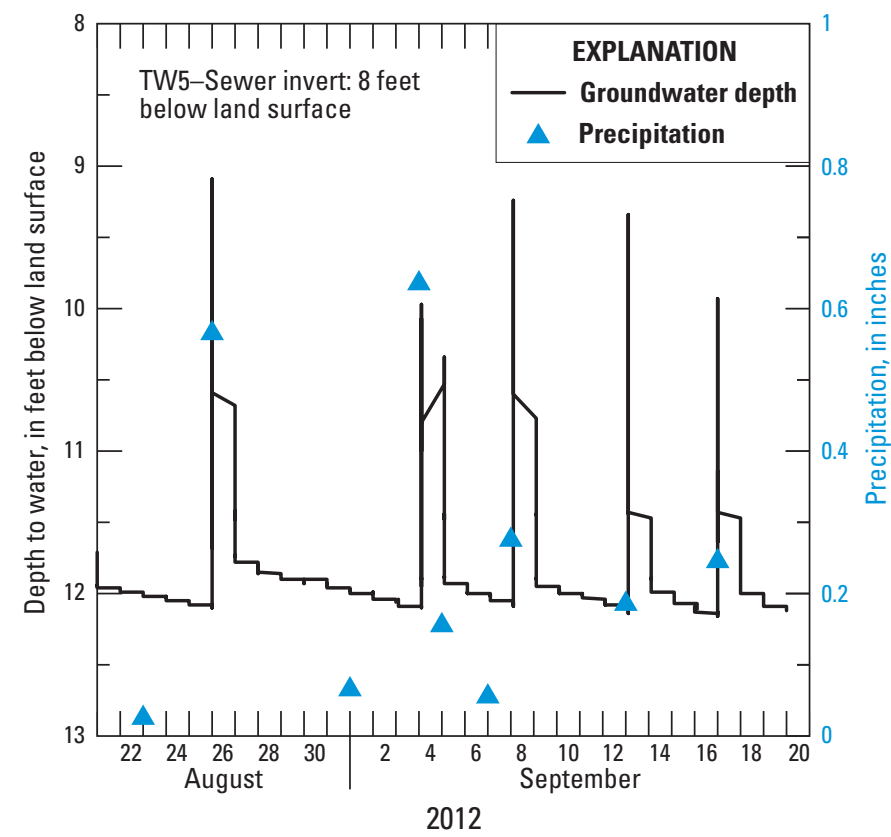

Figure 26. Relation between depth to groundwater at observation well TW5 and amount of precipitation, Elk Grove Village, Illinois, August 21-September 20, 2012.

In addition to the variability in groundwater levels near the sewer line evident from the continuous monitoring at well TW5, the periodic measurements of groundwater levels in the study area wells provided other possible evidence of short-term variability. At well TW6, the groundwater level was measured to within $3.12 \mathrm{ft}$ of ground surface on January 31, 2013 (fig. 25D), but was about $8 \mathrm{ft}$ below ground surface in November 2012 and $6 \mathrm{ft}$ in March 2013. Although the open interval of well TW6 (8.2-13.2 ft) begins just below the depth of the sewer invert ( $8 \mathrm{ft}$ ) (table 2), the measured depths to groundwater typically were shallower than the invert depth. Thus, it is unlikely that the noted variability in groundwater levels is associated with EXF of sewer flow. The elevated water level recorded on January 21, 2013, is attributed to the large storm event 2 days before the groundwater level measurement that produced about 1.25 in. of rainfall. Additionally, the storm resulted in nearby (about $450 \mathrm{ft}$ ) Salt Creek overflowing its normal channel to within about $150 \mathrm{ft}$ of the well. Such flooding likely would have substantially raised the groundwater surface within this floodplain area, which locally can be comprised of course-grained deposits (Scott Bernholdt, Department of Public Works, Elk Grove Village, Illinois, oral commun., 2011) (fig. 8).

\section{Potential for Infiltration}

Based on the recorded water level depths relative to sewer invert depths and the observed range of water level depths at individual locations, the observed groundwater levels are considered to represent the depth to the natural water table as opposed to perched water in the unsaturated trench fill (and adjacent geologic deposits). The comparatively shallow depths to groundwater relative to the greater depths of most sewer lines indicate the predominating potential for INF of groundwater (leakage) into the sewer lines, thus resulting in a bias toward overestimation of sewershed outflow. Although a cause-and-effect relation cannot be presumed, the statistical relation (Spearman's rho; Helsel and Hirsch, 2002) between the depth to groundwater and sewer invert suggests that, in some cases, groundwater INF into adjacent sewers might increase as the relative depth of the sewers increases. As the difference between the depths to groundwater and sewer invert increases, the driving influence of head pressure on INF would be expected to increase. Inspection of figure 27, which relates both minimum and maximum depth of groundwater to the adjacent sewer invert depth, indicates a positive relation $(\mathrm{R}=0.86-0.80)$ for both measurements of water depth. That is, in some cases, as sewer lines increase in depth (about 7-8 $\mathrm{ft}$ in depth for branch lines to about $52 \mathrm{ft}$ for the interceptor), the depth to groundwater near the line increases. These groundwater depths increase from about 3-9 ft at the shallowest branch lines to about $28 \mathrm{ft}$ at the deep interceptor; at intermediate depth trunk lines, such as at observation wells TW2, TW8, TW9, and TW15, groundwater depths typically are about 9-15 ft. System design would not be expected to routinely increase the depth of sewer lines in accordance with increased depth to the water table. There was an unexplained weak inverse relation $(R=-0.30)$ between range in groundwater depth at the wells to sewer invert depth, however, two of the smallest ranges (1.1 ft, TW8; $1.5 \mathrm{ft}$, TW9) were observed in association with two of the deeper inverts $(18.0 \mathrm{ft}$, TW8; $16.5 \mathrm{ft}$, TW9). Certainly, factors other than depth of the sewer inverts relative to the depth to groundwater contribute to a likelihood of INF. These factors could include (1) condition of the sewer lines and connections, (2) status of sewer line upgrade (cured-in-place linings), (3) areal and trench-fill lithologies, and (4) location in the sewershed relative to the "uplands" and Salt Creek lowlands, among others.

Some of the greatest depths to groundwater (about 12-14 ft) were observed (at wells TW8 and TW9) along the west trunk line paralleling the floodplain on the west side of Salt Creek; conversely, along the floodplain on its east side, more typically shallow depths to groundwater (about 3-8 ft) were observed (at well TW6) (table 2; fig. 25D). In natural (before development) glaciated settings of generally low relief, similar lithologic composition, and small area, such as the Elk Grove Village study area (fig. 8), more similar depths to the water table generally would be expected than those observed throughout the study area. Additionally, where wells are near a principal outlet of surface water discharge (stream or lake), their depths often are shallower than wells in the uplands (Fetter, 1994), which also is unlike those observed in the study area. 


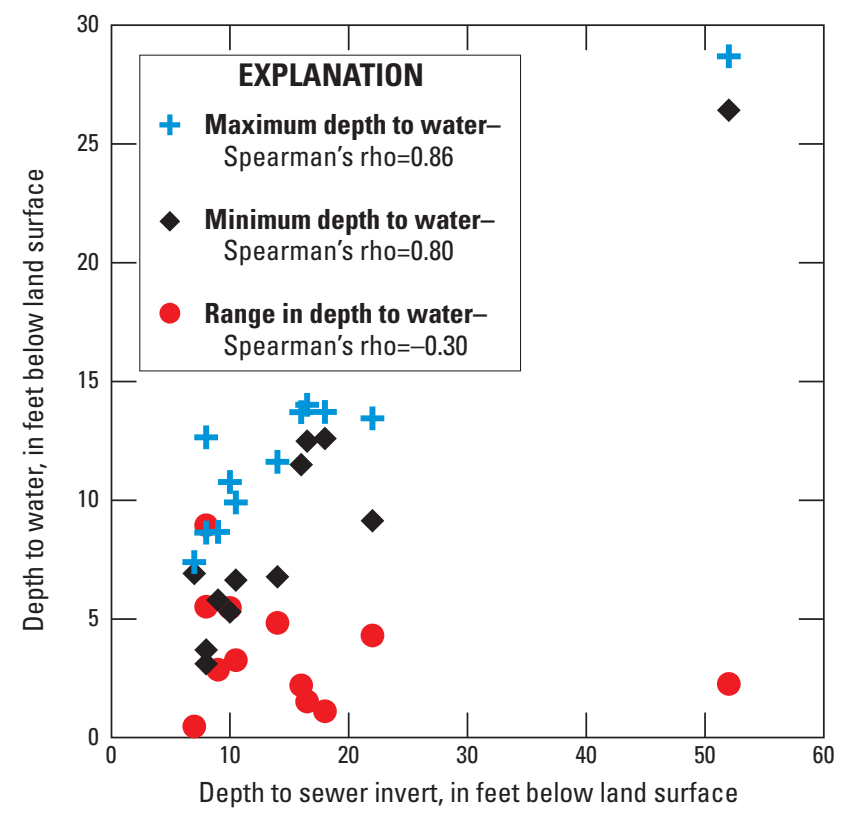

Figure 27. Relation between depth to groundwater, magnitude of the seasonal range in depth to groundwater, and depth to sanitary sewer invert, Elk Grove Village, Illinois, April 2012-March 2013.

Unexpectedly, depressed groundwater levels were recorded at wells TW2 and TW9 (table 2; figs. 25B, G), each installed adjacent to a comparatively deep trunk line that has been lined in recent years to prevent groundwater INF. One explanation might be that leakage to unlined reaches, such as that suspected near wells TW8 and TW15 (figs. 6; $25 I, L)$, remotely influences water levels in connected reaches of sealed or otherwise upgraded lines. Although the sewer pipes of the comparatively deep trunk lines, such as at wells TW2 and TW9, have been lined (figs. 5; 6) in recent years to prevent groundwater INF into the lines, pipes at and near wells such as TW8 and TW15 have not been lined. Permeable materials that sometimes fill the sewer trenches have been identified as capable conduits for possible preferential distribution of sewer-sourced contents and hydraulic communication within a sewer network (Lung and Nice, 2003).

The greatest depth to groundwater was at well TW1 (table 2), overlying the interceptor sewer. This comparatively large depression in groundwater level could suggest that INF at this location is comparatively larger than elsewhere in the sanitary system, as seemingly associated with the deeply buried, large-diameter reach of the sewer system. Thus, INF in this reach of the system might account for a substantial portion of the excess sanitary sewer return flow determined in the estimation of consumptive use (as discussed in the following section "Summary Estimation of Consumptive Use").

Although not explored in this study and not evident in the available groundwater level data, an additional route for possibly substantial groundwater INF into the sanitary sewer system is through the thousands of shallow lateral lines connecting homes and commercial facilities to deeper lines of the municipal sewer system. Many of these lines might lie only a short distance above the area water table, which generally is at a depth of about $4 \mathrm{ft}$ or greater. If these lines are routinely degraded by soil compaction, root damage, and connection issues, then they could readily drain shallow groundwater or possibly smaller volumes associated with interflow within the unsaturated zone. This drainage might be reflected in shallow groundwater levels that fluctuate over a small range, with the height of the water table constrained by the depth of the laterals.

In consideration of the distributed groundwater level patterns and previously discussed excess volume of sanitary sewer returns, it seems that INF to the area's sanitary sewers occurs primarily as slow, nonpoint source leakage; for the most part the leakage is continuous, but can be associated with periodic storm events. More rapid INF also can occur as the result of the failure of large sewer lines; however, these occurrences are expected to be infrequent and terminated by repair shortly following their identification. Further study would be necessary to gain a better understanding of the relation between groundwater level and sewer depth, preferential flow within trench-fill materials, and (or) other factors that might play a role in or relate to the occurrence and extent of groundwater INF to sewers.

Of note, limited inspection of flow within about 20 manholes over the course of this study found no observable leakage through the sidewalls or connections of the variously constructed manholes. Sewer flow observed in many of the manhole-inspected sewer reaches was not always sustained, and when sustained, the rates did not appear to differ greatly among lines of similar sizes or between manhole locations.

\section{Potential for Exfiltration}

Based on findings from the observation well (sample) locations within the sewershed network, EXF of sewer flow to groundwater in the sewershed should be minimal. At most times and locations, the water table was above the sewer inverts. At only three sample locations (wells TW5, TW6, TW12) was the water table determined to temporarily fall below the inverts (fig. 25C, D, I). This occurred generally during the summer to early winter months of 2012 and was related directly to the drought conditions during much of that year. Although the water level findings indicate an areawide limited potential for extensive EXF of sewer flow to groundwater, evidence from $\mathrm{OB}$ sample data suggests possible local occurrences of EXF. However, at most of these locations, any past or present EXF does not appear to be extensive.

Concentrations of OBs were less than the determined background concentration in groundwater of about $50 \mu \mathrm{g} / \mathrm{L}$ in the samples from four wells (TW1, TW12, TW13, TW14) (figs. 6; 25A, I, J, K; table 3). Of particular note are the low OB concentrations in groundwater that is temporarily at a depth below the sewer invert at well TW12. The low OB concentrations in groundwater below the sewer invert at the above well locations are indicative of sewer lines that generally are not subject to EXF. 
Concentrations of OBs were marginally greater than the determined background concentration in groundwater in the samples from four wells (TW2, TW5, TW11, and TW15)

(figs. 6; 25B, $C, H, L$ ), where they ranged from $51-100 \mu \mathrm{g} / \mathrm{L}$. These concentrations are considered moderately indicative of groundwater affected by sewer-sourced OBs; however, only at well TW5 did the groundwater level temporarily fall below the level of the sewer invert. At the other locations, the inverts were consistently greater than $2 \mathrm{ft}$ and as much as $9 \mathrm{ft}$ below the water table. The few notable increases in OB concentrations at wells TW11 and TW5 did not seem related to falling groundwater levels and EXF of sewer flow, as these maximum concentrations were only in the range of about $60-80 \mu \mathrm{g} / \mathrm{L}$ and the increase in concentrations only in the range of about $20-30 \mu \mathrm{g} / \mathrm{L}$. These increases seem more likely associated with increases in sediment concentrations in the samples, which can affect the quantification of OB concentrations by the fluorometer. These results are considered to further indicate that extensive systemwide occurrence of EXF is unlikely.

Concentrations of OBs were recognizably greater than the apparent background concentrations in groundwater in the samples from three wells (TW6, TW7, TW8), where they ranged from 101-200 $\mu \mathrm{g} / \mathrm{L}$, and a fourth well (TW9), where they ranged from about 200-300 $\mu \mathrm{g} / \mathrm{L}$ (fig. 6). These concentrations are considered strongly indicative of groundwater affected by sewer-sourced OBs. The presence of these elevated concentrations, close or similar to those found in sewer flow samples collected from the monitored interceptor (table 3 ), are not easily explained. The sewer inverts at these locations were usually greater than about $2-5 \mathrm{ft}$ below the water table. Only the invert at well TW6 was above the water table for a period limited to the dry summer through fall months of 2012. Additionally, the sewer lines adjacent to wells TW6, TW7, and TW9 were previously upgraded with cured-in-place linings. Both the high water table relative to the depth of the sewer inverts and the upgrading of the sewer lines at these locations should have prevented active EXF of sewer flow to groundwater during the period of this study.

The elevated OB concentrations at well TW6 (fig. 25D) possibly are associated with past flooding by nearby Salt Creek. Overland flooding could result in the filling and subsequent overflow of the manhole adjacent to the well (fig. 6) or direct percolation of floodwaters to groundwater in the lowlands near the well (fig. 8). Even with stormwater dilution that might occur during flooding, base load OB concentrations in Salt Creek and presumably in the sewer adjacent to well TW6 are considered sufficiently high to allow elevation of groundwater concentrations greater than background levels (see appendix 5, "Concentrations of Optical Brighteners in Salt Creek").

The single elevated OB concentration of $178 \mu \mathrm{g} / \mathrm{L}$ detected in the sample from well TW7 is puzzling in that all other measured concentrations were less than the determined background concentrations of about $50 \mu \mathrm{g} / \mathrm{L}$ (fig. $25 E$ ).
However, the confirmative measurement of about $200 \mu \mathrm{g} / \mathrm{L}$ in a duplicate sample, the lack of sediment in the two samples, and their pale yellow coloration was suggestive that the analytical results were valid and the samples representative of sewer-affected groundwater. There seems to be no ready explanation for how groundwater might be affected by sewer flow at this location. The sampled well is at a topographically high location (fig. 8), the water table is consistently above the sewer invert, the adjacent sewer pipe was recently lined, and there is no manhole within about $100 \mathrm{ft}$ that might be subject to surcharge or EXF at a leaky connection to a shallower sewer line. Surcharge could result in overfilling of a manhole and discharge of its sewer flow to the surrounding ground surface for subsequent percolation to groundwater.

The elevated $\mathrm{OB}$ concentrations detected in samples from well TW8 (fig. $25 F$ ) possibly are associated with leakage from a nearby shallower line(s) or a connection to the deeper trunk line at the manhole adjacent to well TW8. At this location, both the deeper trunk line (connected to the manhole at a depth of about $18 \mathrm{ft}$ ) and the shallower branch line (connected to the manhole at a depth of about $10 \mathrm{ft}$ ) are unlined. The water table depth at this location is about $3 \mathrm{ft}$ below the invert of the branch line. Concentrations of OBs detected in samples from well TW9 (fig. 25G) were of magnitude similar to those routinely detected in samples from the monitored interceptor (fig. 25A). As suggested for well TW6, the elevated concentrations in groundwater samples from this well might also be associated with its location near Salt Creek and area flooding that periodically may have occurred.

With each of the above-noted well locations with elevated OB concentrations, there remains the possibility that EXF of sewer flow to groundwater has occurred or is occurring at locations other than those where the samples were collected for this study. Leakage from unlined sections of the sewer network positioned above the water table might be transported to downgradient locations in distributed groundwater flow or along preferential pathways in the trench-fill materials enveloping the connected network of sewer lines (Lung and Nice, 2003). The presence of elevated OB concentrations also might reflect past leakage under different groundwater level conditions or the result of sewer line repair work or overland sump discharge of sanitary sewer backup in residential basements.

The present findings suggest that sewer flow loss by EXF is not extensive at the sewershed scale because:

1. sewer flow concentrations of OBs are almost always higher than those in groundwater;

2. most groundwater-sampling locations show little to no evidence of notably elevated OBs concentrations;

3. problematic occurrences of OBs in groundwater seem best explained by mechanisms other than EXF; and

4. the sewershed water table is generally higher relative to the sanitary sewer inverts. 
EXF may locally play a more prominent role in sewer flow loss. The greatest potential for meaningful underestimation of the role of EXF at the sewershed scale is flow loss that might occur in the thousands of shallow lateral lines serving private properties. Many of these lateral lines would be expected to be installed at depths close to, but above, the typical shallower groundwater levels in the sewershed (about 4-7 ft). However, flow loss associated with an individual line would be expected to be insubstantial relative to the total volume of sanitary sewer discharge from the sewershed.

\section{Direct Swimming Pool Discharge}

Seasonal or maintenance discharge of water from swimming pools was assessed as a possible substantial source of direct returns of publicly or privately supplied water to surface waters in the sewershed. As considered, the discharges principally are to Salt Creek through dedicated connections or indirectly through storm sewer drains (Scott Bernholdt, Department of Public Works Elk Grove Village, Illinois, written commun., 2012). Methods used for this accounting of pool discharge are presented in appendix 1.

On the basis of the GIS and Google Earth approaches for identifying, characterizing, and counting the number of pools in the sewershed, 397 pools were identified from September 2009 GIS imagery and 375 from June 2010 Google Earth imagery (fig. 14). Both approaches are suspected of providing somewhat underestimated total pool counts, as the satellite imageries that were used could miss pools under tree cover or without strong reflections because of sun angles. As such, a pool count of 400 was used for estimation of direct return from pools in the sewershed.

Estimates were made of the volumes of discharge from the private and public pools that were identified. Volumetric estimates were based on the approximate sizes of the pools and on water delivery data provided by the Elk Grove Village DPW (Scott Bernholdt, Department of Public Works Elk Grove Village, Illinois, written commun., 2013). Volumes of larger public pools were calculated separately from those of smaller private pools, because of their notable differences in shape, size, and depth. All supplied water used to fill area pools was considered publicly supplied, as only about 5 percent of the identified pools were in the unincorporated area using private wells. The method assumed that all water filled to the standard volume of a pool (as estimated for this study) is discharged at season's end. Although drainage of about half or less of the pool volume is recommended (Tague, 2014; Collier, 2012), actual drainage practices in the study area are unknown. As such, the conservative assumption is applied with the recognition that the method might overestimate pool discharge.

The water volumes for the various private pools that were identified were calculated collectively, assuming a standard shape, size, and depth representative of the common configuration of the above-ground pools that predominate in the study area. These standards are considered to underestimate pool volumes, because as many as 25 percent of the private pools were marginally larger, deeper in-ground pools. Water volume determined by using a pool count of 400 and the standard diameter and depth of these private pools was estimated as 5.9 Mgal.

By using Google Earth imagery, the number of public pools and their approximate water-filled dimensions and volume were determined. Three pool facilities were identified, including an outdoor public water park with multiple pools of various sizes and depths and a lazy river; an outdoor public lap pool; and an indoor high school pool. Based on the dimensions of these pools approximated by using the Google Earth measuring tool and estimates of depths, an annual pool water volume of about $0.8 \mathrm{Mgal}$ was estimated. Collectively, by using pool volume as a basis, $6.7 \mathrm{Mgal}$ was estimated as unmeasured direct return flow from private and public pool discharge to Salt Creek.

For the comparative estimate of unmeasured discharge to Salt Creek determined from water delivery records for outdoor public pools, total reported deliveries to the three identified facilities were determined to be about 5.3 Mgal (based on 4.56.0 Mgal, depending on interpretation of the delivery data). This volume was assumed to primarily represent that used to fill the pools and subsequently discharged to Salt Creek, but includes a smaller portion for showers, toiletry, and other uses and discharged to sanitary sewers. That portion of delivered water returned to sanitary sewers was estimated as $1.2 \mathrm{Mgal}$ (0.4 Mgal per facility).

The portion of delivery water used as makeup for evaporative loss from the pool surface and splashing or drag out - and thus not discharged to Salt Creek-was estimated as $0.28 \mathrm{Mgal}$ on the basis of equation 4 (appendix 1, p. 67). Makeup is likely overestimated, as precipitation that contributed to pool volumes would be expected to supplement (reduce) the deliveries used for makeup of evaporative loss, thus increasing the volume expected to be discharged to Salt Creek. Based on about 8 in. $(0.67 \mathrm{ft})$ of precipitation in the area during summer 2012, the estimated volume of delivery water diverted as makeup for evaporative loss is considered only 0.13 Mgal.

With the adjustments to the record of 5.3 Mgal of water deliveries to public pools for discharge to sanitary sewers $(-1.2)$, evaporative loss $(-0.28)$, and the contribution of precipitation (0.15), a more fully representative estimate of unmeasured discharge to Salt Creek from public pools is 4.0 Mgal. The estimate of discharge based on water delivery is considered possibly more accurate than the estimate based on pool size $(0.8 \mathrm{Mgal})$, and thus, was the applied estimate for the volume of direct return of pool water to Salt Creek in determination of consumptive use. The actual volume of direct discharge from area public pools likely falls somewhere between these estimated volumes, as it is suspected that the portion of delivery water returned to the sanitary sewer system is underestimated. The population of users at the pool facilities is presumed to be greater than at the comparative facilities. 
Total water volume filling both private pools (5.9 Mgal) and public pools $(4.0 \mathrm{Mgal})$ in the sewershed was estimated as approximately $9.9 \mathrm{Mgal}$. This estimated accounting was included in the final determination of return flows to the immediate water environment for calculation of consumptive use.

\section{Direct Carwash Discharge}

Initial assessment of sources of direct returns of publicly or privately supplied water to surface waters of the study area also indicated carwash discharge as a potentially large source of return flow. Such discharge from residential ("driveway") washing of cars presumably would be indirectly to Salt Creek through storm sewers. Beyond a limited evaluation of residential carwash discharge, no addition to direct return flows was considered, as there was substantial uncertainty associated with the variables used in its volumetric estimation.

About 19,000 residents live within the sewershed. It can be assumed that about 69 percent of residents own a car or other similar vehicle, based on findings of a study of residential carwashing by the city of Federal Way, Washington (2009), a community reasonably similar socioeconomically to the study area. Presumably about 38 percent of these owners personally wash their cars at their residence (that is, "their driveway"), as indicated by survey statistics of the International Carwash Association included in the above-noted report. By further assuming that the carwashings occur once per month during the 5-month period of May-September, then about 25,000 residential carwashings a year are possible in the sewershed. As a "worse-case" scenario, assuming a high-flow hose rate and continuous running of the hose water, use of about 150 gallons per wash can be expected (Save the Sound, Inc. 2002). Resulting use, therefore, would be about 3.8 million gallons per year (Mgal/yr). This volume represents less than 1 percent of the estimated (adjusted) volume of the return "sanitary" flow (778 Mgal/yr).

In the above estimate of discharge to storm sewers, which might result from residential washing of cars, a wash frequency of once per month was presumed. The possible consequence associated with this presumption was further considered. If a higher, although unexpected, frequency of one carwash per week were applied, the resultant volume of discharge could approach as much as $15 \mathrm{Mgal} / \mathrm{yr}$. However, another related source of uncertainty and potential error in the accounting of carwash water use and discharge is associated with the assumption that all the wastewater is discharged to storm sewers. A similar assumption that most wastewater from residential carwashes drains to storm sewers was made in a study by the city of Federal Way, Washington (2009) of the pollutant potential to urban waters from residential carwashing. That study recognized, as did this study, that some portion of the wastewater certainly drains to more pervious surfaces, such as lawns, and infiltrates to groundwater or evapotranspires. That unmeasured portion should separately be considered consumptive use. Thus, if it were assumed that 25 percent of carwash wastewater is lost to consumption by discharge to pervious surfaces, then based on a frequency of one wash per week, a more reasonable estimation of the maximum volume of water that could be discharged to storm sewers would be about $11 \mathrm{Mgal} / \mathrm{yr}$. This volume continues to represent only a small fraction (about 2 percent or less) of the estimated total return flow. As such, it is suggested that the small volume of possible discharge from residential ("driveway") washing of cars reasonably can be ignored in the present estimation of consumptive use and was not included in the estimate of direct returns.

\section{Summary Estimation of Consumptive Use}

By using the reported, measured, and (or) estimated water use and return data determined from this study, consumptive use for the predominantly residential study area can be estimated by application of the expanded version (2) of the consumptive-use mass-balance equation from LaTour (1991). Consumptive use can be expressed as a coefficient representing the percentage of total supplied water not returned to the immediate water environment following its use, which is:

\section{Consumptive use / Total supplied water $(\times 100$, if expressed as percent $)$.}

For the Elk Grove Village study area, there are no known or expected direct discharges to groundwater, thus the following sewershed-specific application of equation 2 for the massbalance estimation of consumptive use results:

$$
C U(\mathrm{gal})=(D P S+S W U)-(R S S+R P S S C)
$$

where

$$
\begin{aligned}
C U= & \text { Consumptive use (with these and following } \\
& \text { volumes reported in millions of gallons), } \\
D P S= & \text { Deliveries of water by the Elk Grove } \\
& \text { Village public water system, } \\
S W U= & \begin{array}{l}
\text { Self-supplied withdrawals within the } \\
\text { unincorporated area served by the Elk }
\end{array} \\
\quad & \text { Grove Village sanitary sewer system, } \\
R S S= & \text { Water returns to the sanitary sewer system, } \\
& \text { and } \\
\text { RPSSC } & \text { Water returns from swimming pools to } \\
& \text { storm sewers or directly to Salt Creek }
\end{aligned}
$$

By using the reported, measured, and (or) estimated volumes, the following volume representing consumptive use is derived from equation 5 :

$$
\begin{gathered}
-221.97 \mathrm{Mgal}=(555.90 \mathrm{Mgal}+10.28 \mathrm{Mgal})- \\
(778.25 \mathrm{Mgal}+9.9 \mathrm{Mgal}) .
\end{gathered}
$$

This volume of consumptive use expressed as a coefficient is -0.39 . It is readily apparent that the resulting estimation of consumptive use is invalid, given the cumulative volume of estimated water returns by way of the sanitary sewer 
system and directly to Salt Creek is larger than the cumulative volume of supplied water from public deliveries and self-supply. The large volume of sanitary sewer returns is represented predominantly by the directly measured sewer discharge. This measured discharge was adjusted to remove seasonal variation that by assumption was attributed primarily to climatically influenced INF considered unrepresentative of residential discharge to sanitary sewers. The excessive volume of sewer flow relative to the volume of supplied water cannot be attributed to field measurement error, as the continuous measurements of flow by automated means were periodically verified by manual measurements. The related estimates of supplied water, either by deliveries from public providers or by self-supplied withdrawals, also are considered well determined, with relatively limited uncertainty.

With application of the adjusted (detrended and offset) estimates of sanitary sewer return flow to the mass-balance determination of consumptive water use, seasonal variation in the sanitary sewer discharge record was presumed to represent seasonal trends in INF. The possible limitation of the adjustment method, which effectively discounts seasonal variation in water use and water return, was recognized but disregarded. The determination to apply the adjustment to the measured discharge data was based on the presumption of a greater likelihood that the seasonal variation was predominantly associated with climatically influenced INF. In actuality, whether the determinations of sanitary sewer returns included a possible seasonal component of flow or not mattered little to the overall objective of estimating consumptive use. Greater volumes of "measured" sanitary sewer returns than supplied water (566.18 Mgal) resulted whether the discharge data were adjusted (778.25 Mgal) or unadjusted return (998.25 Mgal).

Whatever the contribution of seasonal variability of water use and water return flow, the excessive volume mostly seems to represent the considerable contribution of groundwater INF into the sanitary sewer system. Seemingly, even with the notable efforts to upgrade the system with cured-in-place lining of about 44 percent of the aging pipes, it appears that additional upgrading could be beneficial.

As a meaningful coefficient of consumptive use could not be determined from this study, it was not possible to evaluate the reasonableness of the coefficient of consumptive use presently applied by the State of Illinois for Lake Michigan allocation accounting or the range of coefficients principally used by other States and Provinces in the Great Lakes region and elsewhere for management applications relevant to public supply and domestic self-served water use. As an alternative means for this evaluation, the winter base-rate method, as described in LaTour (1991, p. 30) and Shaffer and Runkle (2007, p. 24) is considered. This method focuses on seasonal outdoor water use, which is assumed to account for the majority of consumptive use as the result of evapotranspiration associated with lawn watering or other landscape irrigation.
The method is best applied to computation of consumptive use associated with domestic and public supply uses, where seasonal increases can reasonably be attributed primarily to consumption. Other uses, such as for livestock, mining, and industry or thermoelectric power production, either typically have near-constant water withdrawals throughout the year, or it is difficult to discern whether increases in summer withdrawals are from increases in consumptive use, demand, or both (Shaffer, 2009). In evaluation of three methods for estimating domestic consumptive use, LaTour (1991) determined the winter base-rate method provided the most reasonable estimate of domestic consumptive use.

For the winter base-rate method, domestic use first is determined for the months with minimal outside use; for Illinois, these are considered November-April. This establishes the winter base rate. Outside use is determined as the difference between the winter base rate and domestic use during the warmer months of May-October. For this period, it is assumed that 80 percent of the water applied to lawns or for other landscape irrigation is consumed by evapotranspiration (Latour, 1991), with the remainder directly returned to nearby surface waters primarily through storm drains or to shallow groundwater. As applied to the sewershed, by using only public water deliveries, the following were estimated:

- November-April (indoor use/winter base rate): $233 \mathrm{Mgal}$

- May-October (indoor + outdoor use): $323 \mathrm{Mgal}$

- May-October (outdoor use): $90 \mathrm{Mgal}$

- Consumptive use: $72 \mathrm{Mgal}$

Although slightly higher, the resultant coefficient of consumptive use, 0.13 , compares favorably with that that of 0.10 presently used by the State of Illinois for Lake Michigan allocation accounting; the resultant coefficient also compares favorably with the range, $0.10-0.15$, and median, 0.12 , of coefficients used by other States and Provinces in the Great Lakes region. In consideration of the primary assumptions of the winter base-rate method, its application likely is more appropriate for a predominantly residential community, like Elk Grove Village, than for a larger mixed-use municipality, such as Chicago.

Although accurate estimation of the volume of INF+IN seemingly included as a portion of the estimated sanitary sewer return flow in the sewershed was beyond the scope of the study, a simple alternative approach is considered to assess the possible volume solely representing sanitary sewer return flow. As reported by U.S. Environmental Protection Agency (2013b), on average, 70 percent of daily water use in the United States is for indoor use. This includes usage for toilets, clothes washing, showers and baths, and faucets and leakage, with discharge almost exclusively to sanitary sewers. Almost none of the indoor use is considered lost to consumptive use (LaTour, 1991). Annual sanitary sewer return flow of supplied 
water might be approximated by the following equation, with supplied water in the sewershed determined to be about 566 Mgal:

$$
R F(\text { gal })=S W * 0.70
$$

where

$$
\begin{aligned}
R F= & \begin{array}{l}
\text { Sanitary sewer return flow, in gallons } \\
\text { (reported in millions of gallons) }
\end{array} \\
S W= & \text { supplied water, and } \\
0.70= & \text { Adjustment for percentage of indoor water } \\
& \text { use. }
\end{aligned}
$$

Thus, supplied water return as sanitary sewer flow during the yearlong period of study could approximate $396 \mathrm{Mgal}$. Its comparison to the adjusted "sanitary" sewer flow volume of $778 \mathrm{Mgal}$ suggests $382 \mathrm{Mgal}$ of INF+IN. Comparison to the unadjusted "sewer" flow volume of 988 Mgal suggests 592 Mgal.

Another simplified approach to approximate the volume of INF+IN could consider use of an available estimate of consumptive use as it applies to the determined volume of supplied water in the sewershed. For this approach, it is assumed that 100 percent of nonconsumed water return is by way of sanitary sewers. The median coefficient of 0.12 determined for domestic and public supply use in the Great Lakes Basin (Shaffer and Runkle, 2007) can be considered representative of consumptive use in the predominantly residential sewershed. Therefore, 88 percent of use can be considered nonconsumptive. Annual sanitary sewer return flows of the 566 Mgal of supplied water can be approximated by the following equation

$$
R F(\text { gal })=S W * 0.88
$$

where

$$
\begin{aligned}
R F= & \begin{array}{l}
\text { Sanitary sewer return flow, in gallons } \\
\text { (reported in millions of gallons) }
\end{array} \\
S W= & \text { supplied water, and } \\
0.88= & \begin{array}{l}
\text { Adjustment for percentage of } \\
\text { nonconsumed water. }
\end{array}
\end{aligned}
$$

Thus, sanitary sewer return flow could approximate 498 Mgal. Its comparison to the adjusted "sanitary" sewer flow volume suggests $280 \mathrm{Mgal}$ of INF+IN and to the unadjusted "sewer" flow, 490 Mgal.

Finally, the volume of INF+IN might be approximated by use of the estimate of indoor water use determined from the previous application of the winter base-rate method to estimate consumptive use in the sewershed. That estimate of $466 \mathrm{Mgal}$ of annual indoor use suggests $312 \mathrm{Mgal}$ of INF+IN when compared to the adjusted "sanitary" sewer flow volume and $522 \mathrm{Mgal}$ when compared to the unadjusted flow volume.

The volume of INF in the absence of any contribution from storm-associated IN can be separately approximated by simple consideration of the diurnal nighttime minimum discharge as determined from a sewer discharge hydrograph (Kracht and others, 2003). This approach assumes sanitary discharges to the sewer system are at a minimum in the early morning hours (approximately 0200-0400), but recognizes that some sanitary use and discharge continues to occur during this period. For the Elk Grove Village sewershed, the annual volume of INF can be approximated from the minimum instantaneous sewer discharge that occurred on numerous occasions during early fall dry-weather periods of 2012 (fig. 24A). Given the unadjusted record of minimum discharge of $0.65 \mathrm{Mgal} / \mathrm{d}$, INF volume could approach $240 \mathrm{Mgal}$. As this estimate is based on an instantaneous measurement and there appears to be seasonal variation in the rates of INF, it is presumed that the actual annual volume of INF is greater than this estimated volume. Additional processing of the sewershed's available sewer discharge record possibly could provide a more accurate approximation of annual volume of INF. For comparison with the other simplified estimates of INF+IN, the estimated volume of $19.5 \mathrm{Mgal}$ IN can be added to this estimate of INF, for a total volume of about $260 \mathrm{Mgal}$.

\section{Challenges, Limitations, and Lessons Learned}

The attempt to determine consumptive water use from a pragmatic, field-based, mass-balance approach was considered an explorative study, as there were many unknowns in this approach. Some of the possible difficulties were:

1. identifying a sewershed that was (A) large enough to provide reasonable differences in volumes of water use and sewer flow returns, thus compensating for various anticipated inaccuracies in water use and sewer flow measurement, and (B) small enough to more comprehensively and accurately understand its hydrogeologic, sewer infrastructure, water use, and stormwater discharge characteristics, with consideration of the temporal and funding constraints of the study;

2. identifying a sewershed with separated storm and sanitary sewer systems, which was necessary for substantially reducing the effort to estimate sanitary sewer flow and the uncertainties and error associated with that effort; collecting and processing those data, given the possibility of necessary adjustments for storm-induced IN, groundwater INF, and (or) sewer flow EXF to and from the system and equipment issues in the hostile sewer setting;

3. identifying a community with metered water use data and processing those data, given the possibility of receiving them in nondigital format, being collected over various time frames, and containing an inordinate amount of data entry errors, thus adding complexity to their processing for statistical evaluation and estimation; and 
4. finding a willing community partner, thus a potential source of substantial knowledge about the abovenoted characteristics of the sewershed, access to water use data, property access for instrument installations, GIS-based information on the sewershed network, and other useful resources, and hopefully freely provided.

Identifying an acceptable study area proved more challenging than anticipated, given the extensive experience of the participating project staff with monitoring sewer systems and their professional connections with sewered communities and agencies in northeastern Illinois. However, without that experience and those connections, the effort to identify a sewershed that satisfied most of the requirements of the study and a willing community partner would have been immeasurably more difficult and required more time and funding to complete the project. The number of acceptable communities for the study proved limited from the start because of the relatively few with separated storm and sanitary sewer systems, particularly in the city of Chicago and its older neighboring communities.

Concerns about spatially relating public water deliveries to the constrained sewershed proved to be unfounded. In Elk Grove Village, address-based records publicly are maintained for the homes and commercial facilities served by both the distributed sanitary and water supply systems. Presumably, similar records are maintained by other communities suitable for such a study, and gaining access to those records could be reasonably easy. If the water use data represent synchronous meter readings across the sewershed, then these data can be provided as an aggregated total for the entire sewershed. Individual addresses of homes and commercial facilities should be necessary only if some estimation of the data is necessary, as was the case for the Elk Grove Village study area and can be useful for general quality assurance and addressing specific use aspects, such as this study's interest in deliveries associated with public swimming pools.

Although digital records were provided for this study, the format of provided data could be of concern if provided as nondigital records (paper; word-processing or portabledocument formats). The compilation and possible aggregation of these records could require substantial time to compile and possibly aggregate and this effort might be beyond the resources or desire of a community to freely make this effort and (or) resources of the water use researcher. Aggregation of public water delivery data also could contribute to an unknown extent of uncertainty, as data quality issues such as an inaccurate spatial relation to the sewershed or encoding errors might not be identified.

The public water delivery data provided by the Elk Grove Village DPW is assumed to be accurately measured and recorded. Some error might be introduced with the (1) delivery ("consumption") measurements, should the meters in use not be routinely calibrated; (2) recording of measurements, should transcription errors occur; and (3) data rounding, as the meter readings typically represent use in thousands of gallons. The extent of any associated error cannot readily be known or quantified. Given the observed professionalism of the Elk Grove Village DPW and its available resources, it can be presumed that attention is paid to accurate functioning of the meters and tabulation of the readings. At most, a relative uncertainty of \pm 10 percent might be presumed in the provided record of public water deliveries, with actual error likely less (table 7).

Identifying and accounting for self-supplied water in the sewershed that is not reported by the public water provider proved to be a relatively quick and accurate task for this study, as few, if any, operating private wells are present in the sewershed. Where those wells are present, they are constrained almost exclusively to the single unincorporated neighborhood served by the public sewer system, and within this neighborhood, the population generally was well known from the 2010 U.S. Census Bureau data. Any meaningful error associated with this population's water use (self-supplied withdrawals) primarily would result from application of an inaccurate coefficient of per capita use. Based on other water use studies (for example, Mills and Sharpe [2010]), the greatest error that might be expected is about \pm 50 percent of the estimated use (based on a typical use of 40-120 gal/d/p, compared to $80 \mathrm{gal} / \mathrm{d} / \mathrm{p}$ ), but more likely in the range of \pm 10 percent (70-90 gal/d/p). In this study, application of the most conservative measure of per capita use $(120 \mathrm{gal} / \mathrm{p} / \mathrm{d})$ would result in an additional 5.1 Mgal of self-supplied water. A minor miscount of private wells and the population they serve could account for an additional 1.6 Mgal, as previously noted. The impact of these errors in estimation of self-supplied water use would be small, as the total probable self-supplied water use, at most, represents only about 3 percent of the water use in the sewershed, as determined from public deliveries.

In other similar studies, identifying the potential sources of self-supplied water and then estimating that use could be a more time-consuming effort, depending on the availability of public records. More importantly, it could be a significant source of error in accounting for supplied water if the number of private wells in the study area were large relative to public water deliveries (where metered records of actual water use generally are available). Undertaking such a study in a sewershed that is not served by a public supplier should be highly avoided. Records of actual water use are almost never available for private wells or surface water sources of private use. In addition, although the population of a well-defined study area can be relatively well defined by U.S. Census Bureau data, the accuracy of such a census can be a significant factor if the area is rapidly losing or gaining population and the study is performed long after the typical decadal timing of the Census. With its related potential as a substantial source of error in estimation of water use (whether self-supplied or publicly delivered), and the resulting estimation of consumptive use, attention must be directed to accurately estimating the per capita use rate particular to a study area. Fortunately, for this study, the 2010 Census closely coincided with the study period and the population in the study area generally is stable. 
Table 7. Summary of input components of the consumptive use mass-balance equation for the study area, Elk Grove Village, Illinois, March 2012-February 2013.

\begin{tabular}{|c|c|}
\hline Component & Relative data quality \\
\hline Deliveries by public water system & $\begin{array}{l}\text { Municipality measured and reported for all users in sewershed } \\
\text { (uncertainty about } 10 \text { percent or less). }\end{array}$ \\
\hline Self-supplied groundwater withdrawals & $\begin{array}{l}\text { Estimated for unincorporated residential area, with about } 2 \text { percent } \\
\text { of study area population; accounts for about } 3 \text { percent or less of } \\
\text { water use (uncertainty about } 10 \text { percent or less). }\end{array}$ \\
\hline \multirow[t]{4}{*}{ Returns to surface water, by means of sanitary sewers } & Raw flow, measured (uncertainty about 5 percent). \\
\hline & $\begin{array}{l}\text { Storm flow discharge (IN), estimated primarily from raw flow } \\
\text { (measured) hydrograph (uncertainty about 10-20 percent). }\end{array}$ \\
\hline & $\begin{array}{l}\text { Detrended/offset flow (baseflow) less IN, estimated. Does not } \\
\text { account for (include) possible seasonal variance in sanitary } \\
\text { sewer discharge or loss of sewer flow by exfiltration (EXF); does } \\
\text { not account for gain of sewer flow by infiltrating groundwater } \\
\text { (INF) or non-estimated portion of IN (uncertainty approaching } \\
40 \text { percent, with bias to overestimate sanitary sewer flow). }\end{array}$ \\
\hline & $\begin{array}{l}\text { Estimated sewer flow exceeds water deliveries and withdrawals by } \\
\text { about } 200 \text { million gallons. }\end{array}$ \\
\hline $\begin{array}{l}\text { Returns to surface water, by means other than sanitary sewers } \\
\text { (by way of storm sewers or directly) }\end{array}$ & $\begin{array}{l}\text { Estimated from probable swimming pool volumes, accounting for } \\
\text { about } 5 \text { percent or less of returns (uncertainty about } 10 \text { percent or } \\
\text { less). }\end{array}$ \\
\hline Returns to groundwater, by injection or other direct means & No known or expected direct returns in sewershed. \\
\hline
\end{tabular}

Automated continuous measurement of sewer flow by ADVM typically provided data of acceptable quality. Periodic comparative wading measurements during site visits indicated the quality of most discharge measurements to be good (within 5 percent of actual discharge). There were occasional periods of missing record or measurements of lesser quality (fair to poor-within 8 percent to greater than 8 percent of actual discharge). Lesser quality measurements resulted from occasional buildup of debris on and around the ADVM; however, use of the established stage discharge rating helped improve the accuracy of the discharge estimates under these conditions.

Undesirable discharge of storm-associated IN to the sanitary system was potentially a large source of error in the accounting of sanitary sewer return flow, and it could be overlooked and included in the measured sewer discharge as sanitary sewer return. Such IN would not be representative of the assumed sanitary sewer returns of supplied water. Within the study's sewershed, certain neighborhoods were suspected of contributing a meaningful share of IN to the sanitary system (Scott Bernholdt, Department of Public Works, Elk Grove Village, Illinois, oral commun., 2011); however, project resources did not allow for identification of areas that might be contributing substantial volumes of IN or detailed quantification of the contribution. The volume of storm-associated IN in the sewershed instead was estimated by using a hydrograph separation approach. This volume was not removed from the measured discharge dataset, which was then processed (adjusted) to better estimate the sanitary sewer return portion of the measured sewer discharge.

The possible error associated with estimating IN by the approach used in this study is considered comparatively small given (1) larger precipitation events that might result in this contribution to sanitary sewer discharge to occur infrequently and (2) the contribution represents only a fraction of sanitary sewer return flow represented in the annualized estimation of consumptive use. In other studies the contribution of IN to the sanitary sewer system and error associated with its estimation may be greater, particularly as influenced by the spatial and temporal scale of the study. In this study, storm-associated IN represented only about 2 percent of estimated sanitary sewer return flow. Relative uncertainty of this estimation of IN is considered to be within about \pm 10 percent; however, the estimation focused only on the larger indications of IN resulting from more substantial storm events.

Of even greater concern, is the potential for widely distributed, unaccounted-for discharges of comparatively small volumes of IN that would be difficult to detect in the sewer flow record (hydrograph), particularly when a storm event cannot be associated with a subtle rise and fall of flow. Collectively these contributions might represent a substantially large volume of flow that unintentionally could be included in the accounting of supplied water sanitary sewer returns. 
Estimation uncertainty would expectedly be greater for quantification of the volumes of these less identifiable occurrences of IN than that for the more readily detectable occurrences associated with large storm events.

The EXF of sewer flow to groundwater seemingly is only a minor unaccounted-for source of error in the study's sewer flow accounting of metered water returns. Although the extent of EXF that occurs cannot easily be quantified, this unaccounted-for loss to measured sewer flow justifiably can be assumed minimal for the purposes of this determination of return sanitary sewer flow and consumptive use.

The greatest potential for error in accounting of sewer returns of supplied water is associated with the gain of sewer flow resulting from groundwater INF to sewer flow. These gains are difficult to measure in the field and differentiate in a sewer flow hydrograph from expected daily and seasonal fluctuations in supplied water sanitary sewer returns. Compounding the problem is the difficulty in determining to what extent the gains may be affected by countering losses of flow by EXF to groundwater. For this study, no more than a cursory attempt was made to assess the relative magnitude of INF that included lesser expected volumes of distributed subtle IN. Various exploratory approaches suggested INF volume represented from 26 to 60 percent of sanitary sewer return flow, when considered against the measured, unadjusted flow, and from 36 to 49 percent, when considered against the adjusted "sanitary" sewer flow.

In the attempt to account for nonsanitary contributions to sanitary sewer return flow, the measured sewer discharge was adjusted by an approach that detrended and offset the data and removed an estimated volume of storm-attributed IN. Despite the obvious shortcomings of this approach, which could include a remaining substantial volume of IN and (or) INF, it also potentially discounted the possibility of seasonal variations in the use of water and its discharge to sanitary sewers. Independent of the error associated with the initial measurement of sewer flow and its adjustment for readily indicated IN, should the assumption justifying data detrending and offsetting to presumably remove "seasonality" trends be erroneous, the possible error in measurement could approach a 25 percent underestimation of flow that does include a component of seasonal water use and its return (988 Mgal unadjusted "sewer" flow compared to $778 \mathrm{Mgal}$ adjusted "sanitary" flow).

For this study, the uncertainty associated with the estimation of sewer discharge seemingly ranges from about 5 to 40 percent. The least uncertainty is associated with the direct measurement of sewer flow representing all discharge sources (storm and sanitary). The upper limit of uncertainty is suggested by the comparison of the resulting estimates of sanitary flow returns (adjusted volume) and supplied water. The volumetric estimate of sewer returns exceeds that of supplied water by nearly 40 percent, with the clear bias to overestimate sanitary flow. Accurate accounting for the gains and losses to sanitary sewer flow attributable to IN, INF, and EXF clearly is key to reducing the substantial uncertainty associated with this field data-driven method for defensible determination of consumptive water use.

The reader is cautioned against applying any resulting estimates from this study to recognizably dissimilar settings or categories of users. This study attempted to provide an estimate of consumptive use predominantly associated with residential use primarily from public supply deliveries. Estimates of consumptive use can vary substantially by water use category. Within the study sewershed, most of the categories of users, including industrial, irrigation (agricultural and golf course), livestock, mining, and thermoelectric power, are absent. Many of these are represented by coefficients of consumptive use that typically are markedly greater and less than the coefficients of 10-15 percent typically representing public supply and domestic water use (Shaffer and Runkle, 2007). A portion of the water use in the sewershed is for commercial use. Records that were available for this study (Scott Bernholdt, Department of Public Works, Elk Grove Village, Illinois, written commun., 2011) suggest that commercial use represents about 15-40 percent of public supply deliveries, but more likely about 25 percent. However, this undetermined volume introduces limited uncertainty to the estimation of consumptive use of this study effort. In the Great Lakes Basin and climatically similar areas, coefficients of consumptive use for commercial use generally fall within the same range as those for residential use (Shaffer and Runkle, 2007). As such, any estimate of consumptive use that might result as part of this or a following study should not be skewed to any meaningful extent by a community of users that is not fully representative of residential water use and that might include some commercial use.

The reader also is cautioned to consider the atypical climatic conditions during this study. The hot, dry, drought conditions presumably resulted in greater use of water, particularly for consumptive activities, such as pool filling, landscape irrigation, and carwashing. Consumption by evaporative loss would be expected to be comparatively high during the climatic conditions of the study. Thus, the reader should avoid broadly applying any resulting estimates to other time periods with greatly differing climatic conditions. Additionally, it should be recognized that other patterns of water use that might differ in propensity to consumption can vary from year to year. For example, fire-fighting activity might be greater in some years than others. In general, use of a range of consumptive coefficients is recommend to properly account for variances of season and climate patterns and their effect on consumptive use (Kimberly Shaffer, U.S. Geological Survey, written commun., 2013).

Useful lessons were learned from this study which when could better ensure a less labor-intensive and less costly undertaking with results that are more accurate. These lessons include:

- Select the proper sewershed and community partner. This selection is first and foremost, with each component equally important. 
- The more recently established the sanitary sewer system, the more likely modern technologies and performance controls will be designed into the system to limit unintended return flow; this simplifies the effort required to parse out and quantify flow associated solely with sanitary return. An ideal system should:

1. be separated from the storm sewer system,

2. use sewer pipe and manhole materials that are durable and well-sealed to greatly limit INF/ EXF (avoiding vitrified clay pipe and bricklined manholes),

3. include sensing technologies and (or) wellmanaged inspection programs for detecting INF/EXF leakages and IN associated with storms or other unintended inputs, and

4. use mostly or fully automated systems for recording water deliveries in a systemwide, synoptically short time frame.

- The more technologically and environmentally progressive, well-funded, and cooperatively minded the community, the more likely effective programs will be in place for detecting and promptly addressing INF, EXF, and IN issues. The community also is more likely to have extensive technical data and mapping resources and the ready willingness to contribute freely these extensive and most necessary resources to the study effort, along with their technical insights and periodic field assistance. An ideal community should incorporate a spatial database (GIS) for their data associated with sewer system design (infrastructure and topography) water use (withdrawals and deliveries), and sanitary return flow.

- Select the simplest study area in regards to geohydrologic setting and alternatives to public water deliveries.

- With the expectation that INF and EXF leakages occur in all sewer systems, then conducting studies where the geohydrologic setting is relatively straightforward will limit the instrumentation and geohydrologic data collection effort necessary to properly characterize (qualitatively or quantitatively) the INF and EXF leakage. An ideal geohydrologic setting should:

1. have limited topographic relief without pronounced surface water drainage(s). Because of the limited vertical relief of the water table expected with this terrain, fewer points for monitoring groundwater should be necessary to characterize the relation between water table and sewer invert depths across the sewershed; this relation can influence the magnitude of leakage and propensity towards either INF or $\mathrm{EXF}$, and

2 . be comprised predominantly of low permeability, fine-grained lithologic materials, which should limit the magnitude of INF and (or) EXF leakage, and thus, reduce uncertainty associated with quantifying leakage.

- Public supply deliveries greatly simplify the effort and uncertainty associated with accounting of supplied water within the sewershed, particularly when metered and recorded within a GIS spatial database. Quantifying the volume of self-supplied water from private wells, particularly domestic wells, typically requires more estimation that is more uncertain and can depend on extensive effort to identify all actively used wells and determination of a representative coefficient for per capita use. Ideal delivery data should be collected over a short time frame that captures near simultaneous water use within the sewershed, and thus, avoids the additional necessity to estimate use by a means that accommodates temporal offsets in meter records.

- Test all automated measurement equipment prior to field deployment and incorporate sufficient quality assurance measures.

- Quality assure measurements by using related data to substantiate assumptions and findings. For example, relate:

1. precipitation to rapid increases in sewer flow to identify possible storm-associated IN, which should not be included in the estimation of sanitary return flow, and

2. depth of water table to depth of sewer invert to determine if sewer flow likely will be underestimated because of a systemwide propensity for EXF or overestimated because of a propensity for INF.

- A fluorometer can be useful for detecting and measuring $\mathrm{OB}$ concentrations in groundwater and sewer flow to assess the integrity and unintended use of the sanitary sewer system; elevated concentrations in groundwater can be indicative of EXF issues and depressed concentrations in sewer flow might be indicative of INF and (or) IN issues.

- OB measurement of discrete samples is feasible. Collection of the samples is technically simple and quick, and their analysis is essentially cost-free beyond the initial purchase of the meter. 
- The meter is potentially useful for continuous, automatic measurement and logging of OBs within sanitary sewers; however, modifications in the design of the meter and its deployment are considered necessary in order to realize this potential.

- An ADVM can be used effectively for measurement of sewer discharge rates in sewers of proper size and fluid depth.

Measurements allow determination of baseline discharge rates and approximation of periodically elevated rates attributed to stormwater IN.

\section{- Allow sufficient funding for the effort.}

The collection of background data to adequately describe the study area, including hydrogeology, sewer infrastructure, and sources of water supply; measurement and estimation of supplied and returned water volumes; quality assurance efforts; data analysis; and reporting of findings can be costly. Additional field data collection and related estimation efforts to quantify INF and EXF, which contributes substantial uncertainty to sewer flow return estimates, will add additional costs.

The present study lays the groundwork for possible future efforts to better estimate sewershed-scale sanitary return flow apart from gains in flow from INF and losses in flow from EXF. Estimation restricted to the sanitary component of flow is essential to obtaining a defensible and useful estimate of consumptive use by the mass-balance method of this study.

Direct inspection of the entire unlined portion of the sewer system to determine the principal reaches contributing to INF and EXF, along with measurements of the associated gains and losses to flow in reaches where substantial leakage is detected, might be the most direct approach to sewer-scale accounting for these contributions to sanitary return. However, at this scale direct inspection and measurement of all unlined reaches could prove labor intensive, costly, and may be presently technically infeasible in small-diameter and (or) low-flow reaches. A systemwide approach to estimating INF and EXF contribution might be feasible by using numerical modeling; however, this approach still would require substantial system-specific data on infrastructure conditions and hydrogeologic properties to sufficiently constrain the model for accurate use.

Another systemwide estimation approach that might be more feasible than those suggested could be isotopic-based, relying on differences in the isotopic signatures of sanitary source water (sewerage and included drinking water) and meteoric source water (precipitation and shallow groundwater). Rieckermann and others (2010) describe methods for estimating the proportion of groundwater in the measured sewer flow (from INF) by using differences in the stable isotopic signatures of the drinking water component of sewer flow and the infiltrating water. Such an approach might only require collection of a relatively small number of water samples under a range of flow and meteoric conditions (base flow to substantial storm-affected flow) for isotopic analysis. Sewershed-scale sanitary returns also might also be estimated by metering (or measuring, with possible future enhancement of the ADVM) a representative sampling of returns at the point of residential or commercial discharge and up-scaling these results to the larger sewershed scale. Use of the diurnal nighttime minimum discharge determined from a sewer flow hydrograph also has been indicated as a possible approach for reasonably approximating the INF contribution to sanitary flow (Kracht and others, 2003). Other approaches for evaluating the relative extent and (or) magnitude of INF, IN, and (or) EXF might incorporate the use of natural tracers; Rieckermann and others (2010) describe a method based on tracer (bromide, lithium) mass loss in a dosed sewer reach to estimate EXF. Measurements of dissolved organic matter by passive spectral (colored dissolved organic matter or CDOM) or fluorescence (fluorescent component of dissolved organic mater or FDOM) methods (Goldman and others., 2012) for these determinations also might be considered or the full potential of using OBs further explored.

The most direct sewershed-scale approach to measure solely sanitary return flow for estimation of consumptive use would be to isolate one or more subwatersheds in the study area where the sewer pipes are fully lined; with little to no INF or EXF expected in the subwatershed(s), the measurement of sanitary flow should be technically straightforward and accurate. Although up-scaling the results would be necessary, the estimates of sanitary return should be less uncertain than those determined from up-scaling of direct measurements from a limited sampling of points of discharge. For the subsewershed approach, the study area would need to be of sufficiently large size and population to represent typical residential water use and to avoid measurement errors and uncertainties that become increasingly unacceptable as scales of study become increasingly smaller. Requirements of the ADVM or other instrumentation, particularly the sewer pipe diameter and flow stage, might also dictate the size of the study area for accurate measurement of return flow.

\section{Summary and Conclusions}

Presently (2014), the large and growing population within the Great Lakes Basin and its demand for water is straining the limits of local water supplies. Municipalities both inside and outside the Basin have sought to obtain water from the Great Lakes. Public awareness of the value of this resource is increasing. As greater demands are placed upon water supplies in this and other regions of the Nation and world, demand is increasing for monitoring water withdrawals and water use. One principal metric for evaluating and managing water use is consumptive use. This is the portion of water withdrawn for a particular use, such as residential supply, that is evaporated, transpired, incorporated into products or crops, consumed by humans or livestock, or otherwise removed from the 
immediate water environment. The amount of consumptive use, which vary by particular type of water use, are determined either by a water (mass)-balance approach or use of a coefficient derived by a variety of methods, often with a great degree of uncertainty. Because of the difficulty of obtaining the necessary data, application of the mass-balance approach typically is restricted to the facility scale. The general governing mass-balance equation is: Consumptive use $=$ Water supplied - Return flows.

The study described in this report explored a mass-balance field-based computation of consumptive use in a residential setting at the sewershed scale. In addition to this objective, the data requirements, feasibility (difficulty and expense), and relative uncertainties (accuracies) associated with application of the approach at this scale were evaluated. The utility of novel technical methods also was explored, including use of an acoustic Doppler current-velocity meter (ADVM) for measuring discharge in sanitary sewers and optical brighteners $(\mathrm{OBs})$ to assess gains and losses to and from sanitary flow. The study was conducted during 2011-13 within a $3.5 \mathrm{mi}^{2}$ sanitary sewershed confined to a predominantly residential area of Elk Grove Village, Illinois. Data collection focused on the period of March 1, 2012-February 28, 2013.

Background evaluation of the hydrogeologic setting and sewershed infrastructure indicated predominantly fine-grained area soils and about 44 percent of the separated sanitary system lined to limit flow into and out of the sewers. An accounting of all primary sources and volumes of supplied water and return flows necessary for reasonable estimation of consumptive use identified:

1. public water distributed by the Elk Grove Village Department of Public Works,

2. self-served groundwater withdrawals in an unincorporated neighborhood within the sewershed with public sanitary sewer service,

3. return flows to the sanitary sewer system, and

4. direct return of water discharged to Salt Creek (the primary surface water drainage) primarily by way of storm drains.

Water volumes were reported for deliveries, measured for sanitary sewer returns by using an ADVM in an interceptor sewer, estimated for domestic withdrawals by using a well count and a per capita coefficient, and estimated for pool discharges by using a volumetric accounting of private pools and deliveries to public pool facilities. All water volumes required some degree of estimation. A network of 12 observation wells was installed throughout the sewershed immediately adjacent to sewer lines to determine the depth of the water table relative to that of the sewer line inverts and to collect groundwater samples for analysis of possible OBs from the sanitary sewer system. These data provided qualitative information on gains through inflow (IN) and infiltration (INF) and losses through exfiltration (EXF) of sewer flow by pipe leakage which might otherwise not be considered in the sewer flow return measurements. Sewer flow hydrographs also were evaluated to identify and estimate storm-associated IN in order to account for more accurate sanitary-specific flow volumes.

Although water supply deliveries were metered, additional estimation to determine water use was required because of temporal offsets in meter recordings. Regardless of this estimation, the uncertainty associated with this water use accounting was considered to be considerably less than that associated with the accounting of sanitary sewer flow return. Additionally, it was determined that other aspects of water use, including self-supplied groundwater withdrawals and unmeasured direct returns of supplied water to surface waters, could be accounted for within reasonable limits of uncertainty.

The volume of sanitary sewer return flow (778 Mgal/yr) was determined to substantially exceed the volume of supplied water (566 Mgal/yr), thus, for this study setting, voiding the present utility of the applied mass-balance approach for estimating consumptive water use. Evidence of a water table, which typically is shallower than the area's sewer lines and sometimes depressed near more deeply buried sewer lines, suggests groundwater INF into the sanitary sewers (primarily trunks and interceptor) contributes to the excess volume of return flow. Technical obstacles and project resources precluded attempts to accurately quantify the volumes of INF, storm-associated IN, or the seemingly more limited EXF; separately, about 2 percent of return flow was estimated as IN. As estimated from various simplified methods, 26-60 percent of the return flow measured in the sanitary sewer represented INF+IN. On the basis of the alternative winter base-rate method, consumptive use in the sewershed was estimated as 13 percent, which compares favorably with that used by the State of Illinois for Lake Michigan allocation accounting (10 percent) and other States and Provinces in the Great Lakes region (generally $10-15$ percent). The water balance method explored in this study remains a reasonable approach for estimating consumptive use, should it be applied to settings with little to no INF, IN, and EXF or should technologies and methods be established for reasonable estimation of these gains and losses to sewer flow.

The study also provided other findings considered useful to studies of water use and to performance evaluation of sanitary sewer infrastructure. In urban residential settings, the comparatively small volumes of nonpublic sources of water (self-supplied) and direct (nonsanitary) return flow typically can be ignored in the estimation of consumptive use. An ADVM can be used in sanitary sewers to accurately measure discharge and reasonably estimate storm-associated IN. Hourly to daily patterns of water use readily can be identified and quantified in the sanitary sewer return flow record. Relative volumes of IN gains (and possibly EXF losses) can be substantial, even in sewer systems of communities making significant investments in system upgrades to limit sewer flow gains and losses. Monitoring of optical brighteners in groundwater (and possibly in sanitary sewer flow) can provide a useful means for identifying probable leakage from (and to) sewer lines. 
Under ideal conditions, accurate quantification of consumptive use at the sewershed scale by the mass-balance approach might be possible. Under most prevailing conditions, quantification likely would be more costly and time consuming than that of the present study, given the freely contributed technical support of the host community and relatively appropriate conditions of the study area. Essentials to quantification of consumptive use are a fully cooperative community, storm and sanitary sewers that are seperate, and newer sewer infrastructure and (or) a robust program for identifying, repairing, and upgrading points of leakage or undesirable stormwater inflows into the network of sewers.

\section{References Cited}

Alhajjar, B.J., Chesters, Gordon, and Harkin, J.M., 1990, Indicators of chemical pollution from septic systems: Ground Water, v. 28 , no. 4 , p. 559-568.

Angel, Jim, 2013a, Climate of Chicago-Description and normals: Illinois State Water Survey: accessed March 22, 2013, at http://www.isws.illinois.edu/atmos/statecli/general/ chicago-climate-narrative.htm (data provided by the Illinois State Climatologist's Office, a part of the Illinois State Water Survey [ISWS] located in Champaign and Peoria, Illinois, and on the Web at http://www.isws.illinois.edu/ atmos $/$ statecli).

Angel, Jim, 2013b, Climate results for station 111549 (Chicago O'Hare): Illinois State Water Survey: accessed March 22, 2013, at http://www.isws.illinois.edu/data/ climatedb/data.asp (data provided by the Illinois State Climatologist's Office, a part of the Illinois State Water Survey [ISWS] located in Champaign and Peoria, Illinois, and on the Web at http://www.isws.illinois.edu/atmos/statecli).

Angel, Jim, 2013c, Pan evaporation across Illinois: Illinois State Water Survey: accessed March 19, 2013, at http:// www.isws.illinois.edu/atmos/statecli/Pan-Evap/Panevap. htm (data provided by the Illinois State Climatologist's Office, a part of the Illinois State Water Survey [ISWS] located in Champaign and Peoria, Illinois, and on the Web at http://www.isws.illinois.edu/atmos/statecli).

Bowen, Robert, 1986, Ground water: London, Elsevier Applied Science, p. 58-60.

City of Federal Way, 2009, Residential car washwater monitoring study: city of Federal Way, Public Works Department, Surface Water Management Division, 15 p., accessed April 24, 2013, at http://www.ecy.wa.gov/programs/wq/ stormwater/municipal/MUNIdocs/2009FWCarWashwater MonitoringStudyRev1.pdf.
Collier, Trey, 2012, How to close or winterize your above ground swimming pool: accessed January 15, 2014, at http://www.backyardcitypools.com/Swimming-Pool-Blog/ how-to-close-winterize-your-above-ground-swimmingpool/.

Elk Grove Village, Illinois, 2011, Village of Elk Grove Village public water supply system 2010 Consumer Confidence Report: accessed March 22, 2013, at http://www.elkgrove. com/Modules/ShowDocument.aspx?documentid $=1091$.

Espey, W.H., Melching, C.S., and Mades, D.M., 2004, Lake Michigan diversion committee-Findings of the fifth technical committee for review of diversion flow measurement and accounting procedures, 181 p.: prepared for the U.S. Army Corps of Engineers, Chicago District, Chicago, Illinois, accessed May 6, 2013, at http://www.lrc. usace.army.mil/Portals/36/docs/divacct/technical/Fifth_ Technical_complete.pdf.

Espey, W.H., Melching, C.S., and Muste, Marian, 2009, Final report, Lake Michigan diversion committee-Findings of the sixth technical committee for review of diversion flow measurements and accounting procedures, 198 p.: prepared for the U.S. Army Corps of Engineers, Chicago District, Chicago, Illinois, accessed May 6, 2013, at http://www.lrc. usace. army.mil/Portals/36/docs/divacct/technical/Sixth_ Technical_complete.pdf.

Fetter, C.W., 1994, Applied hydrogeology (3d ed.): New York, McMillan College Publishing Company, Inc., 691 p.

Freeze, R.A., and Cherry, J.A., 1979, Groundwater: Englewood Cliffs, N.J., Prentice-Hall, Inc., 604 p.

Goldman, J.H., Rounds, S.A., and Needoba, J.A., 2012, Applications of fluorescence spectroscopy for predicting percent wastewater in an urban stream: Environmental Science and Technology, v. 46, p. 4373-4381.

Great Lakes Commission, 2011, Great Lakes regional water use database: accessed September 10, 2013, at http://glc. org/waterusedata/data_about_cuc.php.

Great Lakes Commission, 2013, The Great Lakes Basin Compact: accessed May 6, 2013, at http://www.glc.org/about/ glbc.html.

Hardwick, Nancy, 1997, King County Lake Sammamish watershed water quality survey: Water and Land Resources Division, King County Department of Natural Resources and Parks, Washington, accessed May 14, 2013, at http:// your.kingcounty.gov/dnrp/library/1997/kcr1269/1.pdf. 
Helsel, D.R., and Hirsch, R.M., 2002, Statistical methods in water resources: Techniques of Water-Resources Investigations of the U.S. Geological Survey, book 4, chap. A3, $510 \mathrm{p}$.

Hermitte, S.M., and Mace, R.E., 2012, The grass is always greener...Outdoor residential water use in Texas: Texas Water Development Board Technical Note 12-01, 43 p.

Huang, N.E., Shen, Zheng, Long, S.R., Wu, M.C., Shih, H.H., Zheng, Quanan, Yen, Nai-Chyuan, Tung, C.C., and Liu, H.H., 1998, The empirical mode decomposition and the Hilbert spectrum for nonlinear and non-stationary time series analysis: The Royal Society, Proceedings: Mathematical, Physical and Engineering Sciences, v. 454, no. 1971, p. 903-995.

Illinois Department of Natural Resources, 2013a, Lake Michigan water allocation: accessed September 10, 2013, at http://www.dnr.illinois.gov/WaterResources/Pages/ LakeMichiganWaterAllocation.aspx.

Illinois Department of Natural Resources, 2013b, The drought of 2012, a report of the governor's drought response task force: accessed May 9, 2013, at http://www.isws.illinois. edu/hilites/drought/archive/2012/docs/TheDroughtOf2012. pdf.

Illinois State Geological Survey, 2009, Physiographic divisions of Illinois: accessed March 22, 2013, at http://www. isgs.illinois.edu/maps-data-pub/publications/pdf-files/ physio-w-color-8x11.pdf.

Illinois State Geological Survey, 2013, Illinois water well (ILWATER) Internet map service: accessed March 22, 2013, at http://www.isgs.uiuc.edu/maps-data-pub/wwdb/ launchims.shtml.

Kanani, Arash, Ahmari, Habib, and Ferreira da Silva, A.M., 2010, Investigation of horizontal coherent structures in a shallow open-channel flow using velocity signal decomposition, in Dittrich, Andreas, Koll, Katinka, Aberle, Jochen, and Geisenhainer, Peter, eds., Proceedings of the International Conference on Fluvial Hydraulics (River Flow 2010), September 8-10, 2010, Braunschweig, Germany, p. 1059-1066.

Kolata, D.R., and Nimz, C.K., eds., 2010, Geology of Illinois: University of Illinois at Urbana-Champaign, Institute of Natural Resources Sustainability, Illinois State Geological Survey, $473 \mathrm{p}$.

Kracht, O., Gresch, M., de Benedittis, J., Prigiobbe, V., and Gujer, W., 2003, Stable isotopes of water as a natural tracer for infiltration into urban sewer systems: Geophysical Research Abstracts, v. 5, no. 07852, 2 p.
LaTour, J.K., 1991, Determination of water use in Rockford and Kankakee areas, Illinois: U.S. Geological Survey Water-Resources Investigations Report 90-4166, 70 p.

Lung, Wu-Seng, and Nice, A.J., 2003, Mitigating contaminant transport in utility installation: Virginia Transportation Research Council, Final Contract Report VTRC 04-CR14, $79 \mathrm{p}$.

Metropolitan Water Reclamation District of Greater Chicago, 2013, Water reclamation plant data: accessed December 12, 2013, at http://www.mwrd.org/irj/portal/anonymous?Navi gationTarget=navurl://14d6b38927bee2ff03c3c329949839 $03 f 0$.

Meyer, S.C., Roadcap, G.S., Lin, Yu-Feng, Walker, D.D., 2009, Kane County water resources investigations: Simulation of ground-water flow in Kane County and northeastern Illinois: Illinois State Water Survey Contract Report 2009-07, 425 p.

Meyer, S.C., Wehrmann, H.A., Knapp, H.V., Lin, Yu-Feng, Roadcap, G.S., Glatfelter, F.E., Angel, J.R., Thomason, J.R., and Injerd, D.A., 2012, Northeastern Illinois water supply planning investigations: Opportunities and challenges of meeting water demand in northeastern Illinois: Illinois State Water Survey Contract Report 2012-03, 221 p.

Metropolitan Water Reclamation District of Greater Chicago, 2013, Tunnel and reservoir plan: accessed December, 6, 2013, at http://www.mwrd.org//irj/portal/anonymous/tarp.

Mills, P.C., and Sharpe, J.B., 2010, Estimated withdrawals and other elements of water use in the Great Lakes Basin of the United States in 2005: U.S. Geological Survey Scientific Investigations Report 2010-5031, 95 p.

National Oceanic and Atmospheric Administration, 2013, Climatological data annual summary 2012, National Climate Data Center: accessed May, 17, 2013, at http://www1.ncdc. noaa.gov/pub/orders/IPS-ADDEF114-4037-4677-B91997F7A3A156C8.pdf.

Rantz, S.E., and others, 1982, Measurement and computation of streamflow: Volume 2, Computation of discharge: Geological Survey Water-Supply Paper 2175, 284 p.

Rieckermann, Jorg; Kracht, Oliver; and Gujer, Willi, 2010, New measurement methods, in Ellis, Bryan and BertrandKrajewski, Jean-Luc, eds., Assessing infiltration and exfiltration on the performance of urban sewers (APUSS): London, IWA Publishing, p. 11-25. 
Sargent, David, and Castonguay, Wayne, 1998, Water quality sampling - An optical brightener handbook: accessed March 19, 2013, at http://nature.thecompass.com/8tb/ sampling/.

Save the Sound, Inc., 2002, Car washing: accessed December 15, 2013, at http://www.green-ct.org/carwash. htm.

Shaffer, K.H., 2008, Consumptive water use in the Great Lakes Basin: U.S. Geological Survey Fact Sheet 20083032, $6 \mathrm{p}$.

Shaffer, K.H., 2009, Variations in withdrawal, return flow, and consumptive use of water in Ohio and Indiana, with selected data from Wisconsin, 1999-2004: U.S. Geological Survey Scientific Investigations Report 2009-5096, 93 p.

Shaffer, K.H., and Runkle, D.L., 2007, Consumptive water-use coefficients for the Great Lakes Basin and climatically similar areas: U.S. Geological Survey Scientific Investigations Report 2007-5197, $191 \mathrm{p}$.

Straub, T.D., and Over, T.M., 2010, Pier and contraction scour prediction in cohesive soils at selected bridges in Illinois: Illinois Center for Transportation Research Report ICT-10074, 119 p.

Tague, Angela, 2014, How to prepare an above ground pool for winter: accessed January 15, 2014, at www.ehow.com/ how_4500682 prepare-above-ground-pool-winter.html.

Turnipseed, D.P., and Sauer, V.B., 2010, Discharge measurements at gaging stations: U.S. Geological Survey Techniques and Methods book 3, chap. A8, 87 p.

U.S. Census Bureau, 2013a, 2010 Census-Census block maps: accessed March 27, 2013, at http://www.census.gov/ geo/maps-data/maps/block/2010/index.html.

U.S. Census Bureau, 2013b, State and county quickfacts, Elk Grove Village (village), Illinois: accessed April 23, 2013, at http://quickfacts.census.gov/qfd/states/17/1723256.html.

U.S. Department of Agriculture, 2013, Natural Resources Conservation Service, Web soil survey, Cook County, Illinois: accessed April 2, 2013, at http://websoilsurvey.nrcs. usda.gov/app/WebSoilSurvey.aspx.
U.S. Environmental Protection Agency, 1999, Safe Drinking Water Act - Glossary: EPA Publication 810F99023, 4 p.

U.S. Environmental Protection Agency, 2008, Polluted runoff (nonpoint source pollution) - Exercise II. The superior car wash: accessed December 15, 2013, at http://www.epa.gov/ owow/NPS/nps_edu/stopx2.html.

U.S. Environmental Protection Agency, 2012, Great Lakes water quality agreement: accessed May 6, 2013, at http:// www.epa.gov/glnpo/glwqa/.

U.S. Environmental Protection Agency, 2013a, Envirofactssearch results-ICIS: accessed September 12, 2013, http:// iaspub.epa.gov/enviro/efsystemquery.pcs.

U.S. Environmental Protection Agency, 2013b, Water use today: accessed April 23, 2013, at http://epa.gov/ watersense/our_water/water_use_today.html.

U.S. Environmental Protection Agency, 2014, Water senseOutdoor water use in the United StatesWater: accessed December 10, 2013, at http://www.epa.gov/watersense/ pubs/outdoor.html.

U.S. Geological Survey, 2013, Water use in the United States: accessed March 22, 2013, at http://water.usgs.gov/watuse/.

University of Wisconsin-Eau Claire, 2004, Domestic use of water: accessed December 10, 2013, at http://academic. evergreen.edu/g/grossmaz/ABRASHNM/.

WeatherSpark, 2013, Historical weather for 2012 in Chicago, Illinois, USA: accessed April 1, 2013, at http:// weatherspark.com/history/31158/2012/Chicago-IllinoisUnited-States.

Western Carwash Association, 2013, Are you water wise?: accessed May 8, 2013, at http://www.bodybeautiful.com/ WaterWise_brochure.pdf. 



\section{Glossary}

Provided here are descriptions of selected terms used throughout the report. To further aid the reader in understanding of terms, also included are selective references to other information sources and to related materials included in this report.

Acoustic Doppler current-velocity meter As configured for this study, a velocity and flow meter that transmits acoustic pulses (by using a three transducer assembly) to measure water velocity along two beams that are positioned $90^{\circ}$ apart horizontally and directed upward into the water column at an angle of $30^{\circ}$ from vertical, and water depth along the third vertical beam that is pointed directly upward (fig. 12). Part of the transmitted acoustic energy is reflected back toward the transducers by particulate matter (scatterers) moving with the water. The frequency of these reflected signals is shifted because of the Doppler effect, and the magnitude of the frequency shift is a function of the speed of the scatterers along the acoustic beams. The meter converts these frequency shifts into water velocity. By using trigonometry and water velocity calculated from adjacent beams, the meter resolves both water speed and direction.

Annulus The void between the sidewall of the corehole or borehole and the well casing and screen. To allow ready hydraulic communication between the well screen and adjacent saturated geologic deposits, as well as a restrictive barrier to movement of fine-grained geologic materials into the well, the annulus adjacent to the screen interval typically is filled with sand or other coarse-grained material. To restrict the ready flow of surface waters and contained constituents from or near land surface to the screen interval, the annulus principally from land surface to the top of the screen-interval sand pack typically is filled with bentonite clay or low-permeability sediments (cuttings) derived during well construction.

Backwater At any given discharge, the effect on the stage at the measurement point that is attributable to the operative control element(s) is known as backwater (Rantz and others, 1982). Water is "temporarily backed up" or retarded in its course rather than at its normal or stable condition of stage and flow. In stream gaging, a rise in stage produced by a temporary obstruction such as ice or weeds, or by the flooding of the stream below. In sewer flow gaging, a rise in stage produced by a temporary obstruction such as debris lodging on or near the acoustic Doppler current-velocity meter.

Base flow Sustained flow of a stream in the absence of direct runoff. It includes natural and human-induced stream- flows. Natural base flow is sustained largely by groundwater discharges. Base flow in sewers is sustained by sanitary discharges to the system in the absence of gains of freshwater from infiltration or inflow or losses from exfiltration.

Base flow separation A hydrograph-based method used to determine and quantify the portion of the hydrograph attributable to base flow.

Bituminous Sticky, highly viscous liquid, tarlike form of petroleum used as sealant application in sewer line connections.

Branch Intermediate-diameter pipes (often about 6 inches [in.]) in a distributed sewer system. These pipes typically are laid along street lines, receiving drainage from laterals and discharging drainage to larger diameter trunk lines at manholes. The pipes often are composed of unreinforced vitrified clay, cast or ductile iron, or polyvinylchloride (PVC). Flow within the pipes typically is by gravity drainage.

Commercial use Water use by motels, hotels, restaurants, office buildings, other commercial facilities, military, and nonmilitary institutions.

Consumptive use The part of water withdrawn for a particular use, such as residential, that is evaporated, transpired, incorporated into products of crops, consumed by humans or livestock, or otherwise removed from the immediate water environment.

Consumptive-use coefficient The percentage of water removed from the immediate environment by evaporation, transpiration, incorporation into products of crops, or consumption by humans or livestock.

Community water supply A public water supply system that delivers water for human consumption through pipes and other constructed conveyances if such a system regularly serves at least 25 year-round residents or has at least 15 service connections used by year-round residents. Community water systems might serve towns, cities, military bases, apartment complexes, or mobile home parks (U.S. Environmental Protection Agency, 1999).

Conveyance loss Water lost from pipes through leakage during its transmission from supplier to place of use. The loss may be from the storage tanks and (or) service lines of the water supply facility or the lines at the place of use where leakage is not diverted to a sanitary or storm sewer drain. 
Discharge The volume of water (or other fluid flow, such as sewerage) that passes a given location within a given period of time. Usually expressed in cubic feet per second. Measurement can be made manually, such as by wading in water bodies of appropriate depth and flow rate by using a mechanical or acoustic current meter, or by automated means, such as with the use of an acoustic Doppler current-velocity meter.

Domestic supply or use Water used for all residential (household) purposes, including indoor uses, such as drinking, food preparation, bathing, washing clothes and dishes, flushing toilets; and outdoor uses, such as watering lawns and gardens, filling swimming pools, and washing cars and home exteriors.

Domestic self-supply Water withdrawn by a private well or surface water intake for residential use.

Evaporation The change of water from a liquid form into a vapor state such as water evaporating from swimming pools, large bodies of water, and runoff from carwashing or irrigation systems; also includes evaporation through dehumidifiers, heating and cooling processes in industrial facilities and thermoelectric power plants.

Evapotranspiration A collective term used to include water discharged to the atmosphere as a result of plant transpiration and evaporation from soil and surface water bodies.

Exfiltration Leakage of sewer flow from sanitary sewers through defective pipe joints, broken pipes, and improperly sealed manholes, such as brick-constructed manholes with deteriorating mortar. Exfiltration can occur where local groundwater elevation is lower than the sewer pipe.

Great Lakes Basin The surface watersheds in eight United States and two Canadian provinces that drain to the Great Lakes.

Immediate water environment In water use, "immediate water environment" refers to the return of water withdrawn or diverted from groundwater or surface water sources either by direct injection to aquifers or to streams and other surface water bodies by direct discharge or following wastewater treatment. Returns require immediate or "quick" availability to the water at a natural source for reuse. For example, returns to groundwater by percolation through soil or from percolation (infiltration) basins are not considered returned to the immediate water environment because of the comparatively long time required to return to its natural source for reuse.

Infiltration Groundwater leakage into sanitary sewers through defective pipe joints, broken pipes, and improperly sealed manholes, such as brick-constructed manholes with deteriorating mortar. Infiltration can occur where local groundwater elevation is higher than the sewer pipe or where perched groundwater collects and (or) flows parallel to the sewer pipe in gravel bedding in sewer pipe trenches. Used in the hydrologic sense, "infiltration" generally refers to movement of water through soil or rock from land surface to the unsaturated zone and potentially to the saturated zone. To distinguish the separate uses of the term "infiltration" in this report, the later use of the term is referred to as percolation.

Inflow Water entering sanitary sewers primarily from unauthorized connections, which can include sump pumps and roof, cellar, or yard drains. Also may include unintended surface drainage into manholes. Inflow is greatest during storm events that are substantial enough to induce excessive runoff or periods of extended precipitation when water tables are high enough to induce basement flooding.

Interceptor In a purely gravity-flow sanitary sewer system, the largest sized sewer line (pipe) at the downslope-most location in the system. The lines typically are constructed of reinforced concrete, as in Elk Grove Village. Downslope flow from sewage source locations to an interceptor is through a connected network of increasingly deeper and larger diameter lines.

Interflow Lateral flow in the unsaturated zone that infiltrates (percolates) into the subsurface and moves laterally downslope before entering groundwater, reemerging to ground surface, or discharging to a stream. The depth of infiltration and lateral movement that define interflow are influenced by soil permeability (hydraulic conductivity) that decreases by depth.

Invert The level of the inside bottom of a sewer pipe. This level allows consistent adjustment of the slope of the sewer line at locations along its reach to ensure gravity flow of fluids within the line. The level typically is referenced to a datum such as the North American Vertical Datum of 1988. For this report, the level is referenced to distance below land surface.

Lateral The shallowest and smallest diameter sewer pipes in a distributed sewer system. These pipes are connected to the source of sewage discharge, including homes and commercial facilities; typically range in diameter from about 4 to 6 in,; and are composed of unreinforced vitrified clay, cast or ductile iron, or polyvinylchloride (PVC). Flow within the pipes is exclusively by gravity drainage.

Lift station A gravity sewer sump where accumulated sewerage is then pumped to a higher elevation for continued gravity drainage or discharge within a pressurized line to a remote location.

Manhole A vertical pipe, typically from 3 to $4 \mathrm{ft}$ in diameter, to which smaller and larger diameter pipes connect and drain sewerage by gravity flow. The vertical pipes provide access for inspection and maintenance of the sewer pipes and allow the venting of sewer gases.

Makeup The additional water provided to replace the water in swimming pools lost to evapotranspiration, leakage, or spillage.

Mass balance A mathematical indicator, as an equation, showing the mass inputs and outputs of a process, with the principle of what comes in must equal what goes out. 
Oakum Fibrous material prepared from hemp or jute. Used along with pine tar or bituminous caulking at connections in sewer system piping, particularly with cast iron pipe.

Optical brighteners Fluorescent white dyes often added to laundry soaps and detergents to produce the appearance of a whiter color in cotton fabrics. Cotton fabrics are naturally yellowish because they absorb blue rays present in sunlight. Optical brighteners absorb ultraviolet rays in sunlight and fluoresce in the blue region of the visible light spectrum, which results in a brighter white appearance of clothing. Their presence is commonly associated with domestic wastewaters, as their principal commercial use is in laundry detergents and textile finishing. Their detection in groundwater can be indicative of a deteriorating sewer transport system leading to exfiltration through cracks, deteriorating pipe connections, and mortar in older brick-constructed components (manholes, for example). Commercial production of brighteners for use in the manufacture of paper, textiles, and detergents is dominated by the use of stillbene compounds. These compounds are subject to degradation by microbes, exposure to gases, including oxygen, and photic decay (fading) from long-term exposure to ultraviolet (UV) light.

Pan evaporation A measurement of water loss due to evaporation by using a standardized open-surface container (pan) for periodic measurements of water loss. Evaporative loss integrates various climatic components including temperature, solar radiation, wind, and humidity, among others. The National Oceanic and Atmospheric Administration's National Weather Service uses a Class A evaporation pan for its measurements. The unpainted, monel (nickel-copper alloy) or galvanized pan's dimensions are 47.5 in. diameter by $10 \mathrm{in}$. deep. The pan is supported on a leveled wooden base a few inches off the ground. Starting with a daily water level of $2 \mathrm{in}$. from the top of the pan, the loss of water is recorded every 24 hours, with subsequent refilling of the pan to the starting 2-in. level for the next recording period. Pan evaporation often is used to estimate lake evaporation by using a conversion factor of 0.75 (Angel, 2013b).

Per capita use Water use measured in quantity (gallons) per day per person.

Perched water A localized, often temporary, zone or lense of saturation that can occur in the unsaturated zone above a layer or lense of low-permeability sediment such as clay. These conditions often occur during heavy rainfall, when the ground surface is temporarily saturated, but localized saturation can occur at depth as well.

Permeability The capacity of a rock or sediment to move water or other fluid through its pore space.

Public supply deliveries Amount of water delivered from a public supplier to users for domestic, commercial, industrial, thermoelectric power, or public use purposes. Delivered water may be metered (quantities measured) for billing or other purposes or unmetered.
Qualitative evaluation A means for evaluating the accuracy of a discharge measurement. The method requires the hydrographer to consider various field conditions and measurement procedures and their cumulative effect on measurement accuracy, rated against hypothetical actual discharge. Field conditions include the cross section, flow, weather, and other flow conditions. The description of these conditions along with the type of equipment, number of verticals, velocity measurement method, and other measurement conditions provide the basis for the accuracy ratings of excellent ( 2 percent), good ( 5 percent), fair ( 8 percent), and poor (more than 8 percent) (Turnipseed and Sauer, 2010, p. 79).

Return flow Water that reaches a groundwater or surface water source after release from the point of use, and thus, becomes available for further use.

Sanitary sewer A separate system of pipes, primarily installed underground, to transport sewage from homes, commercial buildings, and industrial facilities to wastewater treatment-water-reclamation facilities. Sewage principally includes toiletry wastes and drainage from tubs and showers, and dish and clothes washing.

Stage The height of a water surface (water level) above an established datum plane. In this study, stage separately refers to the height of the flowing sewerage above the inside bottom of the sewer pipe (invert).

Stage-discharge rating The relation between the surface elevation of the water in a water body, such as a stream (or sewer, in this study), and the discharge. The relation is represented by a graph that usually plots water level (surface elevation of the water), as ordinate, against the discharge or flow, as abscissa.

Storm sewer A separate system of pipes, primarily installed underground, to transport runoff of rain and other drainage water in public streets, parking lots, and other properties to discharge in area streams and stormwater retention basins.

Surcharge Condition where a sewer line is flowing full and flow is dependent on pressure head. The condition can result in discharge of sewer flow under pressure through unsealed connections between pipes or manholes, through damaged pipes, or to ground surface through backup in manholes. Causal factors can include material blockage in sewer lines, flow restrictions resulting from design flaws in pipe bend radius, or sewer flow rates exceeding the design limits of pipe diameter, grade, and roughness.

Transducer A device that receives a signal in the form of one type of energy and converts it to a signal in another form. In this study, the acoustic transducers in the acoustic Doppler current-velocity meter use acoustic signals to determine water velocity and water stage.

Tremie A pipe through which well construction materials, such as sand and bentonite clay, are poured to more properly place them at depth in the annulus surrounding the well screen and casing. 
Trunk Intermediate-diameter sewer pipes in a distributed sewer system, which typically are connected to smaller diameter branch pipes at manholes and drain or feed sewerage to a larger diameter interceptor. These pipes typically range in diameter from about 12 to $24 \mathrm{in}$. and are composed of reinforced materials, such as concrete or ductile iron. Flow within the pipes may be by gravity drainage or pressurized by pumping.

TRUSS composites Pipe designed for sanitary systems that is composed of thermoplastic composites. The pipe has a semirigid wall design consisting of a double-wall system with concentric inner and outer walls braced by a truss-type structure. The truss voids are filled with lightweight, foamed-cement slurry for additional stiffness and compressive strength. Pipe construction provides stiffness to limit pipe deflection and ensure watertight joints.

Unaccounted-for use Water that is either lost through conveyance losses or supplied from a public supplier and used for such purposes as fire fighting, street washing, flushing of water lines, and maintaining municipal parks and swimming pools (public uses). Generally, water used for public purposes and considered "unaccounted for use" is water that is not billed for by the public supplier. In a separate usage in this report, "unaccounted for" refers to that portion of water not considered or included in an estimation effort; for example, groundwater infiltration is unaccounted for in the estimation of sanitary sewer direct return flow.
Unsaturated zone The interval of the subsurface between the ground surface and the water table, where the soil pores are partially saturated and water is at a pressure that is less than atmospheric pressure.

Vitrified clay Clay that has been subject to a process that fuses clay particles to a very hard, glasslike form. Often used for smaller diameter sewer pipes because of its resistance to the corrosive components of most domestic and industrial sewage. Its brittleness limits its usefulness for larger diameter lines and in unstable soil and hydraulically pressured trench settings.

Water table The uppermost surface of the saturated zone, where groundwater is free to rise and decline. More explicitly, the groundwater surface on which the fluid pressure in the pores of a porous medium is exactly atmospheric. The location of this surface is revealed by the level at which water stands in a shallow well open along its length and penetrating the surficial deposits just deeply enough to encounter standing water in the well bottom (Freeze and Cherry, 1979). 


\section{Appendix 1. Estimation of Direct Discharge from Swimming Pools and Carwashing to Storm Sewers as Other Unmeasured Return Flow}




\section{Appendix 1A. Swimming Pools}

For the estimation of direct discharge from swimming pools to Salt Creek principally by storm sewers, there were two primary assumptions. These were (1) all pool discharge was through drains to Salt Creek, without sanitary sewer discharge of pool water, and (2) all water discharged from pools at season's end represented the fully filled volume of a pool (based on the standard volume estimated for this study), with no discharge of lesser volumes that may be manufacturer recommended or standard practice.

To determine the volume of water that might be discharged from the area's swimming pools to storm sewers or directly to Salt Creek, the number of public and private pools in the sewershed first was estimated. For this estimation, a "snapshot" of identifiable pool objects (permanent in ground, permanent above ground, quick-set [nonpermanent]), and large complex (apartment or sports facility pools) was completed by using two different areal imagery datasets (fig.14). An approach that used a geographic information system (GIS) was used to identify area pools from satellite imagery of September 19, 2009; Google Earth imagery of June 30, 2010, was visually inspected for identifiable pools (satellite imagery representing a summer month and a date closer to the study period of 2012 was unavailable). These separate accountings were used to derive a representative number of pools in the sewershed. From this pool count, the volume of discharge was estimated. From this snapshot, it was determined that all but a few pools in the sewershed are privately owned.

The total water volume of private pools was estimated from the total pool count, by assuming a standard shape, size, and depth. Because more than about 75 percent of the pools were similarly configured round, above-ground pools, a standard diameter of 25 feet ( $\mathrm{ft}$ ) and depth of $4 \mathrm{ft}$ were applied for the volumetric estimation. Use of these standards might somewhat underestimate total volume, because the remaining 25 percent of private pools appear to be marginally larger and deeper in-ground pools.

The water volumes of the three public pools that were identified were calculated separately. There were notable differences between the private and public pools and variability in their shape, size, and depth. Google Earth images and the distance-measuring tool included in Google Earth were used to approximate the surface area of each public pool, and depths ranging from 3 to $8 \mathrm{ft}$ were used to account for pool configurations ranging from a lazy river to diving pools. For most estimations, a $4 \mathrm{ft}$ depth was used.

These estimated water volumes for the village's public pools were evaluated against volumes determined from a second method by using data from metered water volume delivery for the public pool facilities, as provided by the Elk Grove Village DPW (Scott Bernholdt, Department of Public Works, Elk Grove Village, Illinois, written commun., 2013). Although water delivered to the facilities primarily is used to fill the pools and is subsequently discharged indirectly or directly to Salt Creek, a portion is returned to the sanitary sewers by way of shower and toiletry use and possibly by other uses, such as backwashing of filters. Possible meter records that provide the specific volume of water used to fill the pools was not available for this study. Additionally, some of the delivered water to the two outdoor pools is used as makeup for water lost to evaporation from the pool surface and splashing and drag out from swimmers; this water is considered consumed and not accountable as an unmeasured direct return. For the delivery-based estimate of direct returns from public pools, the volumes of sanitary sewer discharge and evaporative loss were estimated and applied to (subtracted from) the direct return. The direct return was further adjusted to account for the contribution of precipitation to pool volumes; this addition accounts for the portion of delivered water that otherwise would be expected to be used for makeup for evaporative loss, thus increasing the volume expected to be discharged as a direct return. It should be noted that a similar adjustment for evaporative loss was unnecessary for volumetrically based estimates of direct return from public and private pools, as any supplemental water volume for pools included in this estimation primarily would represent makeup for evaporative loss without subsequent discharge to Salt Creek.

To determine a representative volume of sanitary sewer return from the public pool facilities for the adjustment of direct return, village facilities with a number of water users relatively similar to that of the pool facilities were considered. The identified facilities included a junior high school and an adult care center, each of which were delivered about 0.42 million gallons (Mgal) during the annual study period. Although the volume of sanitary sewer return estimated from this approach cannot account for possible pool-specific returns, such as backwashing of filters, it presumably compensates for any such loss of estimated volume by the unique inclusion of returns associated with large-scale food preparation and utensil washing. This estimated volume of sanitary return was applied to the volumes of water delivered to each of the public pool facilities to better estimate their direct returns.

To estimate evaporative water loss from the in-ground public pools, lake evaporation rates were used along with a conventional pan-to-lake evaporation conversion factor of 0.75 (Angel, 2013c). Pan-evaporation data from the months June-August were applied, as public pools typically open about Memorial Day (May 28, 2012) and close after Labor Day (September 3, 2012). These data were obtained from the Chicago Botanic Garden in Glencoe, Illinois (Angel, 2013c) (fig. 1).

The maximum monthly June-August pan-evaporation rates representing a single year during 1998-2009 (Angel, 2013c) were considered to best approximate pool evaporation rates during the hot, dry drought conditions of 2012. The maximum June-August total during the 12-year period of record was 19.89 inches (in.), in 2000, with similar totals in 1998 (19.87 in.) and 2005 (19.86 in.). Drought conditions during 2005 were similar to those of 2012, with above-normal 
temperatures and below-normal precipitation throughout much of the State. From these records, a pan evapotranspiration rate of 20 in. $(1.67 \mathrm{ft})$ was applied to the present estimate of evaporative loss.

Evaporative loss from the outdoor public pools in the sewershed was estimated by the equation:

$$
E L(\mathrm{gal})=(L E(\mathrm{ft}) * 0.75) * P A\left(\mathrm{ft}^{2}\right) * 7.48\left(\mathrm{gal} / \mathrm{ft}^{3}\right)
$$

where

$$
\begin{aligned}
E L= & \text { evaporative loss from swimming pools, } \\
& \text { in gallons (gal; reported in millions of } \\
& \text { gallons), } \\
L E= & \text { total reported/estimated lake evaporation, } \\
& \text { June-August, in feet (converted from } \\
& \text { inches), } \\
= & \text { pan-to-lake evaporation conversion factor, } \\
= & \text { total surface area of pools, in square feet } \\
& \left(\mathrm{ft}^{2}\right), \text { and } \\
= & \text { conversion factor from cubic feet }\left(\mathrm{ft}^{3}\right) \text { to } \\
& \text { gallons. }
\end{aligned}
$$

The total surface area of pools at the two outdoor facilities is $29,500 \mathrm{ft}^{2}$, as estimated from measurements of the pools from Google Earth images.

The final applied volumetric estimate of direct return of pool water from public pools to Salt Creek was determined by comparing the results of the two methods of estimating the pool volumes (from pool count and water delivery records). As planned, the two estimates would be averaged to determine the final applied estimate if the estimates were within 50 percent of each other. This approach was considered to accommodate the uncertainty associated with the separate estimation methods. For more discrepant estimates, the estimate based on water delivery records would be used, after adjustments for sanitary return flow, evaporative loss, and precipitation contribution.

\section{Appendix 1B. Carwashing}

For commercial carwashes, most wastewater is reported as discharged to sanitary sewers (Western Carwash Association, 2013); however, the potential for its discharge to storm sewers was considered in this study. By using a place-based Google Maps search, no such facilities were identified in the sewershed. Thus, it was unnecessary to establish an approach for estimating potentially unaccounted-for discharges from commercial carwashes to storm sewers.

For washing of cars at private residences, reasonably accurate estimation of wastewater volumes that are discharged by surface drainage to nearby storm sewer drains generally is infeasible, particularly within the resource constraints of this study. However, extensive literature on the percentage break down in various indoor and outdoor domestic uses of water suggest that the likely volume of unaccounted-for direct returns of water from domestic washing of cars, particularly at private residences and not commercial carwashes, is small relative to the volumes used and discharged (returned) for other purposes. About 65-70 percent of domestic water use typically is considered to be for indoor uses; of the often-cited remaining 30-35 percent for outdoor uses, irrigation is considered the predominant use (University of Wisconsin-Eau Claire, 2004; Hermitte and Mace, 2012; U.S. Environmental Protection Agency, 2014). The consumptive use of carwashing may be mentioned in passing in water use literature, but seemingly, it never is quantified. The assumption of insignificant volumes of water used and discharged for the purposes of this study is considered quite reasonable, given that

1. washing of privately owned cars is random, infrequent, and limited to warm-weather months,

2. car owners often use commercial wash facilities, which for this study were determined to all be outside the sewershed, and

3. relatively small volumes of water are used for each wash (about 20-150 gal or more depending on whether or not a shutoff hose nozzle is used) (City of Federal Way, 2009; Save the Sound, Inc. 2002; U.S. Environmental Protection Agency, 2008).

A limited attempt was undertaken to assess what might constitute the "small" volume of residential carwash wastewater that presumably is discharged, although it was not included in the estimation of unaccounted-for storm sewer discharge for this study. For this assessment, a Web search was conducted to identify a quoted maximum, minimum, and average volume of water used for residential "driveway" carwashing. Additional citable references also were identified to determine a representative percentage of car owners in a community similar in makeup to the sewershed (predominantly middle class, suburban, predominantly residential, for example), and the percentage of car owners that typically wash their cars in driveways. A representative frequency for these washings in the range of once per week to once per month was considered, with once a month selected on the basis of personal observation of these habits in the authors' home community in east-central Illinois (also predominantly middle class, residential) and its prevalence in a related study (Hardwick, 1997). Such carwashing was assumed to be restricted to the warm-season months of May-September. A primary source of data for this assessment and its assumptions was a study of residential carwashing by the City of Federal Way, Washington (2009). 



\section{Appendix 2. Well Construction and Lithology at Selected Observation Wells Installed Adjacent to Sanitary Sewers in the Study Area, Elk Grove Village, Illinois}




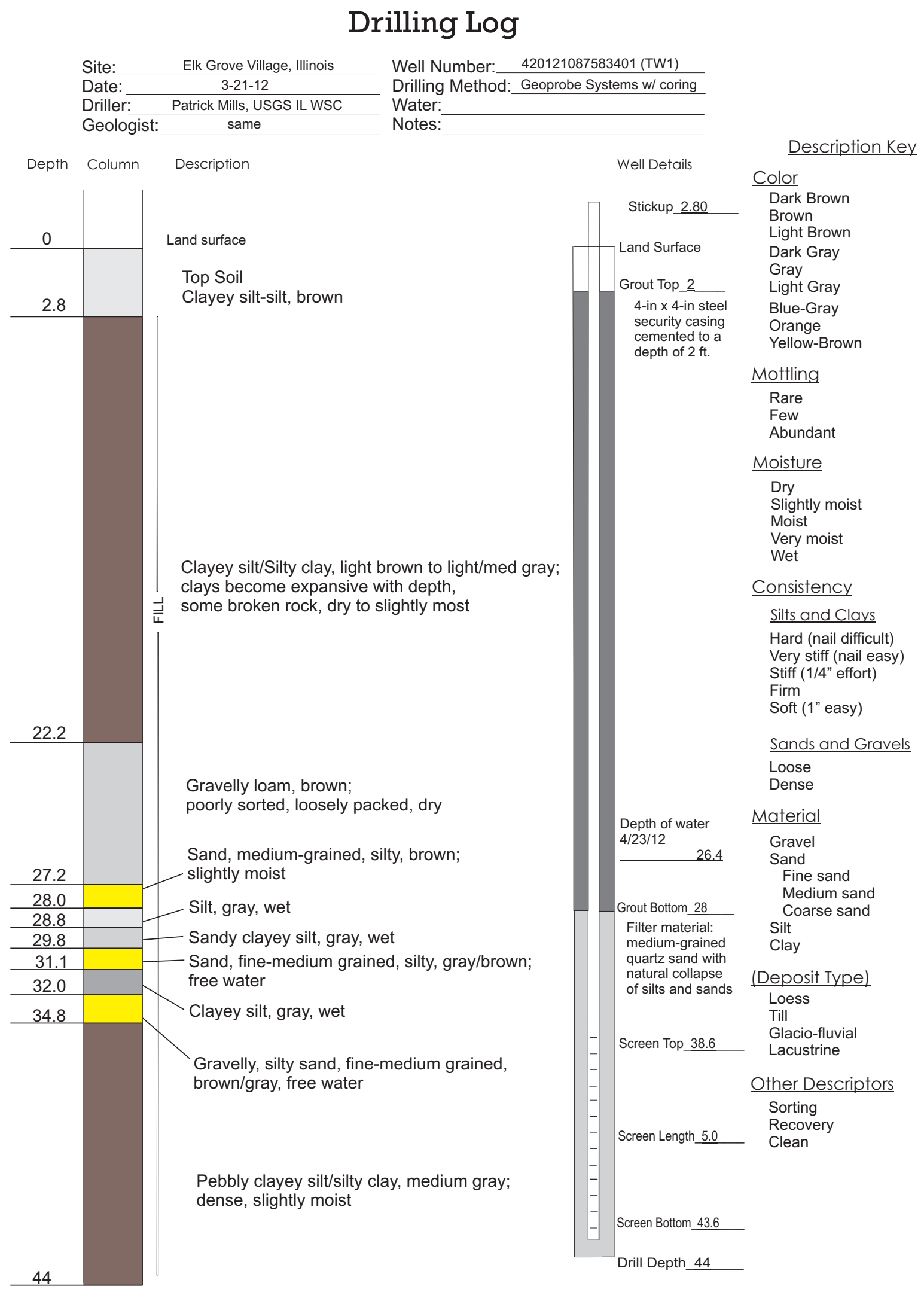

Appendix 2A. Well Construction and Lithology at Selected Observation Wells Installed Adjacent to sanitary Sewers in the Study Area, Elk Grove Village, Illinois: $A$, Well TW1. 


\section{Drilling Log}

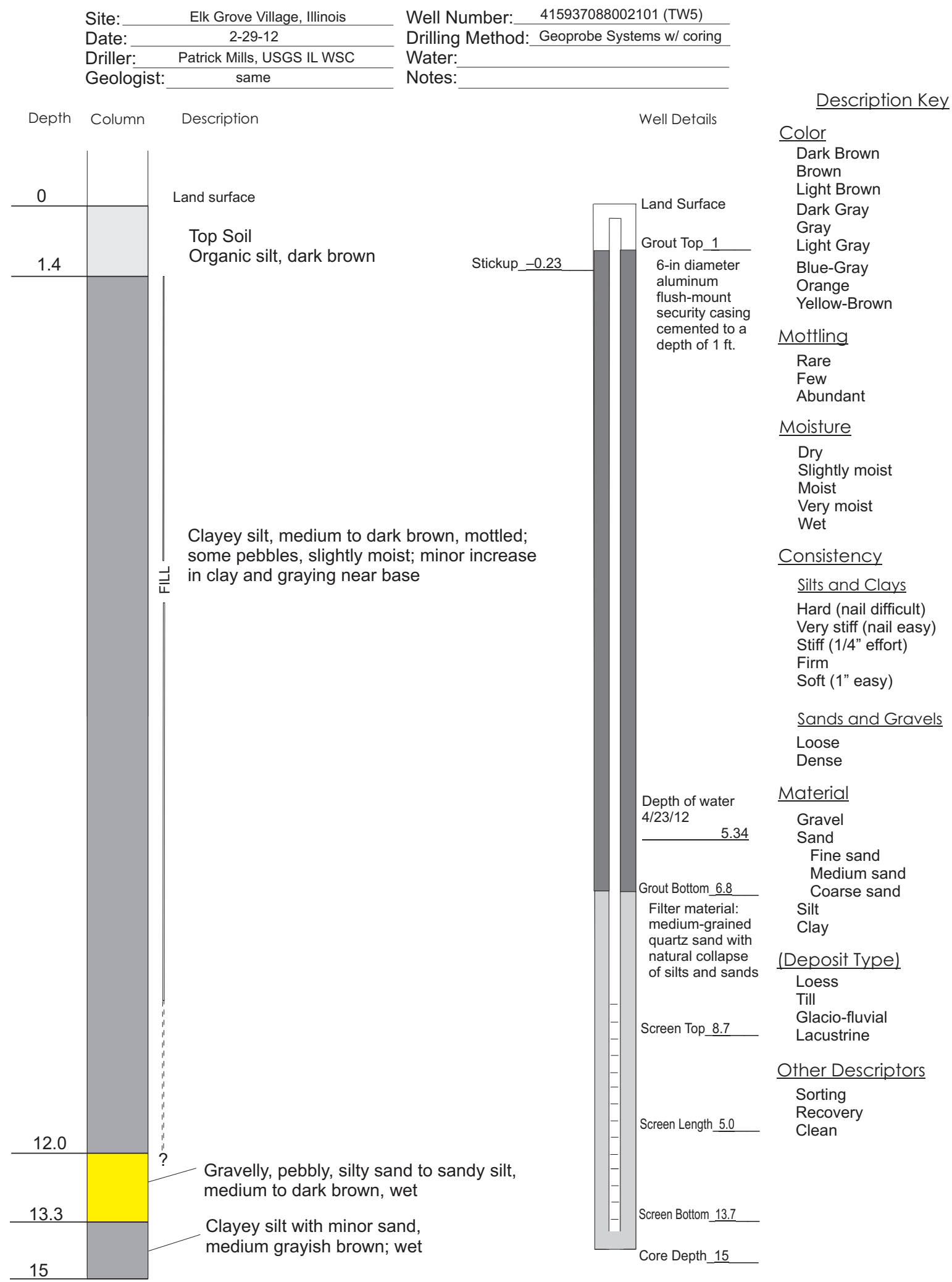

Appendix 2B. Well Construction and Lithology at Selected Observation Wells Installed Adjacent to sanitary Sewers in the Study Area, Elk Grove Village, Illinois: $B$, Well TW5. 


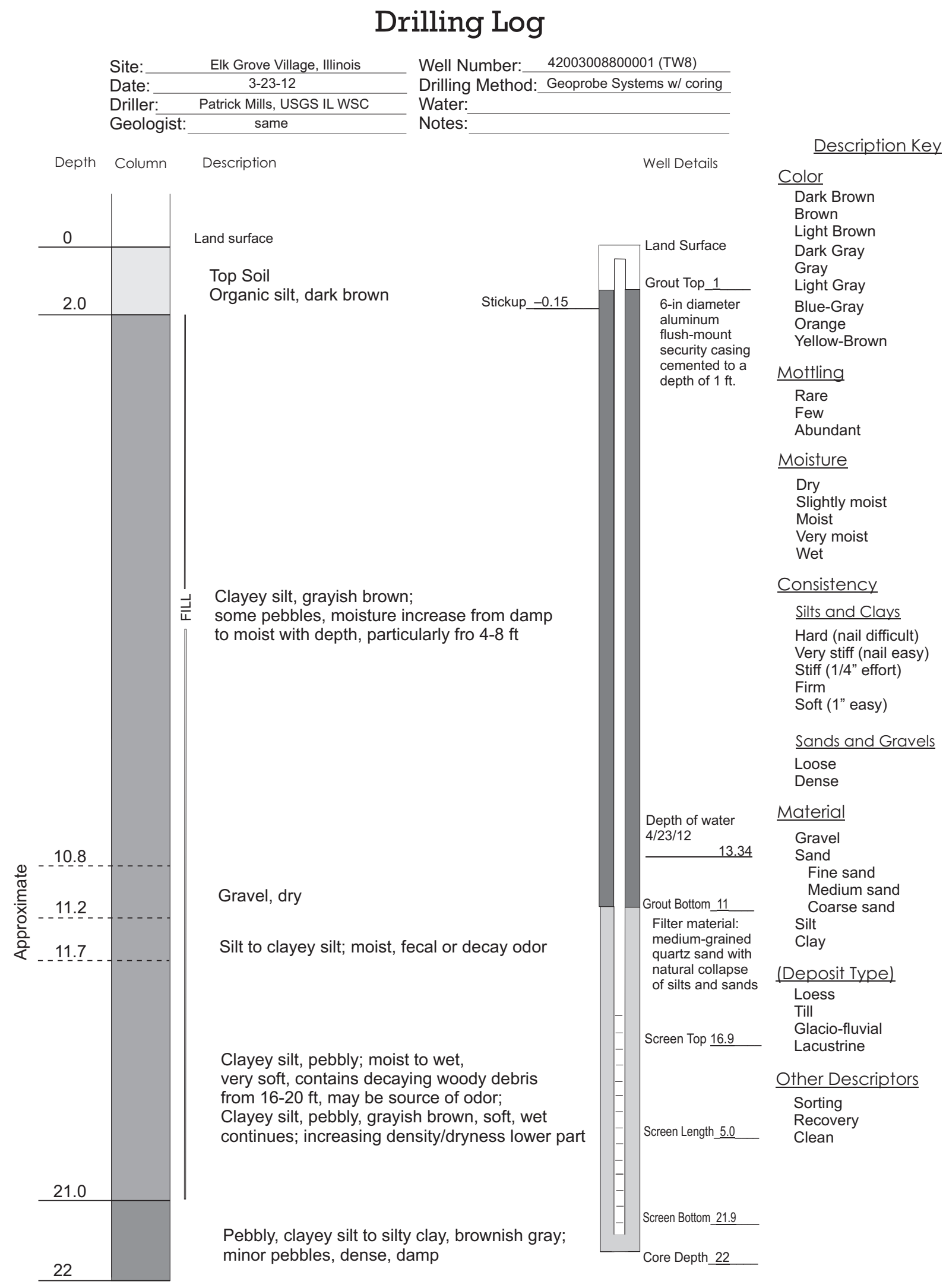

Appendix 2C. Well Construction and Lithology at Selected Observation Wells Installed Adjacent to sanitary Sewers in the Study Area, Elk Grove Village, Illinois: $C$, Well TW8. 


\section{Drilling Log}

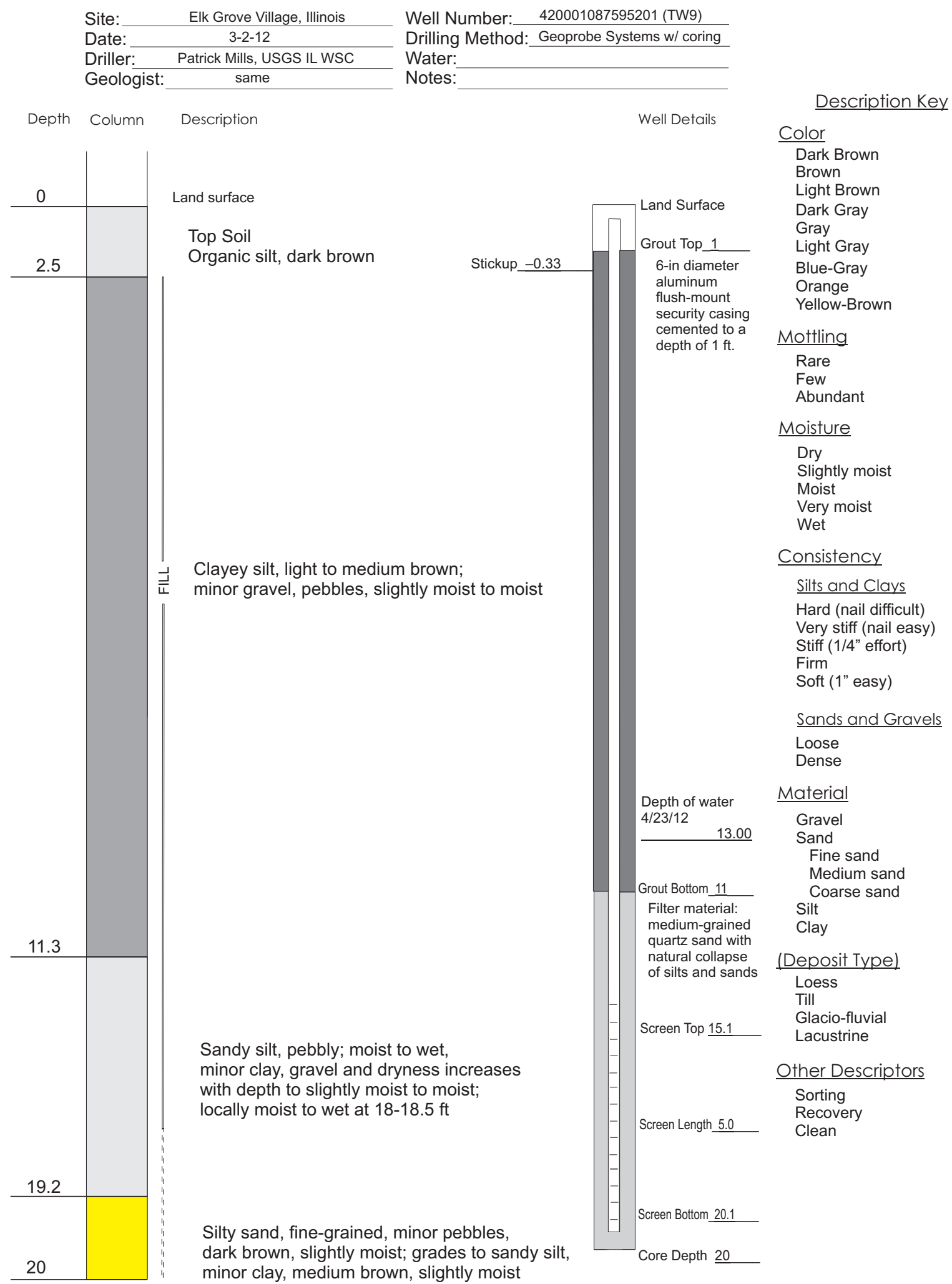

Appendix 2D. Well Construction and Lithology at Selected Observation Wells Installed Adjacent to sanitary Sewers in the Study Area, Elk Grove Village, Illinois: $D$, Well TW9. 



\section{Appendix 3. Collection and Quality Assurance of Optical Brightener Samples}


Described here are the methods used for collection and analysis of samples from groundwater, surface water, and wastewater in sanitary sewers for optical brighteners (OBs). Also described are the various quality assurance measures taken to ensure that determined concentrations of the OB samples reasonably represented in situ concentrations. Partial results of the bench tests for quality assurance are presented, and the full results are available by contacting the U.S. Geological Survey (USGS) Illinois Water Science Center.

Prior to deployment of the field fluorometer, bench tests were conducted (fig. $15 F$ ). The tests were done to determine the (1) possible range in field OB concentrations, (2) appropriate type of sample bottle, (3) stability of the OB samples, (4) functional accuracy of the fluorometer, and (5) reliability of the sample measurement technique.

To determine the possible range in field $\mathrm{OB}$ concentrations, samples were collected of the discharge from the initial wash cycle and the first rinse cycle of a typical clothes-washing cycle. The recommended volume of concentrated liquid detergent for a large wash load (one capful of about 50 milliliters $[\mathrm{mL}]$ ) was used for the test. These sample concentrations were compared with those of lab-grade inorganic blank water, clean tap, and various sediment-laden waters. The blank water was not specifically certified free of OBs; however, they were never detected during bench tests with the field fluorometer. The concentration range tests used sample containers of various size $(125 \mathrm{~mL}$ to 4 liters [L]) and type (opaque brown and translucent white polyethylene (PE), clear and translucent brown glass, and stainless steel), which aided selection of the most appropriate bottle type for collection of field samples. The tests indicated wash and rinse cycle concentrations of about 2,300 and 2,800 micrograms per liter $(\mu \mathrm{g} / \mathrm{L})$, respectively. Concentrations of the comparative samples were 0-7 $\mu \mathrm{g} / \mathrm{L}$ (mean, $2 \mathrm{mg} / \mathrm{L}$ ) for deionized water; $2-7 \mathrm{mg} / \mathrm{L}$ (mean, $4 \mu \mathrm{g} / \mathrm{L}$ ) for tap water; and $8-13 \mu \mathrm{g} / \mathrm{L}$ (mean, $11 \mu \mathrm{g} / \mathrm{L}$ ) for sediment-laden water.

Based on the bench-test results and other considerations, 125-mL opaque polyethylene (PE) bottles were selected for collection of field samples. This bottle type was selected because (1) bench tests of the bottles filled with blank water detected no OBs, indicating the inertness of the bottle material, and (2) the opaque composition can inhibit degradation of the photosensitive OB compounds. This bottle size was selected to best allow analysis of samples with the field fluorometer. Most of the groundwater samples were of small volume (about $250 \mathrm{~mL}$ or less after well purging prior to sampling), because the observation wells were of small diameter (1 inch [in.]), open to generally shallow depths (typically less than 22 feet [ft]), and within low-permeability, fine-grained fill and sediments. This small volume precluded conventional analysis in a larger vessel that can fully contain the 4-in. diameter field fluorometer and its array of sensors (fig. 15E). The bottle size allowed singular containment of the OB-specific sensor and maximized the necessary depth of sensor submersion and horizontal and vertical spacing between the sensor lens and bottom and sidewalls of the bottle.
To determine the stability of the samples, concentrations of test and field samples were analyzed over various time intervals (within 24 hours to 2 weeks of collection). Optical brighteners are subject to adsorption to soil particles, and degradation, in part, by exposure to ultraviolet [UV] light for a long period (photic decay) (Alhajjar and others, 1990; Sargent and Castonguay, 1998). The selected samples represented a range of concentrations from about 26 to $2,800 \mu \mathrm{g} / \mathrm{L}$. Concentrations of OBs in the samples typically decreased gradually through time; concentrations in about 75 percent of the samples decreased over a period of at least a week. Based on these results, all field samples were analyzed within 36 hours of their collection, with most analyzed within 24 hours.

To determine the functional accuracy of the fluorometer, samples of $400 \mu \mathrm{g} / \mathrm{L}$ (the manufacturer-provided calibration standard) and $1,500 \mu \mathrm{g} / \mathrm{L}$ (degraded wash discharge) were diluted by 50,25 , and 12.5 percent to assess the linearity of the OB measurements (concentrations proportional to percentage of dilution). Resultant concentrations were within 5 percent or less of expected concentrations of the calibrationstandard samples and within about 25 percent of expected concentrations of the wash discharge samples. The greater error in measurement of the wash discharge samples is attributed to inaccuracies in mixing and measuring the highly concentrated sample during dilutions.

Because $125-\mathrm{mL}$ bottles were used for sample collection and analysis, as previously discussed, a minor adjustment was made to the fluorometer manufacturer's recommended method for concentration measurement. Instead of a lateral clearance greater than 2 in. between the OB sensor lens and the sidewall of the bottle and vertical clearance greater than 3 in. between the lens and the bottom of the bottle, these respective clearances in this study's method were only about 0.5 and $1 \mathrm{in}$. To evaluate the extent to which the reduced clearances of the sensor lens might affect the accuracy of sample measurement, a blank sample, a sample of known concentration $(400 \mu \mathrm{g} / \mathrm{L})$, and samples of various dilutions were analyzed. The measurement results were within 5 percent or less of those using the recommended clearances, thus sufficient for determining the relative magnitude of $\mathrm{OB}$ concentrations and distinguishing between samples collected at different times and locations, as necessary for this study.

Groundwater samples were collected by methods necessitated by the small volume of water available from the shallow, small-diameter observation wells open to low-permeability sewer-trench fill and glacial sediments of the study area. The methods were considered suitable for providing samples that acceptably represent in situ OB concentrations for the purposes of this study. Groundwater samples from all but one observation well were collected at slow flow rates (about $0.1-0.2$ gallon per minute [gal $/ \mathrm{min}]$ ) by peristaltic pump, by using PE sample tubing. Use of a peristaltic pump is appropriate for collection of OB samples; because of their low volatility, they are not affected by negative sampling pressures. The intake of the sample tubing intake was placed at least $0.5 \mathrm{ft}$ above the base of the well to limit uptake of any accumulated 
sediments. Most samples were only minimally turbid; the most turbid samples generally were associated with the wells open to the fine-grained fill and sediments of lower permeability.

Samples from observation well TW1 (fig. 2) were collected with a small-diameter, bottom-filling, stainless steel bailer (fig. 16A). Depth to water in this well exceeded the operational limit (about $25 \mathrm{ft}$ ) for use of a peristaltic pump.

Water characteristics typically measured in the field (temperature, $\mathrm{pH}$, specific conductance, and dissolved oxygen) were not monitored during sampling of the observation wells. To more successfully obtain a sample representative of recently infiltrated groundwater, removal (purging) of a minimum of one well volume of water was attempted before the sample was collected; purging of a larger number of well volumes usually ran the risk of pumping a well dry, followed by multiday water level recovery. In such cases, project resources did not allow for a return for sampling. Where possible, three well volumes were purged before sampling, but in some cases, less than one volume was purged. Purging of well TW1 prior to sample collection was infeasible, given its large water volume in storage (about $2.6 \mathrm{~L}$ ) and the small volume of the bailer (about $20 \mathrm{~mL}$ ). Samples were collected from the screen interval of the well in order to most successfully represent recent $\mathrm{OB}$ concentrations in groundwater. Concentrations in this well were expected (and proved) to represent background concentrations, as the well depth is about $3 \mathrm{ft}$ shallower than the top of the adjacent interceptor sewer.

All sample bottles were rinsed with sample water immediately prior to sample collection. Following sampling, the wells were purged of water until empty when yield rates allowed. All tubing used in the collection of samples was prewashed by using a soapy tap-tap-deionized sequence of wash-rinse water.

Water samples from Salt Creek and the interceptor were collected by first prerinsing the PE sample bottle. The sealed bottle was submerged to about the midpoint of these water bodies' approximate 2 - $\mathrm{ft}$ depth, the cap removed, the bottle filled to about three-quarter capacity, and the bottle agitated and emptied for prerinsing. This procedure was repeated to collect the field sample to near bottle capacity.

Periodic duplicate samples were collected to evaluate possible variability associated with the groundwater sampling approach. Additionally, periodic field blanks were collected to assess the effectiveness of the procedure for cleaning the peristaltic tubing after use. Deionized water was pumped through the cleaned tubing for analysis. Duplicate sample concentrations generally were within about 10 percent of each other. No residual OBs were detected in the field blanks.

After sample collection, the sample bottles were placed on ice and returned to the office refrigeration unit for holding until analysis (typically the following day). Refrigeration and rapid turnaround for analysis was intended to limit degradation of the samples. The period of refrigeration also provided necessary time for any contained sediments to settle to the bottom of the sample bottles and, thus, limit their effect on sample analysis. After removal from refrigeration for analysis, the samples were transported and prepared in a manner intended to avoid agitation and redistribution of any sediments.

For the benchtop fluorometer samples, the only difference in the sample-processing procedures from those of the field fluorometer described previously was that the sample bottles were lightly agitated to provide some remixing for more homogenous distribution of concentrations (yet avoiding substantial redistribution of any contained sediment) after the samples sat undisturbed in the refrigerator. The agitation was required because the benchtop fluorometer uses a smaller portion of the collected sample than that used for analysis by the field fluorometer, with about $40 \mathrm{~mL}$ transferred to a glass sample vial for analysis.

The OB concentrations were affected by sediment concentrations in samples and disturbance of the sediments during sample analysis; higher sediment concentration, resulted in the detected fluorescence being less prone to fully (if ever) stabilizing during measurement. Because of this fluctuation, the recorded "raw fluorescence unit" (RFU; see following section) value or OB concentration was approximated based on the rate of change and direction of fluctuation in measurement readings. The recorded value represents either (1) the mean value of measurements that rise and fall over a fluctuating range, or (2) the near-stabilized value of gradually falling or rising measurements. For example, for sample concentrations in the hundreds of micrograms per liter with fluctuating measurement readings, the cyclical fluctuations may be in the order of tens of micrograms per liter and the recorded concentration close to the midpoint value in the fluctuation range. Although reported OB concentrations are considered to reasonably represent the "actual" concentrations (within about \pm 10 percent), they are best considered with respect to the magnitudes of the relations between the various measurements in the study.

Analytical results initially were measured with the field fluorometer and recorded in RFU and, thus, were not reportable as true concentrations. Raw fluorescence is a measure of the relative fluorescence (fluorescence proportional to concentration) of one sample compared to another. The benchtop fluorometer was calibrated against a manufacturer-provided standard of known OB concentration $(400 \mu \mathrm{g} / \mathrm{L})$ for measurement of $\mathrm{OB}$ concentrations in water and sewer flow samples collected in the study. A relation was determined between OB RFUs measured by the field fluorometer and OB concentrations measured by the benchtop fluorometer (concentration $=(0.244 \times \mathrm{RFU})+0.8795)$ and the initial RFU measurements converted to OB concentrations. All OB measurements included in this report are presented as concentrations.

To determine background concentrations of OBs in groundwater of the sewershed, two topographically elevated sites were selected where the groundwater would be expected to be upgradient of any sewer lines that might be losing flow to groundwater through leakage (EXF). Thus, other than the possible contribution of low concentrations of naturally fluorescing compounds from the soils, no OBs should be present in the native groundwater at these background sites. 
These sites included BG7 (near well TW7), at an elevation of about $710 \mathrm{ft}$ above the North American Vertical Datum of 1988 (NAVD 88), and BG14 (near well TW14), at an elevation of about $716 \mathrm{ft}$ NAVD 88 (table 5-1, figs. 2; 6). Water samples were collected within $1-5 \mathrm{ft}$ of the water table by using the Geoprobe Systems stainless steel, wire-wound screen sampler. Those depths below land surface were $13-17 \mathrm{ft}$ at site BG7 and 8-12 ft at site BG14. Background concentrations in groundwater were determined to range between about $42-45 \mu \mathrm{g} / \mathrm{L}$ (at BG14 and BG7, respectively). All other measurements of $\mathrm{OB}$ concentrations determined from collected samples or monitored in situ were evaluated against these background concentrations. These measurements included those of sanitary sewer flow (from the interceptor), groundwater adjacent to sewer lines (from wells), groundwater downgradient of sewer lines (from the Geoprobe Systems sampler), and streamflow (from Salt Creek). Ranges were established to reflect how indicative (moderately and strongly) measured concentrations are of OB-affected sewer discharge or natural waters. These ranges were based on consideration of (1) the above-indicated quality assurance evaluations, particularly expected maximum OB concentrations in sewer flow and variability associated with concentration measurement, and (2) distribution patterns of field-determined concentrations, with respect to relational depths of groundwater and sewer inverts, sewer depths, status of sewer lining upgrade by cure-in-place, and elevational location within the sewershed (upland, flood plain). 


\section{Appendix 4. Monthly Hydrographs of Sewer Discharge and Precipitation in and near Elk Grove Village, Illinois, March 4, 2012 March 3, 2013}




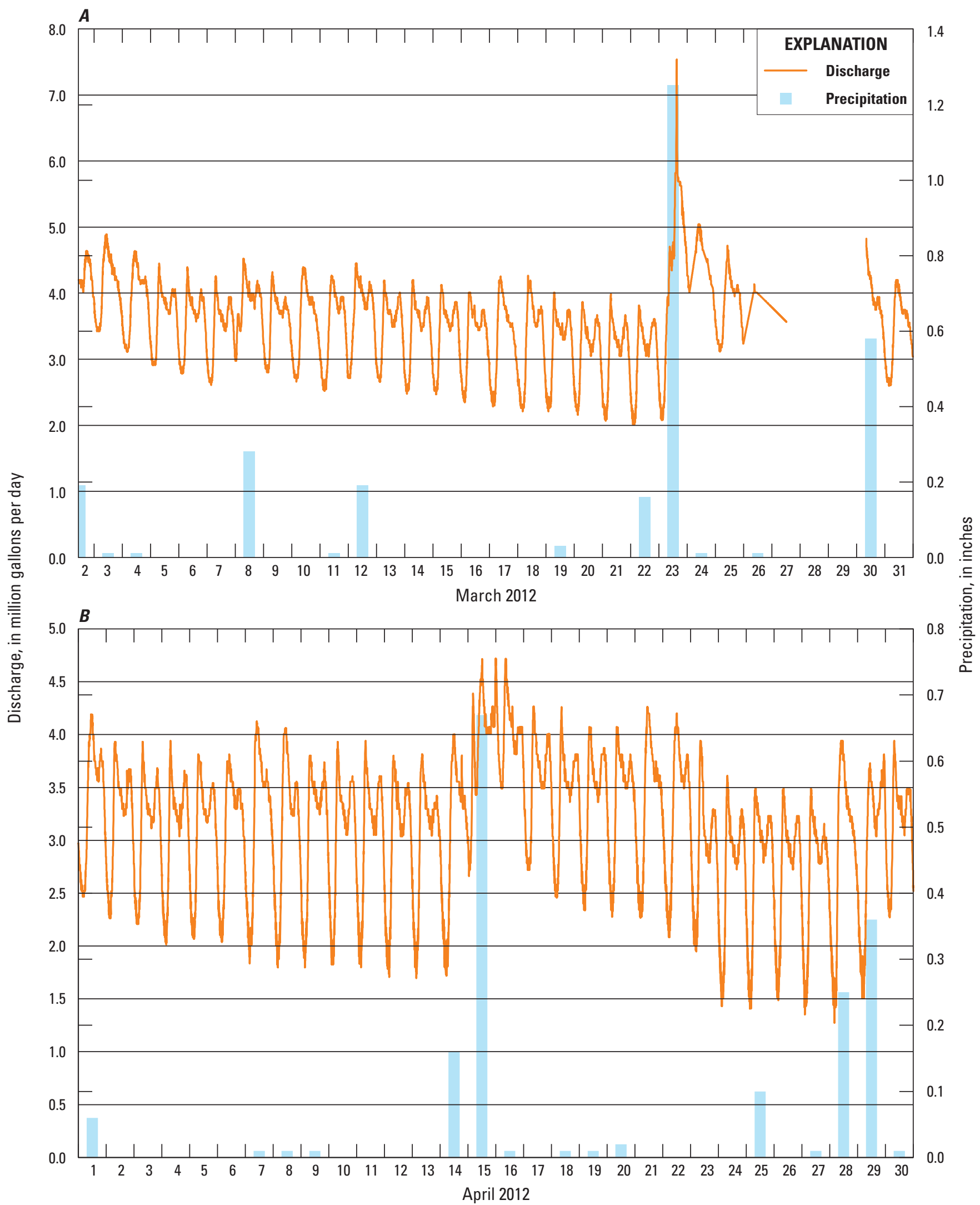

Appendix 4A. Monthly hydrographs of sewer discharge and precipitation in and near Elk Grove Village, Illinois, March 4, 2012March 3, 2013. A, March 2012. B, April 2012. (Discharge [5-minute unit value] measured in the Metropolitan Water Reclamation District of Greater Chicago interceptor at U.S. Geological Survey station Sewer at Oakton at Elk Grove Village. Precipitation [daily] measured at National Oceanic and Atmospheric Administration weather station Chicago O'Hare Airport.) 


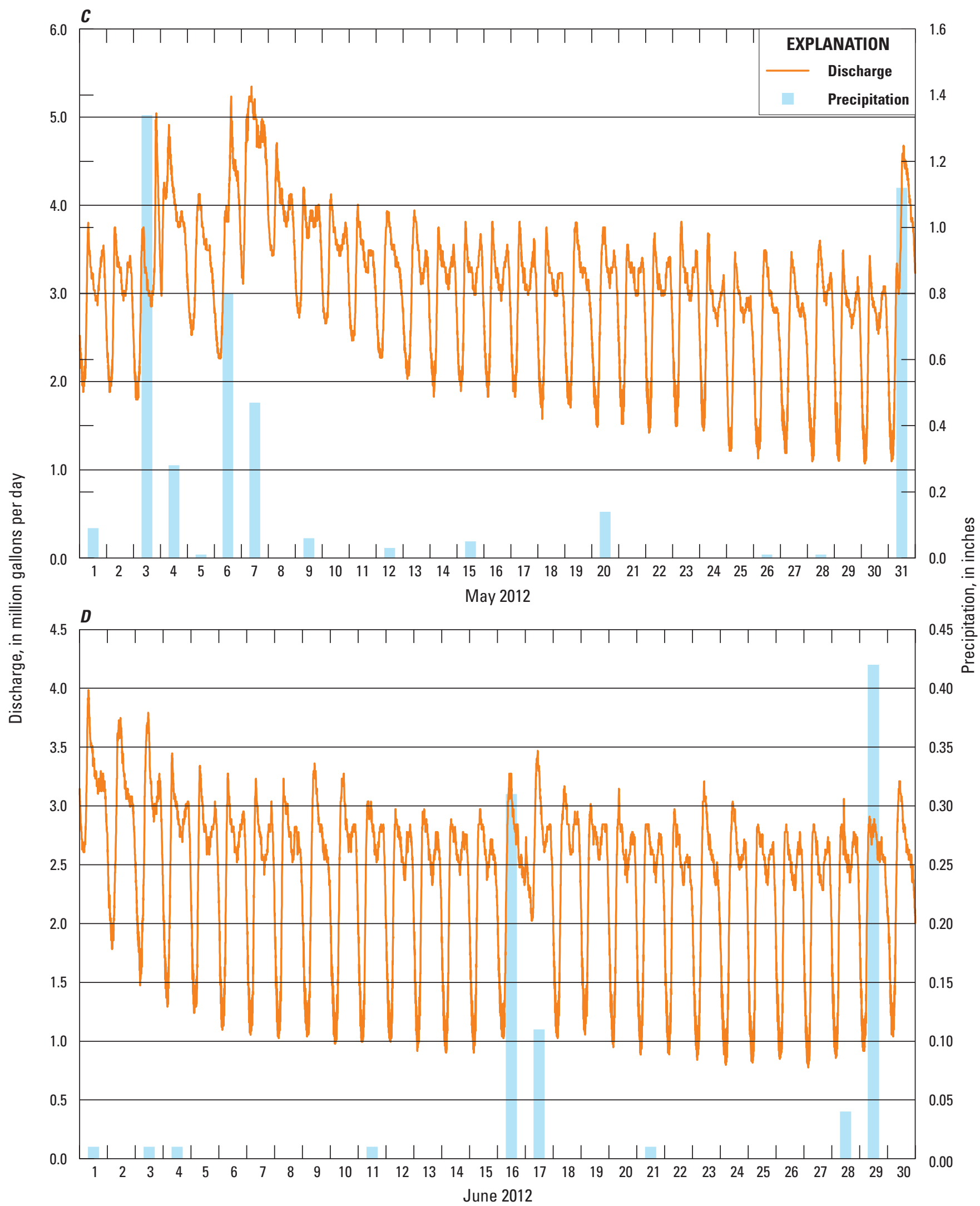

Appendix 4B. Monthly hydrographs of sewer discharge and precipitation in and near Elk Grove Village, Illinois, March 4, 2012March 3, 2013. C, May 2012. D, June 2012. (Discharge [5-minute unit value] measured in the Metropolitan Water Reclamation District of Greater Chicago interceptor at U.S. Geological Survey station Sewer at Oakton at Elk Grove Village. Precipitation [daily] measured at National Oceanic and Atmospheric Administration weather station Chicago O'Hare Airport.) 


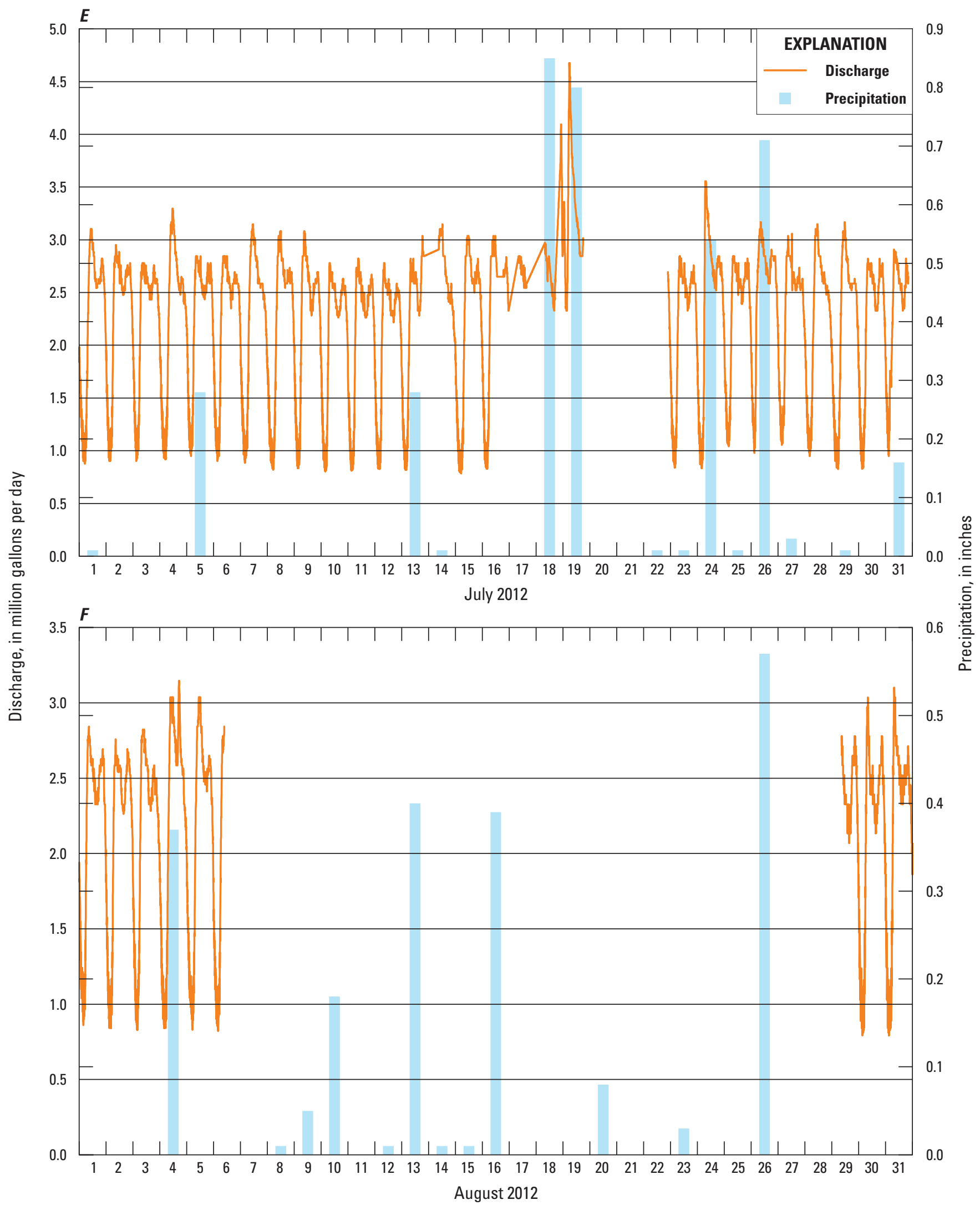

Appendix 4C. Monthly hydrographs of sewer discharge and precipitation in and near Elk Grove Village, Illinois, March 4, 2012March 3, 2013. E, July 2012. F, August 2012. (Discharge [5-minute unit value] measured in the Metropolitan Water Reclamation District of Greater Chicago interceptor at U.S. Geological Survey station Sewer at Oakton at Elk Grove Village. Precipitation [daily] measured at National Oceanic and Atmospheric Administration weather station Chicago O'Hare Airport.) 


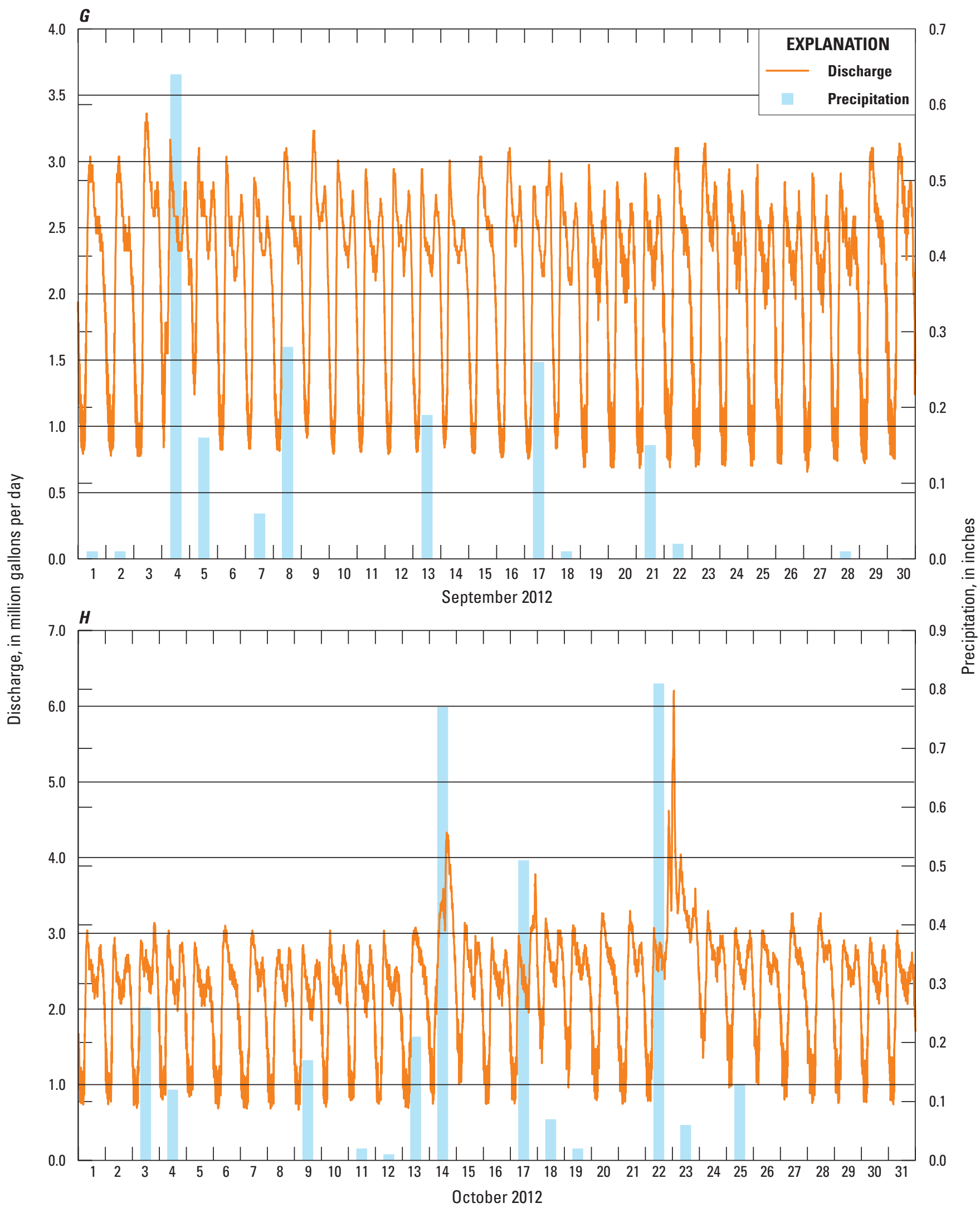

Appendix 4D. Monthly hydrographs of sewer discharge and precipitation in and near Elk Grove Village, Illinois, March 4, 2012March 3, 2013. G, September 2012. H, October 2012. (Discharge [5-minute unit value] measured in the Metropolitan Water Reclamation District of Greater Chicago interceptor at U.S. Geological Survey station Sewer at Oakton at Elk Grove Village. Precipitation [daily] measured at National Oceanic and Atmospheric Administration weather station Chicago O'Hare Airport.) 


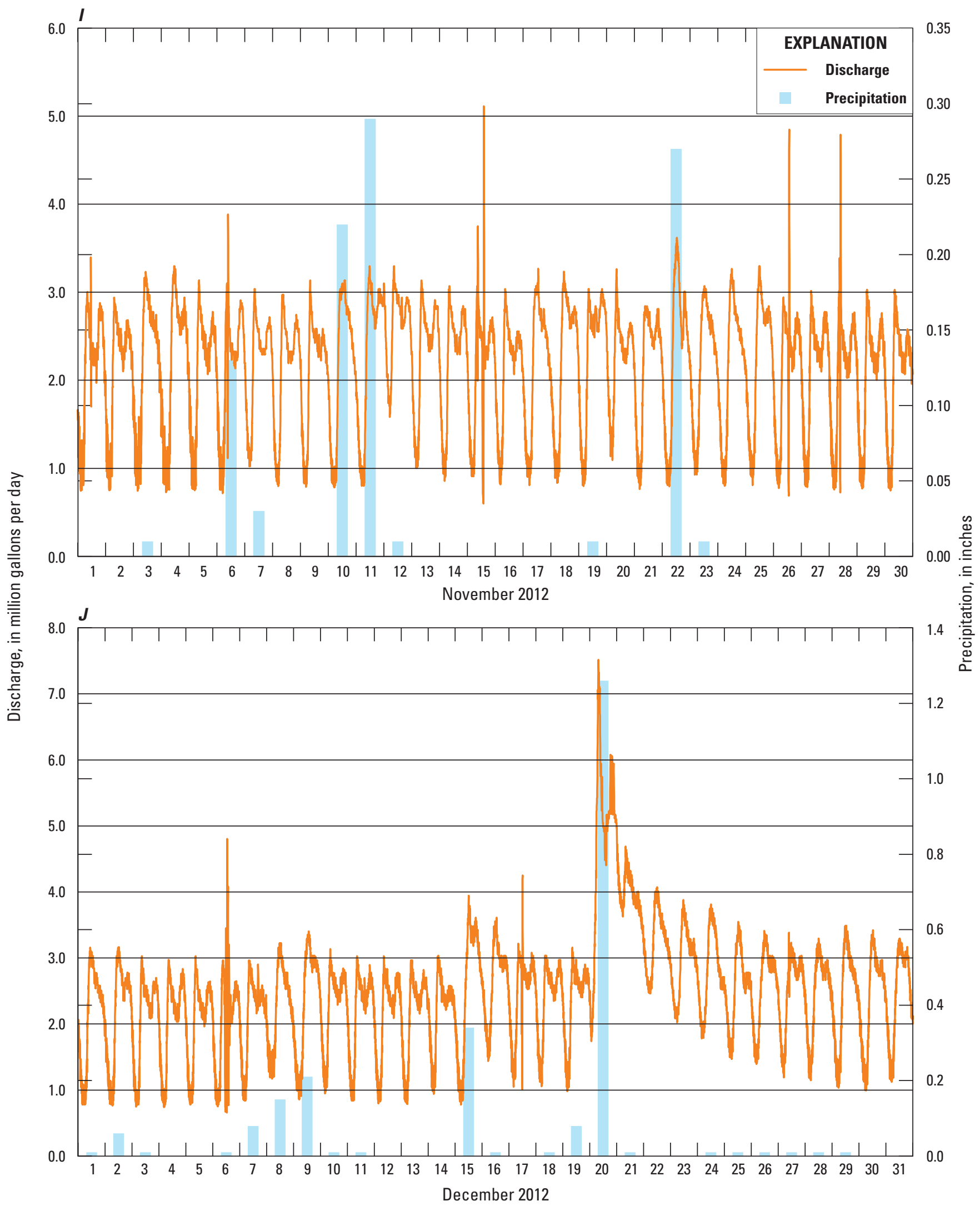

Appendix 4E. Monthly hydrographs of sewer discharge and precipitation in and near Elk Grove Village, Illinois, March 4, 2012March 3, 2013. I, November 2012. J, December 2012. (Discharge [5-minute unit value] measured in the Metropolitan Water Reclamation District of Greater Chicago interceptor at U.S. Geological Survey station Sewer at Oakton at Elk Grove Village. Precipitation [daily] measured at National Oceanic and Atmospheric Administration weather station Chicago O'Hare Airport.) 


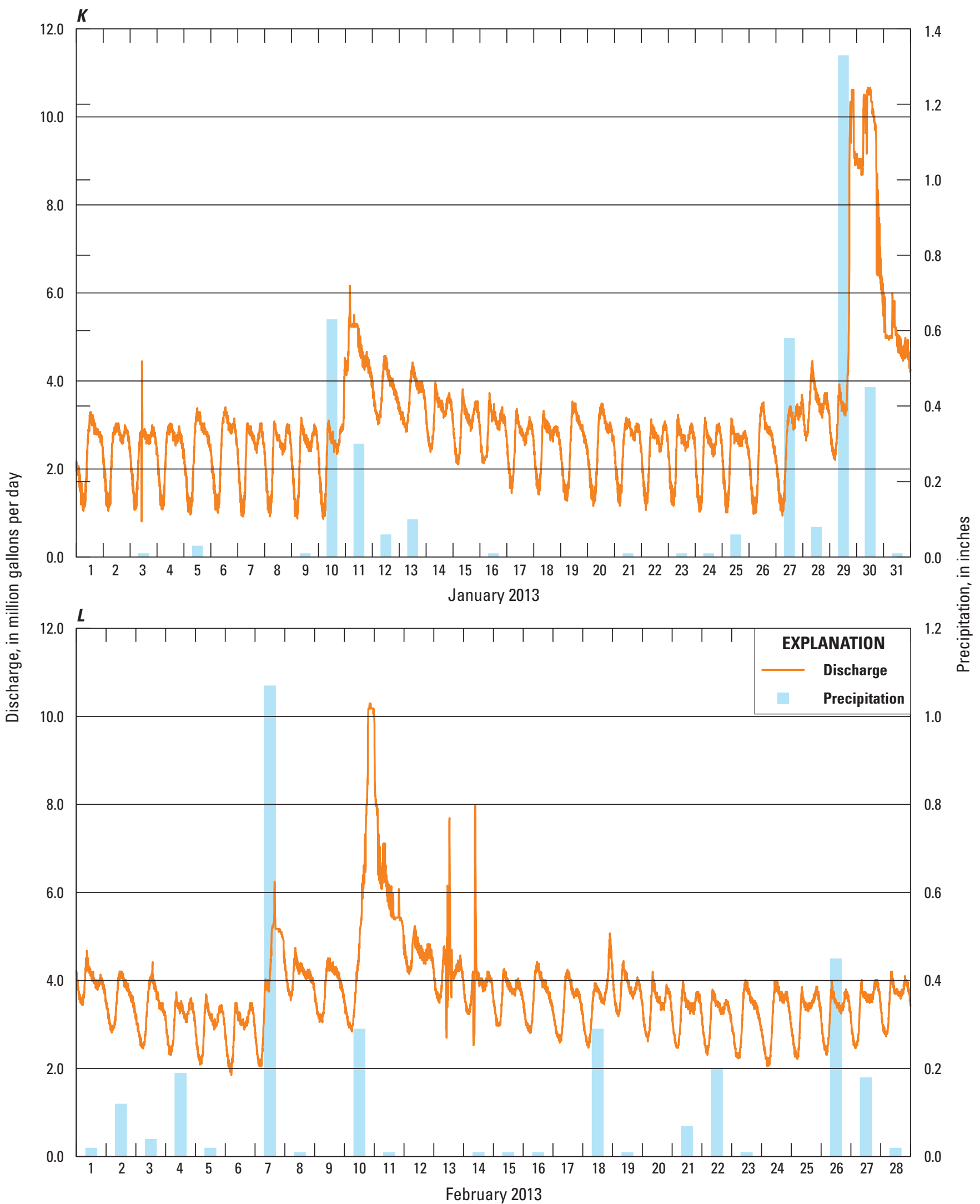

Appendix 4F. Monthly hydrographs of sewer discharge and precipitation in and near Elk Grove Village, Illinois, March 4, 2012March 3, 2013. K, January 2013. L, February 2013. (Discharge [5-minute unit value] measured in the Metropolitan Water Reclamation District of Greater Chicago interceptor at U.S. Geological Survey station Sewer at Oakton at Elk Grove Village. Precipitation [daily] measured at National Oceanic and Atmospheric Administration weather station Chicago O'Hare Airport.) 


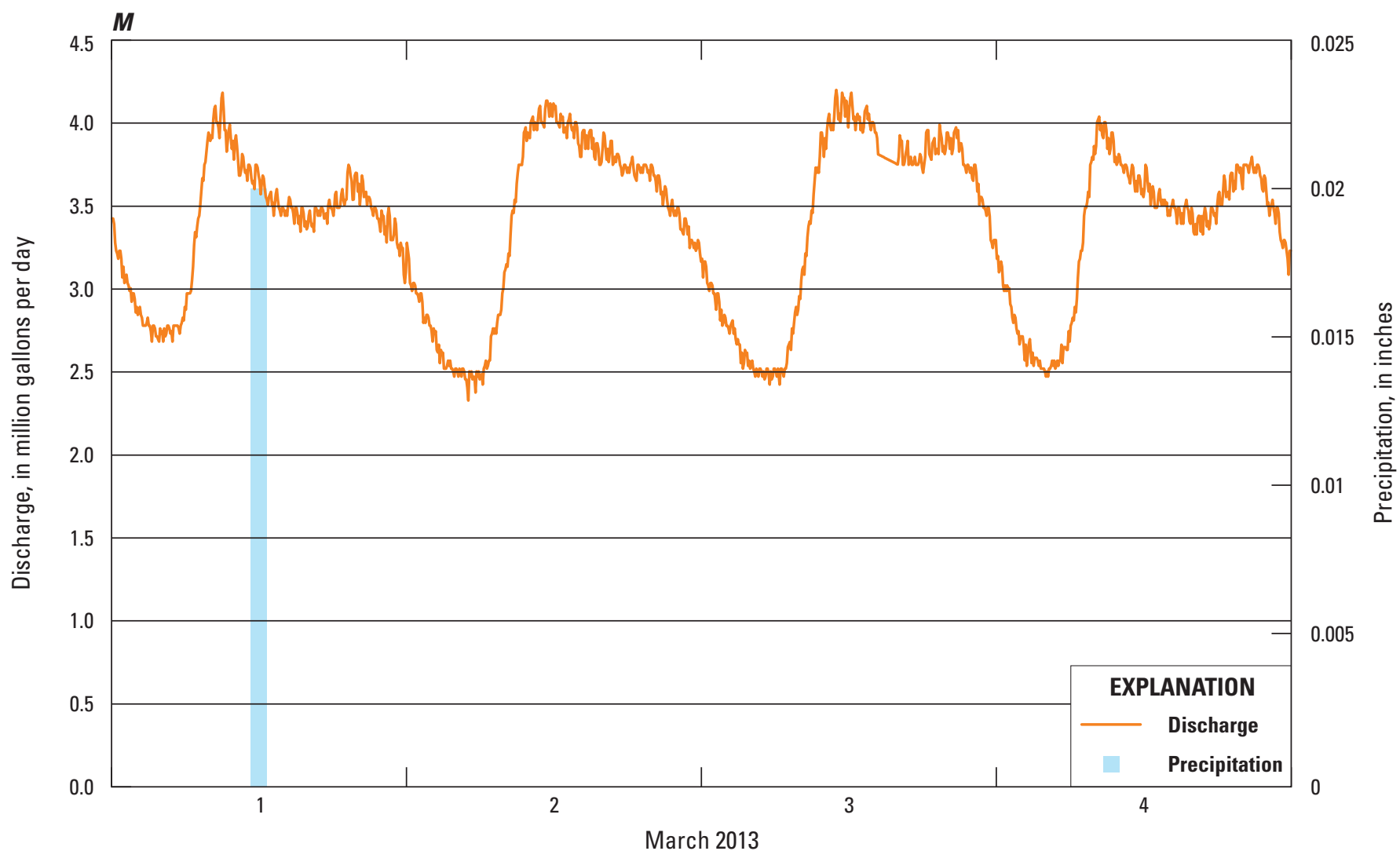

Appendix 4G. Monthly hydrographs of sewer discharge and precipitation in and near Elk Grove Village, Illinois, March 4, 2012March 3, 2013. M, March 2013. B, April 2012. (Discharge [5-minute unit value] measured in the Metropolitan Water Reclamation District of Greater Chicago interceptor at U.S. Geological Survey station Sewer at Oakton at Elk Grove Village. Precipitation [daily] measured at National Oceanic and Atmospheric Administration weather station Chicago O'Hare Airport.) 
Appendix 5. Findings of Related Assessments 


\section{Appendix 5A. Other Concentrations of Optical Brighteners in Groundwater}

Measurements of concentrations of optical brighteners (OBs) at observation well TW9 were comparatively greater than the background concentrations of the study area (table 5-1; figs. 2; 25G). Downgradient samples were therefore collected on June 8, 2012, at two depth ranges below the water table at a site about midway (about 145 feet [ft]) between well TW9 and Salt Creek (table 5-1; figs. 2; 6). Beginning at a depth of about $0.5 \mathrm{ft}$ below the water table, samples were collected at depths below land surface of about 9.6-13.6 ft at site 9DG1 and 15.6-19.6 ft at site 9DG2. Concentrations of OBs determined from these sample intervals were about 115 micrograms per liter $(\mu \mathrm{g} / \mathrm{L})$ for the shallower interval and $90 \mu \mathrm{g} / \mathrm{L}$ for the deeper interval. The concentration of a sample collected from nearby well TW9 on the same day was about $214 \mu \mathrm{g} / \mathrm{L}$. Concentrations of the three samples are approximate, as they were slowly increasing during measurement.

The detection of elevated concentrations of OBs in groundwater downgradient of well TW9 suggests the migration of groundwater affected by sanitary sewer leakage (exfiltration, or EXF) towards Salt Creek, with its possible discharge to Salt Creek. The presence of OBs in groundwater at this distance from the sewer line does not necessarily imply that pathogen-affected groundwater is discharging to Salt Creek in this area. The lateral movement of bacteria and viruses in groundwater, although found in some cases to be greater than that of conservative tracers representing pathogens in groundwater, generally is limited in fine-grained sediments with small pore spaces and low permeabilities. The sizes of these microorganisms generally are greater than the pore spaces of fine-grained sediments. Comparatively rapid rates of mobility principally occur in coarse-grained sediments with comparatively larger pore spaces (Bowen, 1986). Although the specific lithology of subsurface deposits beyond the trench-fill reach of the sewer line is unknown, the trenchfill sediments determined during well construction suggest the native soils are likely to be fine-grained. Clayey silts were found to a depth of about $11 \mathrm{ft}$, with sandy silt mixed with some clay to a depth of about $19 \mathrm{ft}$ (appendix 2D). Additionally, review of the near-surface soil map (U.S. Department of Agriculture, 2013) at this location indicates the soils to be poorly drained silty clay loam to silt loam to a depth of $5 \mathrm{ft}$. In addition to the potentially flow-restrictive lithology in this area, the water table configuration suggests the sewer line may provide a hydraulic barrier to shallow groundwater flow between that line and Salt Creek. At the time of sampling, the apparent depth to groundwater at the downgradient sample location was about $9 \mathrm{ft}$, whereas the measured depth to groundwater at well TW9 remained between about 12-14 ft throughout the period of this study (appendix 2G). The water surface in Salt Creek appears to be about the same elevation (or slightly lower) as that of groundwater at the downgradient sample location. Given the apparent soil composition and water table configuration in this area, the flow of groundwater, OBs, and any contained microorganisms away from the sanitary sewer near well TW9 and toward Salt Creek should not be expected. More study would be necessary to explain satisfactorily the factors contributing to the lowered water table at this location and the unexpected presence of sewer-affected groundwater at some distance from the sewer.

\section{Appendix 5B. Concentrations of Optical Brighteners in Salt Creek}

For a more areawide assessment of the extent of possible sanitary sewer flow loss to groundwater, thus EXF, water samples were collected from an upstream (SC-U) and a downstream (SC-D) location on Salt Creek (table 5-1; figs. 2; 6) for analysis of OBs. The locations were at the stream's northern and southern extents within the sewershed. The paired measurements were used to determine if any detectable $\mathrm{OB}$ concentrations increased from the upstream to the downstream location. A significant increase possibly could be attributed to nonpoint discharge of sewer-affected groundwater to the stream as the result of extensive EXF from sanitary sewers within the sewershed.

Samples were collected from Salt Creek on three occasions, in June and September 2012 and March 2013. The June and September samplings were during the height of the 2012 drought. The March 2013 sampling followed a recent snowmelt. Streamflow rates were measureable from a U.S. Geological Survey (USGS) gaging station (05531044 Salt Creek near Elk Grove Village) located 0.3 miles (mi) upstream of sample site SC-U (fig. 2). Daily mean discharges at this station on the dates of sampling were about 4.9 cubic feet per second $\left(\mathrm{ft}^{3} / \mathrm{s}\right)$ in June 2012, $0.7 \mathrm{ft}^{3} / \mathrm{s}$ in September 2012, and $32 \mathrm{ft}^{3} / \mathrm{s}$ in March 2013. Streamflow rates were more pronounced during the March 2013 sampling than during the June and September 2012 samplings, with the snowmelt, and possibly increased groundwater discharge associated with an elevated water table (figs. $25 C-E, G, H, K$ ), contributing to the increased streamflow. The Salt Creek streamflow rates indicated by measurements at the USGS gaging station generally are substantially lower than the rates within the sewershed, particularly during periods of base flow. The majority of the streamflow in the sewershed is represented by daily discharge of treated wastewater from the Metropolitan Water Reclamation District (MWRD) Egan Water Reclamation Plant outflow, about $0.1 \mathrm{mi}$ downstream of the USGS gaging station (fig. 2). Daily mean discharges from the plant on the dates of sampling were $30.3 \mathrm{ft}^{3} / \mathrm{s}$ in June 2012, $29.4 \mathrm{ft}^{3} / \mathrm{s}$ in September 2012, and $23.5 \mathrm{ft}^{3} / \mathrm{s}$ in March 2013 (Metropolitan Waste Reclamation District of Greater Chicago, 2013). With the wastewater discharges, concentrations of OBs in streamflow entering the sewershed are expected to be greater than determined background levels. 
Table 5-1. Additional hydrogeologic and optical brightener information for the study area, Elk Grove Village, Illinois, June 2012-March 2013.

[CDT, Central Daylight Time; ft bls, feet below land surface; do., ditto; $\mu \mathrm{g} / \mathrm{L}$, micrograms per liter; na, not applicable; dates are expressed as month/day/year; time is expressed as $24-\mathrm{hour}$ time]

\begin{tabular}{|c|c|c|c|c|c|c|c|c|}
\hline $\begin{array}{l}\text { Local } \\
\text { name }\end{array}$ & Water source & Latitude & Longitude & \multicolumn{2}{|c|}{$\begin{array}{l}\text { Sample date and time } \\
\text { (where applicable), } \\
\text { in CDT }\end{array}$} & $\begin{array}{l}\text { Approximate } \\
\text { depth to water, } \\
\text { in ft bls }\end{array}$ & $\begin{array}{l}\text { Open interval } \\
\text { of sampler, } \\
\text { in ft bls }\end{array}$ & $\begin{array}{l}\text { Concentration of } \\
\text { optical brighteners, } \\
\text { in } \mu \mathrm{g} / \mathrm{L}\end{array}$ \\
\hline BG7 & Groundwater; background & $41^{\circ} 59^{\prime} 54.77^{\prime \prime}$ & $87^{\circ} 59^{\prime} 15.93^{\prime \prime}$ & \multicolumn{2}{|l|}{ 06/08/2012 } & 13 & $13-17$ & 45 \\
\hline BG14 & Groundwater; background & $42^{\circ} 01^{\prime} 30.60^{\prime \prime}$ & $87^{\circ} 58^{\prime} 55.30^{\prime \prime}$ & \multicolumn{2}{|l|}{ 06/08/2012 } & 8 & $8-12$ & 42 \\
\hline 9DG1 & Groundwater; downgradient & $42^{\circ} 00^{\prime \prime} 00.50^{\prime \prime}$ & $87^{\circ} 59^{\prime \prime} 50.00^{\prime \prime}$ & \multicolumn{2}{|l|}{ 06/08/2012 } & 9 & $9.65-13.65$ & ${ }^{3} 115$ \\
\hline 9DG2 & Groundwater; downgradient & do. & do. & \multicolumn{2}{|l|}{ 06/08/2012 } & 9 & $15.65-19.65$ & 390 \\
\hline TW9 & Groundwater & $42^{\circ} 00^{\prime} 01.14 "$ & $87^{\circ} 59^{\prime} 51.54 "$ & \multicolumn{2}{|l|}{ 06/08/2012 } & 14 & $15.1-20.1$ & ${ }^{3} 214$ \\
\hline $\mathrm{SC}-\mathrm{U}$ & Salt Creek; upstream extent & $42^{\circ} 00^{\prime} 43.38^{\prime \prime}$ & $88^{\circ} 00^{\prime} 03.19^{\prime \prime}$ & \multicolumn{2}{|l|}{ 06/08/2012 } & 2 & 1 & 80 \\
\hline do. & do. & do. & do. & \multicolumn{2}{|l|}{ 09/27/2012 } & 2 & 1 & 84 \\
\hline do. & do. & do. & do. & \multicolumn{2}{|l|}{$03 / 25 / 2013$} & 2.5 & 1 & 98 \\
\hline $\mathrm{SC}-\mathrm{D}$ & Salt Creek; downstream extent & $41^{\circ} 59^{\prime} 34.34 "$ & $88^{\circ} 59^{\prime} 43.05^{\prime \prime}$ & \multicolumn{2}{|l|}{ 06/08/2012 } & 2 & 1 & 77 \\
\hline do. & do. & do. & do. & \multicolumn{2}{|l|}{ 09/27/2012 } & 2 & 1 & 80 \\
\hline do. & do. & do. & do. & \multicolumn{2}{|l|}{ 03/25/2013 } & 2.5 & 1 & 88 \\
\hline TW1-IN & Sewerflow & $42^{\circ} 01^{\prime} 20.64 "$ & $87^{\circ} 58^{\prime} 33.84^{\prime \prime}$ & $03 / 25 / 2013$ & 1345 & na & na & 240 \\
\hline do. & do. & do. & do. & $03 / 25 / 2013$ & 1825 & na & na & 266 \\
\hline do. & do. & do. & do. & 03/26/2013 & 0730 & na & na & 131 \\
\hline do. & do. & do. & do. & 03/26/2013 & 1020 & na & na & 177 \\
\hline do. & do. & do. & do. & 03/26/2013 & 1325 & na & na & 203 \\
\hline
\end{tabular}

${ }^{1}$ In Salt Creek represents height of water surface from streambed.

${ }^{2}$ In Salt Creek represents height of sample interval above streambed.

${ }^{3}$ Approximate; value increasing slowly during measurement. 
Results of the OB sampling (table 5-1) found respective upstream and downstream concentrations of 80 and $77 \mu \mathrm{g} / \mathrm{L}$ in June 2012, 84 and $80 \mu \mathrm{g} / \mathrm{L}$ in September 2012, and 98 and $88 \mu \mathrm{g} / \mathrm{L}$ in March 2013. Within the sewershed, mean background concentrations of OBs were found to be about $84.5 \mu \mathrm{g} / \mathrm{L}$ in the Salt Creek streamwater compared to $42.5 \mu \mathrm{g} / \mathrm{L}$ in groundwater. Concentrations in the streamwater decreased from 4 to 10 percent between upstream and downstream sample locations. The decrease likely results primarily from a combination of streamflow dilution from dispersion of the initial upstream input of OB-elevated treated-water discharge and contributing discharge of relatively fresh groundwater throughout the study area reach of Salt Creek. The decrease provides no direct evidence of large-scale losses of sewer flow to groundwater from the network of sewer lines in the sewershed.

\section{Appendix 5C. Concentrations of Optical Brighteners in Sewer Flow-Daily Variability}

To assess the temporal variability of $\mathrm{OB}$ concentrations in sanitary sewer flow, the field OB fluorometer was installed in the interceptor sewer near observation well TW1 (fig. 2). The concentrations were to be measured and logged at 15-minute intervals throughout the study's 1-year period of data collection; however, technical issues were encountered with the logging. A shorter term assessment of the temporal variability of OB concentrations, representing daily water use patterns, was conducted. A series of five samples was collected from the interceptor near well TW1 (TW1-IN in table 5-1) over a 24-hour period during March 25-26, 2013. The grab samples were collected by using a weighted-bottle sampler at times that might be representative of a range of water use activities throughout the day. The times included

- an early morning hour (0730 Central Daylight Time), when showers and baths are likely to be taken prior to work and with limited washing of clothes and dishes (the principal sources of OBs in wastewater);

- midmorning to early afternoon hours (1020-1345), when few showers and baths are likely to be taken and with comparatively more washing of clothes and dishes, and

- an early evening hour (1825), when a moderate number of both showers and baths and washing of clothes and dishes might be expected.

No sample was collected during late evening hours, particularly from about 0000 (midnight) to 0400 , when comparatively limited water use might be expected.

Results of the OB sampling at five selected times on March 25-26, 2013 (table 5-1) found concentrations ranged from about $131-266 \mu \mathrm{g} / \mathrm{L}$. The lowest concentration was detected in the sample from the early morning hour, when most showers and baths and least clothes- and dishwashing are expected. The highest concentrations (about 203-266 $\mu \mathrm{g} / \mathrm{L}$ ) were detected in the samples from early afternoon and early evening hours, suggesting more clothes- and dishwashing with relatively fewer showers and baths during these hours. The OB concentrations determined from this temporally sequential collection generally can be considered representative of OB concentrations in the sewershed's sewer flow. The range of concentrations compared favorably with the range of $98-574 \mu \mathrm{g} / \mathrm{L}$ determined from collected samples and in situ fluorometer measurements collected during April 2012May 2013 from the interceptor site (TW1-IN in table 3). 
Publishing support provided by the U.S. Geological Survey Science Publishing Network,

Columbus Publishing Service Center

For more information concerning the research in this report, contact the

Director, Illinois Water Science Center U.S. Geological Survey

405 North Goodwin Avenue

Urbana, IL 61801-2347

http://il.water.usgs.gov/ 
흘.

อ.

$\stackrel{2}{2}$

3

思

言

금

옹

品

蛋

올

ํㅗㅡ

촗

苗

돓.

충

을

$\stackrel{\text { D. }}{\mathrm{D}}$

言

$\stackrel{\text { D. }}{\stackrel{2}{*}}$

言

홍

ํㅠ.

के

귱

7

몸

ISSN 2328-0328 (online)

http://dx.doi.org/10.3133/sir20145176 